\title{
Using memories to assess the intrapersonal comparability of wellbeing reports
}

\author{
Caspar Kaiser*
}

November 2021

\begin{abstract}
Research on subjective wellbeing typically assumes that responses to survey questions are comparable across respondents and across time. Unfortunately, if this assumption is violated, standard methods in empirical research may mislead. I address this concern with three contributions. First, I give a theoretical analysis of the extent and direction of bias that may result from violations of this assumption. Second, I propose to use respondents' memories of changes in life satisfaction to estimate and thereby to correct for differentials in scale use. Third, using the proposed approach, I test whether wellbeing reports are intrapersonally comparable across time. Using British panel data, I find that the direction in which explanatory variables affect latent satisfaction is typically the same as the direction in which scale use is affected. Unemployment and widowhood appear to have particularly strong effects on scale use. Nevertheless, scale shifts are generally not large enough to affect the sign or statistical significance of estimates based on models that do not account for scale shifts. Finally, although discussed in the context of life satisfaction scales, the proposed approach is applicable to a wide range of other subjectively reported constructs.
\end{abstract}

Keywords: subjective wellbeing; life satisfaction; BHPS; vignettes; memories; differential item functioning; reporting function; scale use; welfare comparisons

\footnotetext{
This version has been accepted for publication in the Journal of Economic Behavior \& Organization. I thank Mark Fabian, Joel McGuire, Brian Nolan, Andrew Oswald, Michael Plant, Alberto Prati, Nhat An Trinh, Maarten Vendrik, Jakob Zeitler, and participants of the Oxford Wellbeing Research Centre seminar series, as well as the 2020 GLO/EHERO special session on Happiness Economics for helpful comments and suggestions. I also thank three anonymous reviewers and Eugenio Proto, whose comments substantially improved the paper. Funding from the Wellbeing Research Centre is gratefully acknowledged.

*Wellbeing Research Centre \& Institute for New Economic Thinking, University of Oxford. Email: caspar.kaiser@hmc.ox.ac.uk
} 
Most empirical research on subjective wellbeing is concerned with establishing how explanatory variables are associated with the quality of latent mental states. To establish such associations, respondents are asked to rate their wellbeing on a numerical scale. Aggregate analyses based on this type of data typically assume that ratings of different respondents at different times are comparable. Call this the assumption of common scale use. Previous work has questioned this assumption (e.g. Adler 2013; Fleurbaey and Blanchet 2013; Viscusi 2020). Nevertheless, despite many studies analysing subjective wellbeing, few papers constructively engage with this issue. Are wellbeing reports comparable?

I focus on life satisfaction as one particular kind of wellbeing report. In recent years, the economic literature has increasingly used life satisfaction reports to proxy individual welfare. One well-known justification for this practice is to argue that life satisfaction is a close proxy for peoples' preferences over possible lives. More precisely, if a person reports to be more satisfied with life $A$ compared to life $B$, we believe that she prefers life $A$ over life $B$ (Decancq, Fleurbaey, and Schokkaert 2015). To support this belief, several papers show that people's ex ante preferences over possible lives tend to match people's orderings in terms of anticipated life satisfaction (Benjamin et al. 2012; 2014; Adler, Dolan, and Kavetsos 2017). ${ }^{1}$

However, satisfaction reports depend both on peoples' actual satisfaction, as well as their "reporting function", i.e. the particular manner in which levels of satisfaction are translated into numerical values on a response scale (Oswald 2008). As most recently pointed out in a forceful piece by Bond and Lang (2019), the shape of the reporting function, and whether it differs across and within persons over-time, is not generally known. As a consequence, if a person's reporting function changes between time $t-1$ and $t$, an increase in that person's reported life satisfaction from $t-1$ to $t$ need not imply that this person prefers her life at $t$ over her life at $t-1$ (Köke and Perino 2017). To avoid this issue, we must be able to separate between changes in a person's true life satisfaction and changes in her reporting function.

The paper's main contribution is thus to propose an empirical method to correct for intrapersonal shifts in the reporting function, thereby allowing us to identify changes in respondents' underlying life satisfaction. The proposed method compares reports of current life satisfaction with reports of remembered changes in satisfaction. Intuitively, when observing inconsistencies between these two types of reports, shifts in scale use may have occurred. In the paper, I formalise this intuition and show how ordered probit regressions can be extended to obtain quantitative estimates of the degree to which the reporting function is shifted. The key identifying assumption of the proposed approach is that scale use depends on contemporaneous realisations of covariates, while respondents' memories exclusively depend on past realisations. In turn, this restriction facilitates the separate identification of covariates' effects on wellbeing from covariates' effects on the thresholds of the reporting function.

Although I focus on the comparability of responses to a question about life satisfaction, some of the theoretical points in the paper are more general. In particular, the proposed may well be used

\footnotetext{
${ }^{1}$ Relatedly, Perez-Truglia (2015) finds that consumption preferences inferred from life satisfaction reports correlate with future consumption behaviour. Another route to motivating the analysis of life satisfaction data - one that is more common in the philosophical literature - is to argue that a person's felt degree of life satisfaction constitutes that person's level of welfare directly. For discussion, see, e.g., Sumner (1996) or Plant (2020).
} 
for other subjective data, including e.g., subjective health, happiness, social status, or political preferences.

My main empirical results - based on data from the British Household Panel Survey (BHPS) indicate that variables which positively affect ${ }^{2}$ latent satisfaction are also associated with more 'stringent' scale use, and vice versa for negative effects. Consequently, compared to analyses that maintain common scale use, estimates of effects on latent satisfaction are downwardly biased. Estimates of ratios of coefficients, which may indicate variables' relative importance in determining life satisfaction, are biased, too. Scale use is especially affected by unemployment and widowhood. Nevertheless, differences in results between analyses that account for changes in scale use versus analyses that do not, are not large enough to change conclusions regarding the direction and statistical significance of estimated effects. Substantively this means that although there is a serious theoretical case for the incomparability of satisfaction reports, in practice such concerns seem unlikely to be a decisive problem.

A limitation of the proposed method is that it cannot distinguish between adaptation and lagged changes in scale use. Nevertheless, estimates of the effects of lags and leads of my set of explanatory variables are provided, and their possible substantive interpretations explored. Moreover, for some variables, shifts in scale use may not be homogenous across the entire response scale (e.g., respondents may become more lenient at the top of the scale, but more stringent at the bottom). However, such 'non-parallel' scale shifts turn out to be empirically indistinguishable from heterogeneous effects of covariates across the distribution of satisfaction.

The paper proceeds as follows. In section 2, I introduce the standard set of assumptions adopted in empirical research on life satisfaction. I then focus on the assumption of common scale use, discuss why this assumption may not be met, and explore the biases that result when it is violated. In section 3, I discuss previous approaches to identifying differences in scale use, including the use of vignettes as well as the literature on response styles. I then proceed to propose a different method to correct for differences in scale use, which uses memories of changes in satisfaction. In section 4, I provide an empirical application, using BHPS data. Section 5 concludes.

\section{The problem}

\subsection{Standard assumptions in wellbeing research}

When studying life satisfaction, researchers typically use responses to questions of the form:

\section{'How dissatisfied or satisfied are you with your life overall?'}

When answering this question, each respondent $i$ at time $t$ chooses a response $r_{i t}=k$ from a set of $K$ options. In the BHPS, where this particular question is asked, there are seven response options with extremes labelled as 'Not at all satisfied' (for $k=1$ ) to 'Completely satisfied' (for $k=7$ ). We assume that respondents make their choice by adhering to a rule of the form:

$$
r_{i t}=k \leftrightarrow \tau_{i t, k-1}<s_{i t} \leq \tau_{i t, k}
$$

\footnotetext{
${ }^{2}$ In my empirical estimations, I will often use phrases like "the effect of", " $x$ affects $y$ ”, etc. These terms suggest causal relations which I cannot guarantee to hold. My estimates are only suggestive of such causal relations. However, all of my substantive points continue to hold if all estimated coefficients are interpreted as merely indicating descriptive differences in conditional means.
} 
Equation (1) characterises the 'reporting function' introduced in the introduction. ${ }^{3}$ Here, $s_{i t}$ is the latent level of satisfaction that we are ultimately interested in and that we believe to track individual welfare. The $\tau$ s are 'cutoffs' that need to be crossed to start reporting the next category. When cutoffs are shifted to take higher (smaller) values, I say that scale use becomes more (less) stringent (see figure 1). As shown below, the location of these thresholds are estimated from the data. To account for the fact that response scales are bounded in practice, we assume that $\tau_{i t, 0}=-\infty$ and $\tau_{i t, K}=\infty$.

The literature standardly assumes that the reporting function is common across all respondents and across all times. This assumption can be stated as:

$$
\tau_{i t, k}=\tau_{k}
$$

which I call the assumption of common scale use. This crucial assumption is the main subject of this paper. A second assumption routinely adopted in the literature is that cut-offs are equidistant. That assumption can be stated as:

$$
\tau_{k}-\tau_{k-1}=c,
$$

where $c$ is some constant. We might call (3) the assumption of equidistance, or linearity of scale use. The plausibility and importance of this assumption is analysed in Schröder and Yitzhaki (2017), Bond and Lang (2019), and Kaiser and Vendrik (2020).

In principle, when assumptions (1)-(3) hold, both interpersonal and intrapersonal welfare comparisons on the basis of the satisfaction reports $r$ are possible. Jointly adopting assumptions (1)-(3) is often taken to motivate the use of OLS regressions of $r_{i t}$ on a vector of variables $\boldsymbol{X}$ to infer the associations between $s_{i t}$ and $\boldsymbol{X}$ (Ferrer-i-Carbonell \& Frijters, 2004). ${ }^{5}$ However, if we are unwilling to assume linearity of scale use, we may instead infer differences $\tau_{k}-\tau_{k-1}$ by postulating a structural model for $s_{i t}$ and a distribution for the stochastic error of such a model. When assuming a normally distributed error, this yields the ordered probit approach.

\footnotetext{
${ }^{3}$ We might doubt whether equation (1) is correct, i.e. that $s_{i t}$ indeed determines the choice of $r_{i t}$. Perhaps some other quantity, one that does not carry the sort of presumed normative content that motivates our analysis, drives the choice of $r_{i t}$ instead. See Benjamin et al. (2020) for work in this direction. Another possibility is that latent $S_{i t}$ does not really exist and respondents merely behave as though $s_{i t}$ exists when prompted (Bertrand and Mullainathan 2001). I leave these further doubts aside.

4 The idea of more or less stringent scale use in answers to wellbeing questions is analogous to differences in the stringency of academic grading systems: For a given level of student achievement, a less stringent grading system assigns a comparatively high grade, whereas a more stringent grading system assigns a comparatively low grade.

${ }^{5}$ However, OLS is not necessarily motivated even when assumptions (1)-(3) hold. Instead, in order for OLS to yield correct ratios of coefficients, we require the more demanding assumption that $\mathrm{E}\left(s_{i t} \mid r_{i t}=k ; \boldsymbol{X}\right)=\mathrm{E}\left(s_{i t} \mid r_{i t}=k\right)=$ $a+b k$, where $a$ and $b$ are constants. This assumption entails that independent variables $\boldsymbol{X}$ do not affect the average level of latent satisfaction within each response category. Appendix D shows that OLS regressions can indeed perform worse than ordered probit regressions when $\boldsymbol{X}$ affects average satisfaction within response categories.
} 
Figure 1. Examples of more and less stringent scale use

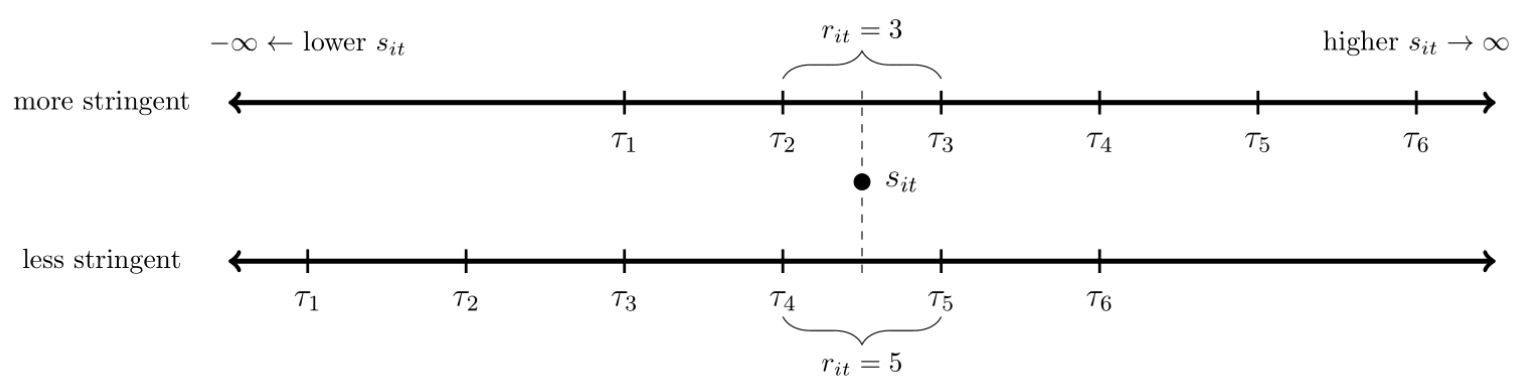

Note: For a given level of $s_{i t}$, we observe a lower level of reported satisfaction $r_{i t}(=3)$ with more stringent scale use and a higher level of reported satisfaction (=5) with less stringent scale use.

However, ordered probit regressions continue to assume common scale use. As argued by e.g. Diamond (2008) and Fleurbaey and Blanchet (2013), it is unlikely that this assumption holds. Both contend that respondents likely report their life satisfaction in relative rather than in absolute terms. Fleurbaey and Blanchet (2013) motivate this by pointing out that the scale with which respondents report their satisfaction is bounded, while many aspects of life are unbounded (like income). Using the response scale to indicate the quantile of one's life in a reference distribution of possible lives solves this problem. In turn, when people's judgements are relative to a reference distribution, and when these distributions vary, then response scales cannot be common.

Schwarz and Strack (1999) argue that such reference distributions likely depend on intrapersonal and interpersonal comparisons. Indeed, Steffel and Oppenheimer (2009) experimentally find evidence to suggest that people calibrate response scales against the past. In that case, better past outcomes make today's scale use more stringent. Similarly, if response scales are calibrated via fixed social comparisons, better outcomes of those in the comparison group will cause scale use to become more stringent.

Of course, respondents' own characteristics may also influence comparisons. For example, present personal characteristics determine expectations about future characteristics (see e.g. Dominitz and Manski 1997). This can have two effects. First, more positive expectations may increase current life satisfaction (Clark and Georgellis 2013). Second, and more importantly in the present context, altered expectations may change the standard against which satisfaction is evaluated, causing respondents to adjust their scale to accommodate future events (Sprangers and Schwartz 1999).

Whom people compare to is also determined by current personal characteristics. Concretely, when a person does well (badly) in some domain, she is more likely to compare herself to others that also do well (badly) in that domain (Falk and Knell 2004). If respondents indeed interpret response scales as relative to peers, then variation in personal characteristics will cause response scales to shift. ${ }^{6}$ See e.g. Gibbons (1999) and Dermer et al. (1979) for suggestive evidence.

Thus, changes in scale use can plausibly occur when personal characteristics change.

\subsection{Biases arising from violations of the common scale use assumption}

In the ordered probit approach we usually estimate a model of the following form:

$$
s_{i t}=\boldsymbol{X}_{i t *} \boldsymbol{\beta}_{*}+\varepsilon_{i t}
$$

\footnotetext{
${ }^{6}$ Additionally, endogenously updated reference groups may reduce the effects on latent satisfaction. Along with adaptation (Odermatt and Stutzer 2019), this could help to explain why people tend to overestimate the impacts of future events on their wellbeing (Wilson and Gilbert 2005).
} 
Here, $\boldsymbol{X}_{i t *} \equiv\left(\boldsymbol{X}_{i t+L}, \ldots, \boldsymbol{X}_{i t+l}, \ldots, \boldsymbol{X}_{i t+F}\right)$, where each entry is a row vector of $\boldsymbol{J}$ independent variables, defined as $\boldsymbol{X}_{i t+l} \equiv\left(X_{1, i t+l}, X_{2, i t+l}, \ldots, X_{J, i t+l}\right)$. Moreover, $\boldsymbol{\beta}_{*} \equiv\left(\boldsymbol{\beta}_{L}, \ldots, \boldsymbol{\beta}_{l}, \ldots, \boldsymbol{\beta}_{F}\right)^{\prime}$, where each entry is a column vector $\boldsymbol{\beta}_{l} \equiv\left(\beta_{1, l}, \ldots, \beta_{j, l}, \ldots, \beta_{J, l}\right)^{\prime}$ of parameters. Constants $L \leq 0$ and $F \geq 0$ respectively denote the numbers of included lags and leads. When no intrapersonal comparisons and anticipation effects are considered, no such lags and leads are included (i.e. $L=$ $F=0) . \varepsilon_{i t}$ is assumed to be a normally distributed error with mean zero and standard deviation $\sigma=1$ (this homoskedasticity assumption is relaxed in section 4.6). A constant is omitted from equation (4).

Assume that reports $r_{i t}$ for $k=1,2, \ldots, K$ are generated by a rule of the form given in equation (1), imposing $\tau_{0}=-\infty$ and $\tau_{K}=\infty$. To specify all other cutoffs, write:

$$
\tau_{i t, k}=\gamma_{k}+\boldsymbol{X}_{i t *} \boldsymbol{\delta}_{*}
$$

For common scale use to hold, it is necessary that $\boldsymbol{\delta}_{*}=\mathbf{0}$, i.e. that neither contemporaneous nor lagged, nor leaded values of covariates affect the location of the thresholds. The contribution of each observation to the log-likelihood of the ordered probit model with the extension of equation (5) is then given by:

$$
\ell_{i t}=\sum_{k=1}^{K} \mathbb{1}\left(r_{i t}=k\right) \ln \left[\Phi\left(\gamma_{k}+\boldsymbol{X}_{i t *} \boldsymbol{\delta}_{*}-\boldsymbol{X}_{i t *} \boldsymbol{\beta}_{*}\right)-\Phi\left(\gamma_{k-1}+\boldsymbol{X}_{i t *} \boldsymbol{\delta}_{*}-\boldsymbol{X}_{i t *} \boldsymbol{\beta}_{*}\right)\right]
$$

Here $\Phi($.$) denotes the standard normal cumulative distribution function. \mathbb{1}($.$) denotes the$ indicator function. Throughout, we maximise $\ell=\sum_{i=1}^{N} \sum_{t=1}^{T_{i}} \ell_{i t}$ to estimate parameters. $T_{i}$ denotes the number of observations for respondent $i$, and $N$ is the number of respondents. Since $\boldsymbol{X}_{i t *} \boldsymbol{\delta}_{*}-\boldsymbol{X}_{i t *} \boldsymbol{\beta}_{*}=\boldsymbol{X}_{i t *}\left(\boldsymbol{\delta}_{*}-\boldsymbol{\beta}_{*}\right)$, equation (6) implies that $\boldsymbol{\delta}_{*}$ and $\boldsymbol{\beta}_{*}$ are not separately identified (King et al. 2004). Only the difference $\boldsymbol{\beta}_{*}-\boldsymbol{\delta}_{*}$ is identified.

A severe consequence of violating common scale use is that we might estimate incorrect signs for some explanatory variables. Suppose $\beta_{j, 0}>0$ and $\delta_{j, 0}>0$ for some explanatory variable $X_{j, i t}$. An increase in the value of $X_{j, i t}$ is here associated with a higher level of $s_{i t}$ and more stringent scale use. Now suppose that $\beta_{j, 0}<\delta_{j, 0}$. In that case, variation in $X_{j, i t}$ impacts the location of the thresholds more strongly than it impacts latent satisfaction. In large samples, our estimate $\beta_{J, 0}-\delta_{J, 0}$ would then be negative. If we interpreted this estimate as an estimate of $\beta_{j, 0}$, we would falsely conclude that the effect of $X_{j, i t}$ on $s_{i t}$ is negative, when in fact it is positive.

The opposite case is likely to occur when considering lagged values of personal covariates. If people adapt to changes in covariates, we should expect a variable whose contemporaneous effect is positive to have a negative lagged effect. However, the lagged effect of such a variable on scale use is likely positive. Hence, we expect that if $\beta_{j,-1}<0$, then $\delta_{j,-1}>0$. If we only estimate the difference $\beta_{j,-1}-\delta_{j,-1}$, and interpret this as a direct estimate of adaptation, we will overstate the true extent of adaptation. ${ }^{7}$ Conversely, in cases where we expect lags of variables to reinforce a smaller contemporaneous effect, such reinforcement will be underestimated.

\footnotetext{
${ }^{7}$ Since, if there is indeed adaptation and a positive lagged scale shift, $\beta_{j,-1}-\delta_{j,-1}<\beta_{j,-1}<0$.
} 
In the case of leads of explanatory variables, the previous section suggested equal signs for $\beta_{j, 1}$ and $\delta_{j, 1}$ : If I expect a good to occur in the future, I should both be more satisfied this year and use the scale more stringently, so as to accommodate the future good. It then follows that anticipation effects on latent satisfaction will be underestimated.

Finally, researchers are often interested how variables $X_{j}$ and $X_{p}$ can be traded off while maintaining constant levels of latent satisfaction $s_{i t}$. Such analyses are especially useful for computing shadow prices and or equivalence scales (Luechinger 2009; Danzer and Danzer 2016; Murtin et al. 2017; Borah, Keldenich, and Knabe 2019; Dolan et al. 2019; Kaiser 2020). To obtain such trade-offs, we must estimate the ratio $\beta_{j} / \beta_{p}$. However, we only obtain an estimate of $\left(\beta_{j}-\delta_{j}\right) /\left(\beta_{p}-\delta_{p}\right)$. Unless $\beta_{j}=\beta_{p}$ and $\delta_{j}=\delta_{p}$, biases occur in this context. Assuming that coefficients are ordered as $\beta_{j} \geq \beta_{p}>\delta_{p} \geq \delta_{j} \geq 0$ implies that our estimated trade-off ratio is (weakly) positively biased. Likewise, assuming that $\beta_{p} \geq \beta_{j} \geq 0, \delta_{j} \geq \delta_{p} \geq 0$ and $\beta_{p}>\delta_{p}$ implies that our trade-off ratio is (weakly) negatively biased. ${ }^{8}$

Thus, when the assumption of common scale use is violated and when response scales are correlated with explanatory variables, we might obtain incorrect signs of coefficients, false impressions of the magnitudes of effects, and biased trade-off ratios between variables.

However, violations of common scale use are unproblematic when merely estimating marginal effects on the probability of responding with a certain category. To see this, note that the probability of responding category $\boldsymbol{r}>k$ conditional on $\boldsymbol{X}_{i t *}$ is given by $\operatorname{Pr}\left(r_{i t}>k \mid \boldsymbol{X}_{i t *}\right)=1-\Phi\left(\gamma_{k}+\right.$ $\left.\boldsymbol{X}_{i t *} \boldsymbol{\delta}_{*}-\boldsymbol{X}_{i t *} \boldsymbol{\beta}_{*}\right)=\Phi\left(\boldsymbol{X}_{i t *}\left(\boldsymbol{\beta}_{*}-\boldsymbol{\delta}_{*}\right)-\gamma_{k}\right)$. Taking the partial derivative with respect to some particular variable, say $X_{j, i t}$, we get $\partial \operatorname{Pr}\left(r_{i t}>k \mid \boldsymbol{X}_{i t *}\right) / \partial X_{j, i t}=\varphi\left(\boldsymbol{X}_{i t *}\left(\boldsymbol{\beta}_{*}-\boldsymbol{\delta}_{*}\right)-\gamma_{k}\right)\left(\beta_{j, 0}-\right.$ $\delta_{j, 0}$ ), where $\varphi($.$) denotes the standard normal probability density function. As discussed above,$ analyses which do not account for changes in scale provide estimates of $\boldsymbol{\beta}_{*}-\boldsymbol{\delta}_{*}$, already. Thus, if we are only interested in estimating expected effects on response probabilities, accounting for changes in scale use serves no purpose.

Some further remarks on the interpretation of absolute magnitudes of coefficients are given in Appendix A.

\section{$3 \quad$ Identification of scale shifts}

\subsection{Previous work}

The psychological literature has been concerned with differences in scale use for some time (Greenleaf 1992a; 1992b). That literature on 'response styles' focuses on respondents' tendencies to use certain parts of the response scale. For example, respondents may show an 'acquiescence response style' when, independent of a statement's content, respondents tend to agree with a given statement. As another example, respondents may show a 'midpoint' response style when disproportionally tending to select neutral response categories (Weijters, Geuens, and Schillewaert 2010). Empirically, that literature identifies response styles by first asking a large set of questions with (assumed to be) uncorrelated content, and subsequently observing whether responses within

\footnotetext{
8 The difference $\left(\beta_{j}-\delta_{j}\right) /\left(\beta_{p}-\delta_{p}\right)-\beta_{j} / \beta_{p}$ can be rearranged to give $\left(\beta_{j} \delta_{p}-\beta_{p} \delta_{j}\right) / \beta_{p}\left(\beta_{p}-\delta_{p}\right)$. The numerator is positive or zero if $\beta_{j} \geq \beta_{p} \geq 0$ and $\delta_{p} \geq \delta_{j} \geq 0$. The denominator is positive if $\beta_{p}>\delta_{p} \geq 0$. The whole expression is therefore positive or zero if $\beta_{j} \geq \beta_{p}>\delta_{p} \geq \delta_{j} \geq 0$. Similarly, the numerator is negative or zero if $\beta_{p} \geq \beta_{j} \geq 0$ and $\delta_{j} \geq \delta_{p} \geq 0$.
} 
individuals tend to cluster in certain regions of the response scale. For an overview of that literature, see e.g., Van Vaerenbergh and Thomas (2013).

However, the psychological literature on response styles does not tend to investigate overall shifts in the reporting function. A separate literature, one that started within political science (King et al., 2004), has focused on this particular problem. That literature relies on presenting respondents with vignettes describing imaginary persons' lives, and asking respondents to rate the life satisfaction of the described persons. Studies by Kapteyn, Smith, and Van Soest (2010), Corrado and Weeks (2010), Angelini et al. (2013), Bertoni (2015) and Montgomery (2017) have adopted this approach. In line with the arguments of the previous section, these studies find that correcting for differences in scale use increases estimates of the effects of explanatory variables on latent satisfaction. Appendix B provides a more comprehensive discussion of the vignette approach.

To achieve identification, two fundamental assumptions need to be met. First, respondents must be assumed to use the same scale when considering their own life satisfaction and the life satisfaction of the vignette (the 'response consistency' assumption). Second, respondents' perceptions of the vignettes must be assumed to be uncorrelated with respondents' personal characteristics (the 'vignette equivalence' assumption. Unfortunately, the validity of both assumptions has been empirically rejected in several applications (Datta Gupta, Kristensen, and Pozzoli 2010; d'Uva et al. 2011; Peracchi and Rossetti 2013). Moreover, administering vignettes is expensive and no panel-datasets containing vignettes exist. ${ }^{9}$ Hence, jointly accounting for unobserved time-invariant characteristics and for differentials in scale use is currently impossible. Therefore, previous work that used vignettes may be biased even if the assumptions discussed above hold. We should thus consider alternative approaches.

The use of memories, as first proposed by Howard and colleagues (Howard et al. 1979; Howard and Dailey 1979; Howard, Schmeck, and Bray 1979), is one such alternative. These studies rely on comparing self-reports taken before a treatment (the 'pre-test') with self-reported memories of the pre-treatment state, which are elicited after the time of the treatment (the 'then-test'). In this approach, a change in scale use is interpreted to occur if differences in treatment status correlates with differences in 'pre-test' and 'then-test' scores.

Hoogstraten (1985), Sprangers et al. (1999), Ahmed et al. (2004) or Townsend and Wilton (2003) are among the studies that employ such 'then-tests'. A recent application can be found in Odermatt and Stutzer (2019). They use German Socio-Economic Panel (SOEP) data from 1984-1988. Following several life events, they find no significant differences between recalled and contemporaneously reported life satisfaction, thus indicating no scale shifts. Fabian (2019) is another example. He asked respondents about their current life satisfaction and their satisfaction ten years ago. Respondents were also asked to graph the change in satisfaction they experienced. Inconsistencies between graphs of changes in satisfaction versus reports about levels of past and present satisfaction may indicate scale shifts. Fabian (2019) finds that $8.5 \%$ of respondents are inconsistent, and $14 \%$ conform to a looser criterion of probable scale change. A final relevant piece is by Köke and Perino (2017) who use BHPS data (like the present study) and data from the German GESIS panel. They find that regressions of observed changes in life satisfaction, and regressions of reported changes in life satisfaction on several demographic characteristics yield inconsistent results. In particular, effects on remembered changes always exceed effects on

\footnotetext{
${ }^{9}$ Indeed, the SHARE survey, which only samples individuals aged 50 or above, seems to be the only widely accessible survey containing vignettes on life satisfaction.
} 
observed changes. Köke and Perino (2017) attribute these differences to respondents failing to correctly recall their past reporting function.

A limitation of each the aforementioned memory-based approaches is that they do not yield concrete estimates of how far variation in explanatory variables shift the thresholds $\tau_{i t, k}$. In addition, how effects on latent satisfaction should be adjusted in the presence of scale shifts, and how to incorporate controls into the analysis, remains unclear. Moreover, the precise assumptions underlying these approaches are opaque, and whether they can be relaxed is unknown. The approach discussed below seeks to overcome these limitations.

\subsection{Outline of approach}

The British Household Panel Survey (BHPS), to be used in the empirical analysis of section 4, asks a question about change in satisfaction:

Would you say that you are more satisfied with life, less satisfied or feel about the same as you did a year ago?

Respondents have three response options (more satisfied, less satisfied, about the same). Let $s_{i t}^{(m)}$ denote a respondent's latent memory of last year's satisfaction. When a respondent replies to be "more satisfied" than last year, it implies $s_{i t}>s_{i t}^{(m)}$. Analogously, when a respondent says that she is "less satisfied" than last year, it implies $s_{i t}<s_{i t}^{(m)}$. Responding with "about same" implies $s_{i t}=s_{i t}^{(m)}+$ $\epsilon_{i t}$, where $\epsilon_{i t}$ can be positive or negative, and we do not know its size.

These considerations, together with equation (1), which stated that respondents report $r_{i t}=k$ iff $\tau_{i t, k-1}<s_{i t} \leq \tau_{i t, k}$, imply the following reporting rule for remembered changes in satisfaction:

$$
\begin{aligned}
& r_{i t}^{(m)}=-1 \quad \& \quad r_{i t}=k \quad \leftrightarrow \quad s_{i t}^{(m)}>\tau_{i t, k-1} \\
& r_{i t}^{(m)}=1 \& r_{i t}=k \leftrightarrow \leftrightarrow s_{i t}^{(m)}<\tau_{i t, k}
\end{aligned}
$$

In this equation, $r_{i t}^{(m)}=-1$ denotes being "less satisfied" compared to last year, and $r_{i t}^{(m)}=1$ denotes being "more satisfied". ${ }^{10}$ Notice that the same thresholds $\tau_{i t, k}$ appear in equations (1) and (7). Following the literature on vignettes, call this the 'response consistency' assumption.

With this assumption, such data can potentially be used to identify threshold locations. To do so, I model memories at $t$ about last year's life satisfaction as follows:

$$
s_{i t}^{(m)}=\theta^{(m)}+\boldsymbol{X}_{i t-1} \boldsymbol{\alpha}+\boldsymbol{X}_{i t} \lambda^{(m)}+\varepsilon_{i t}^{(m)}
$$

Here, $\theta^{(m)}$ is an intercept to be estimated. $\varepsilon_{i t}^{(m)}$ is a normally distributed error term with mean 0 and standard deviation $\sigma^{(m)}=1$. Assume that there are no lags and leads in equation (4). ${ }^{11}$ In that case, and if $\boldsymbol{\lambda}^{(m)}=\mathbf{0}$, the structure of the equation determining memories of satisfaction is the same as the structure of the equation determining current satisfaction. In so far as memories of satisfaction are determined by how satisfied a respondent in fact was, this is a natural choice. Indeed, in order to point-identify the effects of contemporaneous values of covariates on scale shifts, we must assume $\boldsymbol{\lambda}^{(m)}=\mathbf{0}$. Call this assumption present independence.

\footnotetext{
${ }^{10} r_{i t}=k \& r_{i t}^{(m)}=0$ implies $\tau_{i t, k-1}<s_{i t}^{(m)}+\epsilon_{i t} \leq \tau_{i t, k}$. Since we do not know the value of $\epsilon_{i t}$, cases where respondents answer 'about the same' are not informative about which reporting thresholds are crossed.

${ }^{11}$ Heteroskedasticity and the addition of lags and leads are discussed in section 4.5.
} 
Using equations (1), (4), (7) and (8) in a joint model, together with the assumed distributions for each error term and maintaining $\boldsymbol{\lambda}^{(m)}=\mathbf{0}$, individual contributions to the log-likelihood are now given by:

$$
\begin{aligned}
\ell_{i t}= & \sum_{k=1}^{K} \mathbb{1}\left(r_{\mathrm{it}}=k\right) \times \ln \left[\Phi\left(\gamma_{k}+\boldsymbol{X}_{i t} \boldsymbol{\delta}-\boldsymbol{X}_{i t} \boldsymbol{\beta}\right)-\Phi\left(\gamma_{k-1}+\boldsymbol{X}_{i t} \boldsymbol{\delta}-\boldsymbol{X}_{i t} \boldsymbol{\beta}\right)\right] \\
& +\mathbb{1}\left(r_{i t}^{(m)}=-1\right) \times \ln \left[1-\Phi\left(\gamma_{k-1}+\boldsymbol{X}_{i t} \boldsymbol{\delta}-\theta^{(m)}-\boldsymbol{X}_{i t-1} \boldsymbol{\alpha}\right)\right] \\
& +\mathbb{1}\left(r_{i t}^{(m)}=1\right) \times \ln \left[\Phi\left(\gamma_{k}+\boldsymbol{X}_{i t} \boldsymbol{\delta}-\theta^{(m)}-\boldsymbol{X}_{i t-1} \boldsymbol{\alpha}\right)\right]
\end{aligned}
$$

As desired, so long as $\boldsymbol{X}_{i t}$ and $\boldsymbol{X}_{i t-1}$ fail to be perfectly collinear, parameters $\boldsymbol{\beta}$ (effects on current satisfaction), $\boldsymbol{\alpha}$ (effects on memories of past satisfaction) and $\boldsymbol{\delta}$ (scale shift effects) are separately identified in equation (9).

\subsection{Plausibility of identifying assumptions}

The response consistency assumption requires that respondents use the same scale when assessing their current satisfaction and when assessing changes in satisfaction since last year. Both questions ask for assessments of the same kind of concept, i.e., they are both questions about a respondents' own life satisfaction. This is different to the vignette case, in which respondents are asked about two different concepts, namely their own life satisfaction and the life satisfaction of an imaginary person. Compared to the vignette approach, it therefore seems more plausible that respondents indeed adopt the same set of thresholds for both questions.

Similarly, the assumption of response consistency would also be less plausible if respondents were asked about the level of their present and their past life satisfaction. In that situation, respondents might try to remember what they responded last year, leading them to adopt last year's response thresholds. However, in the BHPS data used in this paper, respondents are asked about the change in satisfaction. It would be strongly counterintuitive if respondents were to adopt an inconsistent set of thresholds when making comparisons between past and present satisfaction.

Nevertheless, future research should seek to validate this assumption carefully, e.g. by explicitly prompting respondents to adopt the same standards when responding to either question. In the absence of such data to date, I informally investigate the response consistency assumption by comparing my main results with those from a standard ordered probit model in section 4.5.

Regarding present independence, it is important to note that this assumption does not entail that reports $r_{i t}^{(m)}$ are unbiased reports of past satisfaction $s_{i t-1}$. This would imply the constraint that $\theta^{(m)}=0$ and $\boldsymbol{\alpha}=\boldsymbol{\beta}$. I thus allow for respondents to have biased memories (Wilson, Meyers, and Gilbert 2003). Instead, present independence states that, conditional on values of last year's covariates, one's memories about last year's satisfaction do not depend on values for this year's covariates.

This assumption may nevertheless be violated. Respondents might infer from changes in objective circumstances that their life satisfaction must have changed, too. If life satisfaction did not change in reality, individuals might bias their memories to nevertheless feel a change in the expected direction. Such behaviour would imply opposite signs for the entries in $\boldsymbol{\lambda}^{(\boldsymbol{m})}$ and $\boldsymbol{\beta}$. See Conway and Ross (1984) for suggestive evidence in an educational psychology context. However, memory biases may also be caused by 'mood-congruency', i.e. the general tendency of positive moods to bias memories to be more positive (and vice versa for negative moods; see e.g. Klaassen et al. 2002; Lewis et al. 2005; Prati 2017; Urban et al. 2018). Because moods and satisfaction are correlated, 
'mood-congruency' predicts that people in positive (negative) moods recall their past satisfaction as more positive (negative). In turn, 'mood-congruency' suggests equal signs for corresponding entries in $\boldsymbol{\lambda}^{(m)}$ and $\boldsymbol{\beta}$.

In Appendix E, I analyse what the exact implications of violating present independence are, and suggest some robustness tests based on this analysis.

\subsection{Accounting for fixed effects}

Before turning to an empirical application, I note a final difficulty. As is well-known, failure to account for individual fixed effects biases coefficients in research on life satisfaction (Ferrer-iCarbonell \& Frijters, 2004). The standard approach to deal with this issue is to demean both sides of equation (4). However, since $s_{i t}$ is not observed, this is not an option. Furthermore, alternatively estimating separate parameters for each individual instead is known to yield inconsistent estimates for finite $T$ (Greene, 2004).

To nevertheless correct for this issue, I add individual averages of all explanatory variables to the model. Such a specification was first proposed by Mundlak (1978). Van Praag (2015) recently argued that a specification which includes such averages yields estimates of $\boldsymbol{\beta}_{*}$ that are identical to estimates that would be obtained if it were possible to demean equation (4). Hence, although this is normally thought to be infeasible (Riedl and Geishecker 2014), adequately accounting for individual fixed-effects in an ordered probit context seems possible. In Appendix B, I analyse this point in more detail and reconstruct Van Praag's argument. In turn, Appendix C successfully evaluates the veracity of Van Praag's argument in a Monte Carlo study.

Finally, if latent satisfaction is partly determined by an individual fixed effect, then memories of satisfaction and scale use are likely to also be affected by individual fixed effects. To account for these, averages $\overline{\boldsymbol{X}}_{\boldsymbol{i}}$ are added to these equations, too. Thus, the estimates shown below control for fixed effects in scale use. They are therefore concerned with intrapersonal variation in scale use. This is in contrast to vignette studies, which are always cross-sectional and estimate interpersonal differences in scale use.

\section{$4 \quad$ Empirical application}

\subsection{Data and variables}

I use British Household Panel Survey (BHPS) data. The BHPS was a nationally representative panel survey of individuals in the UK, which ran between 1991 and 2008, and which was succeeded by the "Understanding Society" survey. I include waves 6-10 and 12-18 of the BHPS, corresponding to the years 1996-2000 and 2002-2008. These are all the years in which data on (memories of changes in) life satisfaction is available. Life satisfaction is measured by the question given in section 2.1. Memories of changes are elicited with the question discussed in section 3.2. To make sure that lags of each explanatory variable indeed relate to respondents' circumstances in the preceding year, I exclude observations that do not occur within a timeframe of 10 to 14 months since the previous observation. $^{12}$

\footnotetext{
12 This entails dropping about $11.7 \%$ of the original sample. Results are qualitatively unchanged without this restriction. Exclusively including observations that occur in an exact 12-month interval would have led to a very large loss of observations and would thus have been unfeasible.
} 
I focus on covariates that (a) have been extensively studied in the previous literature, that (b) are available in waves 6-18 of the BHPS, and that (c) are neither time-invariant nor perfectly collinear with their own lags.

Condition (c) is necessary because the separate identification of scale shift effect relies on elements in $\boldsymbol{X}_{i t}$ and $\boldsymbol{X}_{i t-1}$ not being perfectly collinear. As a consequence, the proposed method cannot be used to study scale shifts in gender, age, or scale shifts across time. ${ }^{13} \mathrm{I}$ nevertheless include age, age-squared, wave dummies, as well as region fixed-effects as controls in the equations for latent satisfaction and memories of satisfaction (but not in the equation for shifts in scale use).

Among the variables that do satisfy (a)-(c), respondents' household incomes have been investigated most extensively in the previous literature. There is now near-universal agreement that the effects of income on life satisfaction are positive, but that estimates are smaller when including individual fixed effects (Frijters, Haisken-DeNew, and Shields 2004; Layard, Mayraz, and Nickell 2008; Ferrer-i-Carbonell and Van Praag 2008; Kahneman and Deaton 2010; Di Tella, Haisken-De New, and MacCulloch 2010). To estimate the effects of income, I specifically use log equivalized posttax household incomes (from Levy and Jenkins 2012) that have been deflated to 2005 prices.

Another key variable previously studied are 'reference incomes', i.e. the incomes of those in a respondents' (assumed) reference group. The effects of such reference incomes are largely thought to be negative (Clark and Oswald 1996; McBride 2001; Vendrik and Woltjer 2007; Ifcher, Zarghamee, and Graham 2018), though not universally so (FitzRoy et al. 2014; Senik 2008). Following Ferrer-i-Carbonell (2005), Vendrik (2013), and Kaiser (2020), reference incomes are constructed as the log average income of those with similar age (i.e. respondent's age \pm 5 years) and similar education (i.e. same education on a four category scale).

Another key variable is employment status, particularly unemployment, which is generally thought to reduce life satisfaction (Clark and Oswald 1994; Winkelmann and Winkelmann 1998; Lucas et al. 2004; Kassenboehmer and Haisken-DeNew 2009), as well as self-employment (where the literature shows small positive effects; Blanchflower and Oswald (1998), Binder and Coad (2013)), and retirement (which shows largely positive effects, especially in the short-term; c.f. Wetzel, Huxhold, and Tesch-Römer 2016; Gorry, Gorry, and Slavov 2018).

The estimations also include dummies for marital status and childbirth. Regarding the former, people react negatively to divorce and especially bereavement, though respondents may (partially) adapt over time (Blanchflower and Oswald 2004; Lucas 2005; Clark et al. 2008; Clark and Georgellis 2013). Regarding the latter, previous work typically finds positive effects, though not universally so (Kohler, Behrman, and Skytthe 2005; Angeles 2010; Frijters, Johnston, and Shields 2011; Nelson, Kushlev, and Lyubomirsky 2014).

Furthermore, I provide estimates for disability and poor health, which previous studies have shown to have negative and lasting effects (Oswald and Powdthavee 2008; Clark et al. 2008; Clark and Georgellis 2013; Frijters, Johnston, and Shields 2011). Unlike previous studies, in my baseline

\footnotetext{
13 The u-shape in age (Blanchflower and Oswald 2004; Frijters and Beatton 2012; Blanchflower and Oswald 2019; Cheng, Powdthavee, and Oswald 2017), the near-zero growth rate in average wellbeing (Easterlin 1974; 1995; Stevenson and Wolfers 2008; Kaiser and Vendrik 2019; Easterlin and O'Connor 2020), and the gender gap in satisfaction (Stevenson and Wolfers 2009; Montgomery 2017; Oparina and Srisuma 2020) are key points of contention within the literature. Since scale shifts may play a role in explaining these findings, this is an important limitation of the proposed method which future work should seek to overcome.
} 
estimations, poor health is not captured by responses to a subjective question about respondents' general health (c.f. e.g. Ferrer-i-Carbonell and Frijters 2004). Instead, a dummy to indicate whether respondents report to be limited by poor health in their daily activities is used. A key motivation for this choice of variable is that we want to capture how changes in health may affect scale use on (subjective) life satisfaction. A priori, a subjective question on health that is asked on the same kind of response scale seemed ill-suited to that task. Nevertheless, results using subjective health were almost identical and are available upon request.

Finally, estimates for $\log (1+$ working hours) and $\log$ (household size), which are standardly featured in life satisfaction equations, and where we typically see negative coefficients on both variables, are provided as well.

\subsection{Descriptive evidence}

Before presenting my regression results, Table 1 provides some descriptive evidence. A recent study by Prati and Senik (2020) makes use of the same data and, reassuringly, reports the same descriptive patterns. In contrast to the present paper, they pursue an alternative analysis and instead analyse various types of memory biases.

Table 1. Descriptive evidence on possible scale shifts

\begin{tabular}{|c|c|c|c|c|}
\hline & \multicolumn{4}{|c|}{ 'Last year was...' $\left(r_{i t}^{(m)}\right)$} \\
\hline \multicolumn{5}{|c|}{ Panel A: Memories of life satisfaction by level of reported life satisfaction } \\
\hline$r_{i t}$ & 'worse' & 'about the same' & 'better' & 'don't know' \\
\hline 1 & $21(4.4 \%)$ & $348(24.8 \%)$ & $932(66.4 \%)$ & $62(4.4 \%)$ \\
\hline 2 & $120(5.6 \%)$ & $509(23.9 \%)$ & $1,459(68.6 \%)$ & $38(1.8 \%)$ \\
\hline 3 & $399(6.6 \%)$ & $2,188(36.0 \%)$ & $3,379(55.7 \%)$ & $105(1.7 \%)$ \\
\hline 4 & $1,645(11.8 \%)$ & $7,919(56.7 \%)$ & $4,225(30.3 \%)$ & $173(1.2 \%)$ \\
\hline 5 & $7,316(24.5 \%)$ & $18,394(61.5 \%)$ & $4,015(13.4 \%)$ & $166(0.6 \%)$ \\
\hline 6 & $11,428(34.3 \%)$ & $20,520(61.6 \%)$ & $1,301(3.90 \%)$ & $81(0.2 \%)$ \\
\hline 7 & $4,234(30.0 \%)$ & $9,568(67.8 \%)$ & $274(1.94 \%)$ & $47(0.3 \%)$ \\
\hline Total & $25,204(25.0 \%)$ & $59,446(58.9 \%)$ & $15,585(15.4 \%)$ & $672(0.7 \%)$ \\
\hline \multicolumn{5}{|c|}{ Panel B: Memories of life satisfaction by direction of change in reported life satisfaction } \\
\hline$\Delta r_{i t}$ & 'worse' & 'about the same' & 'better' & 'don't know' \\
\hline Decrease $\left(r_{i t}<r_{i t-1}\right)$ & $3,610(15.5 \%)$ & $12,809(55.0 \%)$ & $6,623(28.5 \%)$ & $230(1.0 \%)$ \\
\hline No change $\left(r_{i t}=r_{i t-1}\right)$ & $10,408(26.0 \%)$ & $23,135(62.8 \%)$ & $4,287(10.7 \%)$ & $182(0.5 \%)$ \\
\hline Increase $\left(r_{i t}>r_{i t-1}\right)$ & $7,161(32.6 \%)$ & $12,398(56.5 \%)$ & $2,268(10.3 \%)$ & $119(0.5 \%)$ \\
\hline \multicolumn{5}{|c|}{$\begin{array}{l}\text { Note: The column with heading 'worse' ('better') gives the number of respondents who said that last year they felt } \\
\text { less (more) satisfied with life than this year. The column with heading 'about the same' gives the number of } \\
\text { respondents who said that last year they felt about as satisfied with life as this year. Bold cells indicate likely shifts } \\
\text { in scale use. Percentages are relative to row-totals. }\end{array}$} \\
\hline
\end{tabular}

Panel A shows that more respondents report that last year was worse $(25.0 \%)$, than that last year was better (15.4\%). In line with intuition, the higher reported satisfaction, the higher the probability of stating that last year was worse. Only $0.7 \%$ of respondents respond that they 'don't know' whether last year was better or worse. Thus, respondents generally feel able to recall their past wellbeing.

Panel B cross-tabulates the observed change in $r_{i t}$ against respondents' remembered change. There are two situations that are evidently inconsistent. The first of these occurs when reported life satisfaction decreased in subsequent years, but respondents nevertheless report that the past was worse $(15.5 \%$ of cases where reported satisfaction decreased). This indicates that scale use has become more stringent. In contrast, when reported satisfaction increases across subsequent years, but respondents report that last year was better, scale use may have become less stringent $(10.3 \%$ 
of cases where reported satisfaction increased). Of course, when respondents state that last year was better (worse) and reported that satisfaction either decreased (increased) or remained stable, scale use need not have changed.

\subsection{Baseline results}

Table 2 presents baseline results for the variables discussed in section 4.1. Estimates are based on the model discussed in section 3.2. The rows in panel A display estimated coefficients on current life satisfaction (i.e. $\boldsymbol{\beta}$ ). The rows in panel B display coefficients on remembered satisfaction (i.e. $\boldsymbol{\alpha})$. Panel $\mathrm{C}$ displays coefficients relating to shifts in scale use (i.e. $\boldsymbol{\delta}$ ) and panel D displays the constants associated with each threshold (i.e. $\gamma_{k}$ ).

Column (1) is based on a restricted specification that neither accounts for individual fixed effects, nor allows for explanatory variables to affect scale use. Column (2) allows for such scale shifts. Column (3) does not allow for scale shifts but does account for individual fixed effects. Finally, column (4) is based on a full specification that accounts for both individual fixed effects and allows for explanatory variables to affect scale use. Since columns (1) and (3) do not allow for scale shifts, panel $\mathrm{C}$ is empty in these.

Starting with column (1), we observe that being unemployed reduces life satisfaction compared to being employed. The self-employed and the retired are more satisfied than employed individuals, although the difference is only significant in the latter case. Each of these estimates is consistent with the previous literature discussed above. Equally in line with previous literature, accounting for fixed effects reduces the size of estimated coefficients but leaves their signs and levels of statistical significance intact (compare columns (1) and (3)).

However, when accounting for scale shifts (see columns (2) and (4)), coefficients generally become larger. Recall from section 2.2 that estimates of $\boldsymbol{\beta}$ in analyses which do not account for scale shifts yield estimates that are equivalent to estimates of $\boldsymbol{\beta}-\boldsymbol{\delta}$ from analyses that do account for scale shifts. Hence, increase in the magnitude of negative (positive) $\boldsymbol{\beta}$ estimates are driven by corresponding negative (positive) $\boldsymbol{\delta}$ estimates relating to scale use. This can be seen more clearly by comparing the relevant estimates shown columns (3) with those in column (4). Take unemployment as a concrete example. In column (3) we obtain $\beta_{\mathrm{UE}}=-0.188$ for the effect on life satisfaction. In column (4) we obtain $\beta_{\mathrm{UE}}=-0.691$. There, I additionally obtain $\delta_{\mathrm{UE}}=$ -0.503 for the effect on scale use. Taking the difference of these, we get $-0.691+0.503=$ -0.188 , which corresponds to the result of column (3).

Substantively, these estimates imply that the unemployed use the response scale much less stringently than those who are employed, leading to an underestimation of the unemployment effect in more standard analyses. In contrast, as indicated by the positive $\delta_{\text {Retired }}=0.171$ coefficient, the retired appear to use the scale somewhat more stringently. 
Table 2. Main Results for BHPS data

\begin{tabular}{|c|c|c|c|c|}
\hline & $\begin{array}{c}\text { Without averages } \\
\text { (1) }\end{array}$ & $\begin{array}{l}\text { Without averages, with } \\
\text { scale shift } \\
(2)\end{array}$ & $\begin{array}{c}\text { With averages } \\
\text { (3) }\end{array}$ & $\begin{array}{c}\text { With averages, with } \\
\text { scale shift } \\
\text { (4) }\end{array}$ \\
\hline \multicolumn{5}{|c|}{ Panel A: Current life satisfaction $(\boldsymbol{\beta})$} \\
\hline $\ln (\mathrm{HH}$ income $)$ & $0.115^{* * *}(0.011)$ & $0.151^{* * *}(0.022)$ & $0.038^{* * *}(0.009)$ & $0.074^{* * *}(0.025)$ \\
\hline \multicolumn{5}{|l|}{ Employed (base) } \\
\hline Self-employed & $0.044(0.030)$ & $0.076(0.062)$ & $0.045^{*}(0.024)$ & $0.047(0.068)$ \\
\hline Unemployed & $-0.297^{* * *}(0.037)$ & $-0.698^{* * *}(0.072)$ & $-0.188^{* * *}(0.031)$ & $-0.691^{* * *}(0.079)$ \\
\hline Retired & $0.222^{* * *}(0.032)$ & $0.282^{* * *}(0.073)$ & $0.117^{* * *}(0.025)$ & $0.256^{* * *}(0.080)$ \\
\hline Not working & $-0.062^{* *}(0.025)$ & $-0.130^{* *}(0.051)$ & $-0.037^{*}(0.020)$ & $-0.136^{* *}(0.055)$ \\
\hline \multicolumn{5}{|l|}{ Married (base) } \\
\hline Widowed & $-0.284^{* * *}(0.033)$ & $-1.151^{* * *}(0.126)$ & $-0.355^{* * *}(0.048)$ & $-1.152^{* * *}(0.147)$ \\
\hline Divorced & $-0.420^{* * *}(0.026)$ & $-0.587^{* * *}(0.064)$ & $-0.282^{* * *}(0.032)$ & $-0.454^{* * *}(0.075)$ \\
\hline Never married & $-0.254^{* * *}(0.020)$ & $-0.451^{* * *}(0.062)$ & $-0.159^{* * *}(0.025)$ & $-0.377^{* * *}(0.074)$ \\
\hline Disabled & $-0.289^{* * *}(0.023)$ & $-0.467^{* * *}(0.051)$ & $-0.162^{* * *}(0.020)$ & $-0.254^{* * *}(0.056)$ \\
\hline Poor health & $-0.580^{* * *}(0.016)$ & $-0.749^{* * *}(0.032)$ & $-0.232^{* * *}(0.013)$ & $-0.423^{* * *}(0.036)$ \\
\hline $\ln (\mathrm{HH}$ size $)$ & $-0.073^{* * *}(0.016)$ & $-0.188^{* * *}(0.047)$ & $-0.101^{* * *}(0.017)$ & $-0.232^{* * *}(0.053)$ \\
\hline Childbirth & $0.136^{* * *}(0.020)$ & $0.329^{* * *}(0.046)$ & $0.095^{* * *}(0.017)$ & $0.219^{* * *}(0.049)$ \\
\hline Ln(Job hours) & $-0.006(0.007)$ & $-0.015(0.014)$ & $0.006(0.006)$ & $-0.011(0.015)$ \\
\hline Reference income & $-0.274^{* * *}(0.036)$ & $-0.087(0.170)$ & $-0.285^{* * *}(0.064)$ & $-0.260(0.201)$ \\
\hline \multicolumn{5}{|c|}{ Panel B: Memory of last year's life satisfaction $\left(\alpha\right.$ and $\left.\theta^{(m)}\right)$} \\
\hline $\ln (\mathrm{HH}$ income $)$ & $0.021(0.017)$ & $0.051^{* * *}(0.019)$ & $0.045^{* *}(0.022)$ & $0.055^{* *}(0.023)$ \\
\hline \multicolumn{5}{|l|}{ Employed (base) } \\
\hline Self-employed & $0.012(0.050)$ & $0.071(0.057)$ & $0.029(0.063)$ & $0.047(0.065)$ \\
\hline Unemployed & $-0.068(0.060)$ & $-0.170^{* * *}(0.062)$ & $-0.118^{*}(0.070)$ & $-0.111(0.072)$ \\
\hline Retired & $0.048(0.062)$ & $0.096(0.072)$ & $-0.055(0.075)$ & $0.016(0.080)$ \\
\hline Not working & $-0.042(0.044)$ & $-0.088^{*}(0.046)$ & $-0.060(0.051)$ & $-0.083(0.052)$ \\
\hline \multicolumn{5}{|l|}{ Married (base) } \\
\hline Widowed & $-0.259^{* * *}(0.061)$ & $-1.057^{* * *}(0.126)$ & $-0.595^{* * *}(0.121)$ & $-1.038^{* * *}(0.153)$ \\
\hline Divorced & $-0.330^{* * *}(0.037)$ & $-0.502^{* * *}(0.063)$ & $-0.291^{* * *}(0.060)$ & $-0.434^{* * *}(0.071)$ \\
\hline Never married & $-0.107^{* * *}(0.030)$ & $-0.301^{* * *}(0.059)$ & $-0.143^{* *}(0.057)$ & $-0.275^{* * *}(0.068)$ \\
\hline Disabled & $0.057(0.042)$ & $-0.083^{*}(0.049)$ & $-0.155^{* * *}(0.056)$ & $-0.175^{* * *}(0.058)$ \\
\hline Poor health & $-0.027(0.027)$ & $-0.121^{* * *}(0.029)$ & $-0.090^{* * *}(0.034)$ & $-0.098^{* * *}(0.035)$ \\
\hline $\ln (\mathrm{HH}$ size $)$ & $0.110^{* * *}(0.023)$ & $0.006(0.044)$ & $0.126^{* * *}(0.040)$ & $0.027(0.051)$ \\
\hline Childbirth & $0.066^{*}(0.039)$ & $0.071^{*}(0.040)$ & $0.111^{* * *}(0.042)$ & $0.101^{* *}(0.043)$ \\
\hline Ln(Job hours) & $0.015(0.012)$ & $0.019(0.013)$ & $0.013(0.014)$ & $0.014(0.015)$ \\
\hline Reference income & $-0.297^{* * *}(0.051)$ & $-0.069(0.167)$ & $0.077(0.163)$ & $0.103(0.194)$ \\
\hline Constant & $-1.339^{* *}(0.523)$ & $-1.716^{* * *}(0.538)$ & $-1.679^{* * *}(0.589)$ & $-1.766^{* * *}(0.600)$ \\
\hline \multicolumn{5}{|c|}{ Panel C: Scale shift $(\delta)$} \\
\hline $\ln (\mathrm{HH}$ income $)$ & & $0.036^{*}(0.020)$ & & $0.036(0.024)$ \\
\hline \multicolumn{5}{|l|}{ Employed (base) } \\
\hline Self-employed & & $0.032(0.056)$ & & $0.002(0.063)$ \\
\hline Unemployed & & $-0.402^{* * *}(0.065)$ & & $-0.503^{* * *}(0.074)$ \\
\hline Retired & & $0.060(0.068)$ & & $0.139^{*}(0.077)$ \\
\hline Not working & & $-0.068(0.045)$ & & $-0.099^{*}(0.051)$ \\
\hline \multicolumn{5}{|l|}{ Married (base) } \\
\hline Widowed & & $-0.867^{* * *}(0.122)$ & & $-0.797^{* * *}(0.141)$ \\
\hline Divorced & & $-0.167^{* * *}(0.059)$ & & $-0.172^{* * *}(0.066)$ \\
\hline Never married & & $-0.197^{* * *}(0.059)$ & & $-0.218^{* * *}(0.069)$ \\
\hline Disabled & & $-0.178^{* * *}(0.048)$ & & $-0.092 *(0.055)$ \\
\hline Poor health & & $-0.169^{* * *}(0.029)$ & & $-0.192^{* * *}(0.035)$ \\
\hline $\ln (\mathrm{HH}$ size $)$ & & $-0.116^{* *}(0.045)$ & & $-0.131^{* *}(0.051)$ \\
\hline Childbirth & & $0.194^{* * *}(0.043)$ & & $0.124^{* * *}(0.047)$ \\
\hline Ln(Job hours) & & $-0.008(0.013)$ & & $-0.018(0.014)$ \\
\hline Reference income & & $0.186(0.166)$ & & $0.025(0.192)$ \\
\hline \multicolumn{5}{|c|}{ Panel D: Cutoff constants $\left(\gamma_{k}\right)$} \\
\hline$\gamma_{1}$ & $-4.982^{* * *}(0.326)$ & $-4.979^{* * *}(0.325)$ & $-5.242^{* * *}(0.368)$ & $-5.240^{* * *}(0.368)$ \\
\hline$\gamma_{2}$ & $-4.560^{* * *}(0.325)$ & $-4.557^{* * *}(0.325)$ & $-4.812^{* * *}(0.367)$ & $-4.812^{* * *}(0.367)$ \\
\hline$\gamma_{3}$ & $-4.003^{* * *}(0.325)$ & $-4.002^{* * *}(0.324)$ & $-4.251^{* * *}(0.367)$ & $-4.250^{* * *}(0.367)$ \\
\hline$\gamma_{4}$ & $-3.353^{* * *}(0.325)$ & $-3.352^{* * *}(0.325)$ & $-3.593^{* * *}(0.367)$ & $-3.592^{* * *}(0.367)$ \\
\hline$\gamma_{5}$ & $-2.461^{* * *}(0.325)$ & $-2.461^{* * *}(0.325)$ & $-2.691^{* * *}(0.367)$ & $-2.691^{* * *}(0.367)$ \\
\hline$\gamma_{6}$ & $-1.387^{* * *}(0.325)$ & $-1.387^{* * *}(0.325)$ & $-1.607^{* * *}(0.367)$ & $-1.607^{* * *}(0.367)$ \\
\hline Obs. (Respondents) & $100,235(18,642)$ & $100,235(18,642)$ & $100,235(18,642)$ & $100,235(18,642)$ \\
\hline
\end{tabular}


As expected, higher incomes are associated with higher life satisfaction. The size of the effect is reduced when accounting for fixed effects, as also observed in the previous literature (again, compare columns (1) and (3)). However, when additionally accounting for changes in scale use in column (4), the income effect is again increased and roughly doubled. Hence, as indicated by the positive coefficients shown in panel C, respondents' scale use is more stringent with higher incomes.

Furthermore, in columns (1) and (3), I obtain negative, statistically significant, and sizable coefficients for the effects of reference income on latent satisfaction. This is in line with the previous literature. However, especially in column (2) I estimate a positive, though insignificant, association between reference incomes and scale use. This contrasts with each of the variables investigated thus far, where the sign of effects on latent satisfaction and the sign of effect on scale use coincided. In turn, the positive scale shift effect of reference incomes reduces the size of the coefficient on latent satisfaction, thereby turning it statistically insignificant in columns (2) and (4). However, in our preferred specification of column (4), the magnitude of the effect of reference incomes on scale use is rather small. It would therefore be premature to conclude that the wellknown finding that reference incomes depress satisfaction is partly driven by changes in reporting behaviour. Nevertheless, this possibility remains a useful avenue for future work.

Those who are neither married nor in a stable partnership are much less satisfied. Comparing columns (1) and (3), the estimate on divorce is reduced when accounting for fixed effects, but increased for those who are widowed. When accounting for scale shifts, the negative effects of not being married are increased. This is particularly so for widowhood, where the associated coefficient is tripled in size, and becomes the largest coefficient in the model. This is also reflected by widowhood having the largest coefficient in the scale shift equation.

Furthermore, scale use is significantly more stringent following childbirth, but less stringent in larger households. The respectively positive and negative effects of these variables on satisfaction are consequently magnified, too.

Overall, each of these results agree with the expectations of section 2.2: Personal characteristics that are associated with higher (lower) levels of latent satisfaction are also associated with more (less) stringent scale use. ${ }^{14}$

When looking at the results for the effects on memories (panel B) the signs of most coefficients equal those relating to current satisfaction. For example, just as being unemployed reduces contemporaneous satisfaction, having been unemployed in the previous year reduces remembered satisfaction. Thus, the results suggest that respondents are generally able to recall the direction in which past personal circumstances affected their past satisfaction. ${ }^{15}$ Moreover, as is intuitive, most coefficients on memories have smaller magnitudes compared to those for current satisfaction. Finally, the constant in panel $(\mathrm{B})$, which corresponds to $\theta^{(m)}$ in equation (8) is negative and significant throughout. This implies that respondents generally have a tendency towards remembering the past as worse than the present. This in line with the descriptive results of Table

\footnotetext{
${ }^{14}$ However, my results contrast with those of Odermatt and Stutzer (2019). Future work may thus evaluate whether their results based on SOEP data also hold when using the formal approach proposed in the present paper.

15 One exception are the positive, but insignificant, coefficients on reference incomes in columns (3) and (4). It is unclear why these coefficients are positive; substantively they would imply that respondents memories of past satisfaction are improved when reference incomes in the previous period were higher.
} 
1 which showed that more people say that last year was worse than this year. This is also in line with results from previous work (e.g. Easterlin 2001; Prati and Senik 2020; Kollamparambil 2021).

Notice that the estimated threshold constants $\gamma_{k}$ shown in panel (D) do not change when accounting for scale shifts. This is because, as expressed in equation (5), scale shifts are assumed to be captured entirely via the $\boldsymbol{\delta}$ coefficients associated with each of the included explanatory variables, leaving each of the estimated $\gamma_{k}$ constants largely unchanged.

Finally, as noted in section 2.3 , trade-offs between variables may be affected by scale shifts. In order to illustrate this point, Table 3 lists estimated ratios $\beta_{j} / \beta_{\ln (H H}$ inc.) for all explanatory variables $j$ of interest. The table shows that, relative to the effect of household income, the effects of unemployment and widowhood are estimated to be larger when accounting for scale shifts. Contrariwise, the effects of divorce, disability, and poor health are smaller when accounting for both scale shifts and fixed effects. However, these differences in coefficient ratios are not statistically significant in the preferred specification that accounts for fixed effects.

Table 3. Ratios of coefficients on each explanatory variable against coefficient on income

\begin{tabular}{|c|c|c|c|c|c|c|}
\hline & \multicolumn{3}{|c|}{ Without averages (no fixed effects) } & \multicolumn{3}{|c|}{ With averages (fixed effects) } \\
\hline & $\begin{array}{l}\text { No shift } \\
(1)\end{array}$ & $\begin{array}{l}\text { With shift } \\
\text { (2) }\end{array}$ & $\begin{array}{c}\text { Difference } \\
(3) \\
\end{array}$ & $\begin{array}{l}\text { No shift } \\
(4)\end{array}$ & $\begin{array}{l}\text { With shift } \\
\text { (5) }\end{array}$ & $\begin{array}{c}\text { Difference } \\
(6)\end{array}$ \\
\hline $\ln (\mathrm{HH}$ income $)$ & 1.000 (n.a) & 1.000 (n.a) & 0.000 (n.a.) & 1.000 (n.a) & 1.000 (n.a) & 0.000 (n.a.) \\
\hline \multicolumn{7}{|l|}{$\begin{array}{l}\text { Employed } \\
\text { (base) }\end{array}$} \\
\hline Self-employed & $0.385(0.261)$ & $0.506(0.420)$ & $0.121(0.382)$ & $1.163(0.672)$ & $0.632(0.937)$ & $-0.530(0.932)$ \\
\hline Unemployed & $-2.579(0.416)$ & $-4.628(0.853)$ & $-2.049^{* * *}(0.780)$ & $-4.889(1.419)$ & $-9.304(3.367)$ & $-4.415(3.217)$ \\
\hline Retired & $1.928(0.325)$ & $1.867(0.549)$ & $-0.061(0.514)$ & $3.050(0.932)$ & $3.447(1.530)$ & $0.397(1.539)$ \\
\hline Not working & $-0.541(0.227)$ & $-0.864(0.362)$ & $-0.324(0.331)$ & $-0.957(0.573)$ & $-1.832(0.990)$ & $-0.875(0.965)$ \\
\hline \multicolumn{7}{|l|}{ Married (base) } \\
\hline Widowed & $-2.465(0.377)$ & $-7.627(1.413)$ & $-5.161^{* * *}(1.335)$ & $-9.213(2.472)$ & $-15.513(5.588)$ & $-6.299(5.370)$ \\
\hline Divorced & $-3.651(0.432)$ & $-3.889(0.717)$ & $-0.238(0.653)$ & $-7.326(1.877)$ & $-6.112(2.289)$ & $1.214(2.376)$ \\
\hline Never married & $-2.208(0.276)$ & $-2.991(0.602)$ & $-0.783(0.557)$ & $-4.126(1.177)$ & $-5.073(1.982)$ & $-0.947(1.949)$ \\
\hline Disabled & $-2.509(0.307)$ & $-3.093(0.567)$ & $-0.583(0.522)$ & $-4.212(1.096)$ & $-3.416(1.369)$ & $0.796(1.471)$ \\
\hline Poor health & $-5.038(0.496)$ & $-4.960(0.758)$ & $0.079(0.704)$ & $-6.021(1.425)$ & $-5.703(1.969)$ & $0.318(2.033)$ \\
\hline $\ln (\mathrm{HH}$ size $)$ & $-0.631(0.150)$ & $-1.248(0.356)$ & $-0.617^{* *}(0.337)$ & $-2.626(0.755)$ & $-3.129(1.256)$ & $-0.502(1.246)$ \\
\hline Childbirth & $1.177(0.201)$ & $2.181(0.423)$ & $1.003^{* *}(0.391)$ & $2.467(0.712)$ & $2.953(1.158)$ & $0.485(1.154)$ \\
\hline Ln(Job hours) & $-0.053(0.059)$ & $-0.097(0.092)$ & $-0.044(0.085)$ & $0.161(0.155)$ & $-0.153(0.206)$ & $-0.313(0.215)$ \\
\hline Ref. income & $-2.379(0.342)$ & $-0.579(1.122)$ & $1.801(1.111)$ & $-7.406(2.295)$ & $-3.507(2.880)$ & $3.899(3.148)$ \\
\hline \multicolumn{7}{|c|}{ 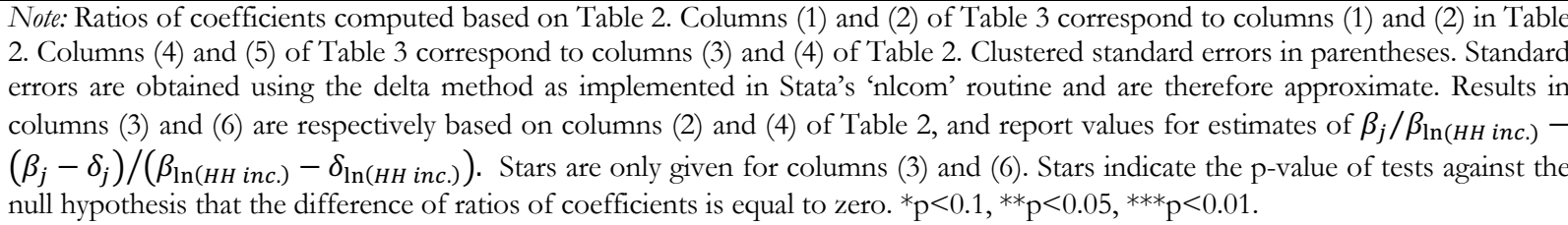 } \\
\hline
\end{tabular}

\subsection{Sensitivity to violations of present independence}

Thus far, I assumed that $\boldsymbol{\lambda}^{(\boldsymbol{m})}=\mathbf{0}$, i.e. present independence. This section explores the implications of relaxing this assumption. With available data, the validity of the present independence assumption cannot be tested.

We can nevertheless evaluate how violations of present independence could affect results. As shown in detail in Appendix E, if the contemporaneous effects on latent satisfaction have the same sign as contemporaneous effects on memory biases, then coefficients are biased towards zero. However, we empirically observe that when accounting for differences in scale use, the magnitudes of estimates on latent satisfaction tend to exceed those obtained when failing to account for scale shifts. This implies that if present independence is violated such that corresponding elements in $\boldsymbol{\beta}$ and $\lambda^{(m)}$ have the same signs, the resulting bias (which leads to an underestimation of the true $\boldsymbol{\beta}$ ) is 
Table 4. Robustness of scale shifts and effects on latent satisfaction when assuming $\left|\lambda_{j}^{(m)}\right|=\left|\beta_{j}\right|$

\begin{tabular}{|c|c|c|}
\hline & $\begin{array}{l}\text { Scale shifts } \\
\text { (1) }\end{array}$ & $\begin{array}{l}\text { Effects on latent satisfaction } \\
(2)\end{array}$ \\
\hline $\ln (\mathrm{HH}$ income $)$ & $-0.001(0.013)$ & $0.037^{* * *}(0.012)$ \\
\hline \multicolumn{3}{|l|}{ Employed (base) } \\
\hline Self-employed & $-0.021(0.033)$ & $0.023(0.034)$ \\
\hline Unemployed & $-0.157^{* * *}(0.041)$ & $-0.345^{* * *}(0.040)$ \\
\hline Retired & $0.011(0.041)$ & $0.128^{* * *}(0.040)$ \\
\hline Not working & $-0.031(0.028)$ & $-0.068^{* *}(0.027)$ \\
\hline \multicolumn{3}{|l|}{ Married (base) } \\
\hline Widowed & $-0.221^{* * *}(0.075)$ & $-0.576^{* * *}(0.074)$ \\
\hline Divorced & $0.055(0.035)$ & $-0.227^{* * *}(0.037)$ \\
\hline Never married & $-0.030(0.037)$ & $-0.188^{* * *}(0.037)$ \\
\hline Disabled & $0.035(0.030)$ & $-0.127^{* * *}(0.028)$ \\
\hline Poor health & $0.020(0.019)$ & $-0.212^{* * *}(0.018)$ \\
\hline $\ln (\mathrm{HH}$ size $)$ & $-0.015(0.027)$ & $-0.116^{* * *}(0.027)$ \\
\hline Childbirth & $0.015(0.025)$ & $0.110^{* * *}(0.024)$ \\
\hline Ln(Job hours) & $-0.012(0.008)$ & $-0.006(0.008)$ \\
\hline Reference income & $0.155(0.102)$ & $-0.130(0.100)$ \\
\hline
\end{tabular}

smaller than the bias resulting from failing to account for changes in scale use (which also leads to an underestimation of the true $\boldsymbol{\beta}$ ).

However, signs for corresponding entries in $\boldsymbol{\beta}$ and $\boldsymbol{\lambda}^{(m)}$ may instead oppose each other. Given the small coefficients on memories of satisfaction, and given previous work showing that the emotional intensity of memories tends to fade with time (Levine and Bluck 2004), it seems implausible for the absolute magnitudes of $\boldsymbol{\lambda}^{(\boldsymbol{m})}$ to exceed those of $\boldsymbol{\beta}$. Adopting the assumption that the magnitudes of $\boldsymbol{\lambda}^{(\boldsymbol{m})}$ are at most equal to those of $\boldsymbol{\beta}$, we can test whether effects of covariates on scale use, i.e. $\boldsymbol{\delta}$, remain significant and have a determinate sign in such a worst case. As derived in Appendix E, this can be done by testing $h_{0}: \hat{\delta}_{j}-0.5 \widehat{\beta}_{j}=0$ for every variable of interest. Column (1) of Table 4 presents results from such an exercise on the basis of the estimates of column (4) of Table 2. The signs of most estimated scale shift effects are robust to this exercise. Self-employment, being retired, and childbirth continue to be associated with more stringent scale use. Unemployment, widowhood, never being married, and household size remain associated with less stringent scale use. However, only the estimates for widowhood and unemployment remain statistically significant. Finally, in Appendix E I also show that assuming $\left|\lambda_{j}^{(m)}\right|=\left|\beta_{j}\right|$ causes all estimates of effects on latent satisfaction to be halved (when signs of $\lambda_{j}^{(m)}$ and $\beta_{j}$ are opposed). Fortunately, from column (2) of Table 4 we see that the statistical significance of each coefficient is unaffected by this reduction in estimated magnitudes.

\subsection{Comparison to standard ordered probit and OLS models}

The baseline models of Table 2 are unusual. It is therefore instructive to compare them to standard ordered probit and OLS models. Results from these are shown in Table 5.

Recall that in every column of Table 2, coefficients are estimated under the response consistency assumption, i.e. that the same set of thresholds is used for memories as for current satisfaction. Since the models of Table 5 do not also model memories, these specifications do not make that assumption. Consequently, if response consistency were to have failed, the ordered probit results given in columns (1) and (2) of Table 5 should deviate strongly from those in columns (1) and (3) of Table 2. However, estimated coefficients are highly similar across these models. The estimated 
differences in cutoff locations are in also agreement. These results therefore support the response consistency assumption.

Furthermore, signs and significance levels of the OLS estimates shown in columns (5) and (6), the latter of which account for fixed effects, match the results of the ordered probit models. Nevertheless, ratios of coefficients do not match perfectly. For example, the ratio of the income to unemployment coefficients is $0.039 /-0.173=-0.225$ in the ordered probit model with individual averages (see column 2), but $0.044 /-0.243=-0.181$ in the OLS fixed effects model (see column 6).

This discrepancy may be driven by the ordered probit model allowing cutoffs to not be equidistant, while the OLS model assumes constant differences in expected $s_{i t}$ across response categories. To verify this conjecture, I ran two tests. First, I constrained cutoffs to be equidistant in the ordered probit models of columns (3) and (4). When doing so, the estimated coefficient ratios are much closer to the corresponding ratios estimated in the OLS models. For example, for the income to unemployment ratio in column (4), I now obtain $0.038 /-0.205=-0.185$, which is much closer to the OLS result. Second, in columns (7) and (8), I again estimated OLS regressions, but transformed the life satisfaction variable in a manner that was first proposed by Stevenson and Wolfers (2008) and Van Praag and Ferrer-i-Carbonell (2008). Both sets of authors assume that latent life satisfaction is a normally distributed variable $Z$ that has zero mean and unit variance. It is then natural to code each response category of the original life satisfaction variable to take on the expectation of $Z$ conditional on the share of respondents that answered with a higher or lower category. Thus, and to be precise, I recoded the original life satisfaction variable as $\tilde{r}_{i}=$ $E\left(Z \mid \mu_{k-1}<Z<\mu_{k}\right)=\left(\varphi\left(\Phi^{-1}\left(\mu_{k-1}\right)\right)-\varphi\left(\Phi^{-1}\left(\mu_{k}\right)\right)\right) /\left(\mu_{k}-\mu_{k-1}\right)$, where $\mu_{k}$ denote the share up until category $k$, and where $\varphi($.$) and \Phi^{-1}($.$) respectively denote the PDF and the inverse$ of the CDF of the standard normal distribution. ${ }^{16}$ In effect, this recoding yields a transformed life satisfaction variable with values that are similarly spaced as the estimated thresholds in an ordered probit regression (indeed, Van Praag and Ferrer-i-Carbonell (2008) call this procedure "probitadapted OLS"). Adopting this approach yields coefficients ratios that are extremely close to those obtained from the ordered probit model. For example, the ratio of the coefficients for income and unemployment is estimated to be $0.032 /-0.149=-0.215$, which is very close to the ordered probit result.

One conclusion to the draw from the comparisons between OLS and ordered probit models is that adding individual averages to the ordered probit model accurately accounts for fixed effects. These results therefore agree with the extended discussion of Appendix $\mathrm{C}$ and the Monte Carlo results of Appendix D. Finally, note that the magnitudes of coefficients in the OLS model are all larger than in the ordered probit models. This is because the OLS model assumes constant differences of 1 in expected $s_{i t}$ across response categories. The constrained ordered probit model with $\sigma=1$ instead estimates differences of 0.811 between thresholds. Hence, coefficients of the OLS model can be expected to be larger by a factor of about $1 / 0.811=1.233$.

16 A numerical example may be useful. In the BHPS data, 23.7\% of the sample respond with the fourth response category or lower, while $53.0 \%$ respond with the fifth response category or lower. As also displayed at the bottom of Table 5, I therefore code the fifth response category as $\left(\varphi\left(\Phi^{-1}(0.237)\right)-\varphi\left(\Phi^{-1}(0.530)\right)\right) /(0.530-0.237)=$ -0.304 . 
Table 5. Comparison to Ordered Probit and OLS models OP OP-Avg. OP, equidistant OP-Avg., OLS OLS-FE POLS POLS-FE cutoffs imposed equidistant cutoffs

imposed

\begin{tabular}{|c|c|c|c|c|c|c|c|c|}
\hline & $(1)$ & (2) & (3) & (4) & (5) & $(6)$ & $(7)$ & $(8)$ \\
\hline $\ln (\mathrm{HH}$ income $)$ & $0.112^{* * *}(0.011)$ & $0.039^{* * *}(0.008)$ & $0.114^{* * *}(0.011)$ & $0.038^{* * *}(0.009)$ & $0.137^{* * *}(0.012)$ & $0.044^{* * *}(0.010)$ & $0.096^{* * *}(0.009)$ & $0.032^{* * *}(0.007)$ \\
\hline \multicolumn{9}{|l|}{ Employed (base) } \\
\hline Self-employed & $0.042(0.029)$ & $0.036(0.022)$ & $0.057^{* *}(0.028)$ & $0.042^{*}(0.022)$ & $0.079^{* *}(0.032)$ & $0.052^{* *}(0.026)$ & $0.036(0.025)$ & $0.030(0.019)$ \\
\hline Unemployed & $-0.291^{* * *}(0.037)$ & $-0.173^{* * *}(0.029)$ & $-0.321^{* * *}(0.038)$ & $-0.205^{* * *}(0.031)$ & $-0.383^{* * *}(0.044)$ & $-0.243^{* * *}(0.036)$ & $-0.252^{* * *}(0.032)$ & $-0.149^{* * *}(0.025)$ \\
\hline Retired & $0.218^{* * *}(0.031)$ & $0.129^{* * *}(0.024)$ & $0.211^{* * *}(0.030)$ & $0.124^{* * *}(0.024)$ & $0.236^{* * *}(0.034)$ & $0.136^{* * *}(0.027)$ & $0.182^{* * *}(0.026)$ & $0.107^{* * *}(0.020)$ \\
\hline Not working & $-0.061^{* *}(0.025)$ & $-0.017(0.019)$ & $-0.084^{* * *}(0.024)$ & $-0.034^{*}(0.019)$ & $-0.104^{* * *}(0.028)$ & $-0.043^{*}(0.022)$ & $-0.055^{* * *}(0.021)$ & $-0.015(0.016)$ \\
\hline \multicolumn{9}{|l|}{ Married (base) } \\
\hline Widowed & $-0.278^{* * *}(0.032)$ & $-0.344^{* * *}(0.047)$ & $-0.272^{* * *}(0.031)$ & $-0.336^{* * *}(0.048)$ & $-0.311^{* * *}(0.034)$ & $-0.371^{\text {*** }}(0.052)$ & $-0.233^{* * *}(0.027)$ & $-0.285^{* * *}(0.039)$ \\
\hline Divorced & $-0.412^{* * *}(0.026)$ & $-0.270^{* * *}(0.030)$ & $-0.425^{* * *}(0.027)$ & $-0.273^{* * *}(0.032)$ & $-0.500^{* * *}(0.031)$ & $-0.318^{* * *}(0.037)$ & $-0.356^{* * *}(0.023)$ & $-0.232^{* * *}(0.026)$ \\
\hline Never married & $-0.249^{* * *}(0.020)$ & $-0.145^{* * *}(0.024)$ & $-0.247^{* * *}(0.020)$ & $-0.145^{* * *}(0.025)$ & $-0.287^{* * *}(0.023)$ & $-0.171^{* * *}(0.029)$ & $-0.213^{* * *}(0.017)$ & $-0.124^{* * *}(0.021)$ \\
\hline Disabled & $-0.284^{* * *}(0.023)$ & $-0.148^{* * *}(0.019)$ & $-0.303^{* * *}(0.024)$ & $-0.161^{* * *}(0.020)$ & $-0.349^{* * *}(0.028)$ & $-0.187^{* * *}(0.023)$ & $-0.241^{* * *}(0.020)$ & $-0.126^{* * *}(0.016)$ \\
\hline Poor health & $-0.569^{* * *}(0.015)$ & $-0.223^{* * *}(0.012)$ & $-0.586^{* * *}(0.016)$ & $-0.233^{* * *}(0.012)$ & $-0.678^{* * *}(0.018)$ & $-0.269^{* * *}(0.014)$ & $-0.486^{* * *}(0.013)$ & $-0.189^{* * *}(0.010)$ \\
\hline $\ln (\mathrm{HH}$ size $)$ & $-0.071^{* * *}(0.015)$ & $-0.101^{* * *}(0.017)$ & $-0.064^{* * *}(0.015)$ & $-0.096^{* * *}(0.017)$ & $-0.073^{* * *}(0.018)$ & $-0.108^{* * *}(0.019)$ & $-0.061^{* * *}(0.013)$ & $-0.085^{* * *}(0.014)$ \\
\hline Childbirth & $0.133^{* * *}(0.019)$ & $0.075^{* * *}(0.016)$ & $0.124^{* * *}(0.019)$ & $0.067^{* * *}(0.016)$ & $0.144^{* * *}(0.022)$ & $0.075^{* * *}(0.018)$ & $0.116^{* * *}(0.017)$ & $0.064^{* * *}(0.014)$ \\
\hline Ln(Job hours) & $-0.006(0.007)$ & $0.009^{*}(0.005)$ & $-0.000(0.007)$ & $0.011^{* *}(0.005)$ & $0.002(0.008)$ & $0.014^{* *}(0.006)$ & $-0.005(0.006)$ & $0.008^{*}(0.004)$ \\
\hline \multirow[t]{2}{*}{ Reference income } & $-0.273^{* * *}(0.036)$ & $-0.294^{* * *}(0.061)$ & $-0.236^{* * *}(0.035)$ & $-0.315^{* * *}(0.061)$ & $-0.224^{* * *}(0.041)$ & $-0.349^{* * *}(0.070)$ & $-0.236^{* * *}(0.031)$ & $-0.243^{* * *}(0.051)$ \\
\hline & \multicolumn{4}{|c|}{ Cutoffs } & \multicolumn{4}{|c|}{ Scale } \\
\hline$\tau_{1}$ & $-4.935^{* * *}(0.320)$ & $-5.253^{* * *}(0.358)$ & $-5.275^{* * *}(0.316)$ & $-5.576^{* * *}(0.354)$ & 1 & 1 & -2.523 & -2.523 \\
\hline$\tau_{2}$ & $-4.506^{* * *}(0.319)$ & $-4.818^{* * *}(0.358)$ & $-4.464^{* * *}(0.316)$ & $-4.757^{* * *}(0.354)$ & 2 & 2 & -1.957 & -1.957 \\
\hline$\tau_{3}$ & $-3.956^{* * *}(0.318)$ & $-4.261^{* * *}(0.357)$ & $-3.653^{* * *}(0.316)$ & $-3.937^{* * *}(0.354)$ & 3 & 3 & -1.512 & -1.512 \\
\hline$\tau_{4}$ & $-2.324^{* * *}(0.319)$ & $-3.621^{* * *}(0.357)$ & $-2.843^{* * *}(0.316)$ & $-3.118^{* * *}(0.354)$ & 4 & 4 & -0.978 & -0.978 \\
\hline$\tau_{5}$ & $-2.465^{* * *}(0.319)$ & $-2.753^{* * *}(0.357)$ & $-2.032^{* * *}(0.316)$ & $-2.298^{* * *}(0.354)$ & 5 & 5 & -0.304 & -0.304 \\
\hline \multirow[t]{2}{*}{$\tau_{6}$} & $-1.397^{* * *}(0.319)$ & $-1.675^{* * *}(0.358)$ & $-1.222^{* * *}(0.316)$ & $-1.479^{* * *}(0.354)$ & 6 & 6 & 0.524 & 0.524 \\
\hline & & & & & 7 & 7 & 1.576 & 1.576 \\
\hline
\end{tabular}

\footnotetext{
Note: Standard errors in parentheses. ${ }^{*} \mathrm{p}<0.1,{ }^{* *} \mathrm{p}<0.05,{ }^{* * *} \mathrm{p}<0.01$. Columns (2), (4), (6), and (8) account for individual fixed effects (c.f. section 3.4).
} 


\subsection{Extensions}

So far, column (4) of Table 2 has been the preferred model. Below, three ways of extending this preferred specification are explored. First, the feasibility of allowing for adaptation and anticipation dynamics is explored. Second, possible non-parallel shifts in scale use are analysed. Third and finally, the implications of modelling heteroskedasticity in the error terms are discussed.

\subsubsection{Lags and leads}

To model adaptation and/or anticipation, further lags and leads of our explanatory variables can be added to the model. Unfortunately however, each vector of lags and leads $\boldsymbol{X}_{i t+k}$ cannot simultaneously be included in the equation for current satisfaction (eq. 1), the equation for memories of satisfaction (eq. 8), and the equation for scale use (eq. 5). Instead, each vector $\boldsymbol{X}_{i t+k}$, may at most be included in any two of these equations. Otherwise, the separate coefficients in each of these equations are not identified.

For example, in the model of column 4 in Table 2, $\boldsymbol{X}_{i t}$ is included in both the equation for current satisfaction and in the equation for scale use. As a consequence, $\boldsymbol{X}_{i t}$ cannot also be included in the equation for memories of satisfaction. In contrast, lags of explanatory variables, i.e. $\boldsymbol{X}_{\boldsymbol{i t}-\mathbf{1}}$, were only included in the equation for memories. It is therefore possible to either allow $\boldsymbol{X}_{\boldsymbol{i t}-\mathbf{1}}$ to also affect current life satisfaction (to model adaptation), or to affect scale use (to model lagged scale shifts), but $\boldsymbol{X}_{\boldsymbol{i} \boldsymbol{t}-\mathbf{1}}$ cannot be included in both equations. This implies that we are fundamentally unable to separate adaptation from lagged scale shifts.

To illustrate this, Appendix Table F1 presents results for several specifications that include leads and lags. In column (1), I extend column (4) of table 2 by additionally adding lagged terms to the scale shift equation. When doing so, I find that lagged terms for own widowhood, divorce, and never being married, have, just like the contemporaneous terms, a significantly negative effect on scale use (i.e. making respondents more lenient). In contrast, the lagged coefficients relating to selfemployment, disability, poor health, reference income, and household size are significantly positive. The lagged coefficient on income is significantly negative, and has about the half the magnitude of its contemporaneous counterpart.

Despite being in line with the experimental results of Steffel and Oppenheimer (2009; c.f. section 2.1), these estimates could also be interpreted to indicate over-time adaptation or reinforcement of the actual effect on satisfaction. This is made evident in column (2). There, lags of all explanatory variables are added to the current satisfaction equation. At the same time, all of them are removed from the equation on scale shifts. Column (3) further adds a two-year lag to the memory equation. ${ }^{17}$ In both specifications, I obtain significantly negative lagged effects of self-employment, disability, poor health, household size, and reference incomes, and a significantly positive coefficient for lagged income. Each of these indicate reinforcement (rather than adaptation) of effects over time. In contrast, the lagged coefficients on widowhood, divorce, and never being married are positive and significant. Thus, in line with much of the previous literature, columns (2) and (3) can be read

\footnotetext{
${ }^{17}$ If current satisfaction depends on contemporaneous and one-year lagged realisations of covariates, memories should, symmetrically, depend on realisations of covariates from one and two years ago
} 
as evidence of partial adaptation to these life events (Clark and Georgellis 2013; Frijters, Johnston, and Shields 2011; Odermatt and Stutzer 2019).

Unfortunately, which interpretation - adaptation/reinforcement or lagged scale shifts - is correct cannot be disentangled with the data at hand. To overcome this limitation should be an important area for further work.

Finally, to model possible anticipation dynamics, I add an additional lead to the equations on current satisfaction and scale use in column (4). I obtain large and significant anticipation effects on satisfaction for most variables, including those relating to employment status and marital status, as well as on disability, poor health, childbirth and job hours. Regarding scale use, I obtain significant and positive coefficients for the leads of childbirth, and significantly negative coefficients for widowhood, divorce, and never having been married. In every case, the anticipation effect has the same sign as the contemporaneous effect. Again, this is in line with previous work on lags and leads (Clark et al. 2008; Clark and Georgellis 2013; Gupta et al. 2015; Hanglberger and Merz 2015), as well as the theoretical expectations set out in section 2.1. However, although this would have been theoretically preferable, and for the same reasons as discussed above, no leads or contemporaneous terms could be added to the memory equation. ${ }^{18}$

\subsubsection{Parallel and non-parallel shifts}

The models of Tables 2 and 5 exclusively allowed for scale shifts with equal magnitude and direction across all cutoffs. In other words, the models assumed that cutoffs are shifted parallelly (Xu \& Xie 2016). However, it may be that explanatory variables impact the location of each cutoff differently. For example, variables may cause scale use to become more stringent at high levels of reported satisfaction, but less stringent at low levels of reported satisfaction. This idea is illustrated in Figure 2.

In order to allow for such non-parallel shifts, we might postulate a nested model for the set of thresholds:

$$
\begin{gathered}
\tau_{i t, 1}=\gamma_{1}+\boldsymbol{X}_{i t} \boldsymbol{\delta}_{1}, \\
\tau_{i t, 2}=\tau_{i t, 1}+e^{\gamma_{2}+X_{i t} \boldsymbol{\delta}_{2}}, \\
\cdots \\
\tau_{i t, K}=\tau_{i t, K-1}+e^{\gamma_{K}+\boldsymbol{X}_{i t} \boldsymbol{\delta}_{K}}
\end{gathered}
$$

This non-linear specification has the advantage that the ordering of cutoffs is always preserved, no matter the signs of $\boldsymbol{\delta}_{\boldsymbol{k}}$ (Greene and Hensher 2010). However, this specification is inelegant since we assume a non-linear functional form for all but the first cutoff. A linear specification is therefore more natural. Such a specification may be given by:

$$
\begin{gathered}
\tau_{i t, 1}=\gamma_{1}+\boldsymbol{X}_{i t} \boldsymbol{\delta}_{1} \\
\tau_{i t, 2}=\tau_{i t, 1}+\gamma_{2}+\boldsymbol{X}_{i t} \boldsymbol{\delta}_{2}, \\
\cdots \\
\tau_{i t, K}=\tau_{i t, K-1}+\gamma_{K}+\boldsymbol{X}_{i t} \boldsymbol{\delta}_{K}
\end{gathered}
$$

\footnotetext{
18 The fact that we do observe anticipation effects for most variables suggests that a similar dynamic occurs for memories, i.e. that respondents remember to have anticipated the occurrence of future events. This would entail that the present independence assumption is violated (i.e. that $\boldsymbol{\lambda}^{(\boldsymbol{m})} \neq \mathbf{0}$ ). The fact that the $\boldsymbol{\beta}$ coefficients of contemporaneous and leaded variables on current satisfaction always have the same sign suggests that $\boldsymbol{\beta}$ and $\boldsymbol{\lambda}^{(\boldsymbol{m})}$ also have the same sign. As shown in Appendix E, equal signs for $\boldsymbol{\beta}$ and $\boldsymbol{\lambda}^{(\boldsymbol{m})}$ imply a bias towards zero of the estimated scale shift effects.
} 
Figure 2. Parallel and non-parallel shifts in scale use.

Panel A. Parallel Shift

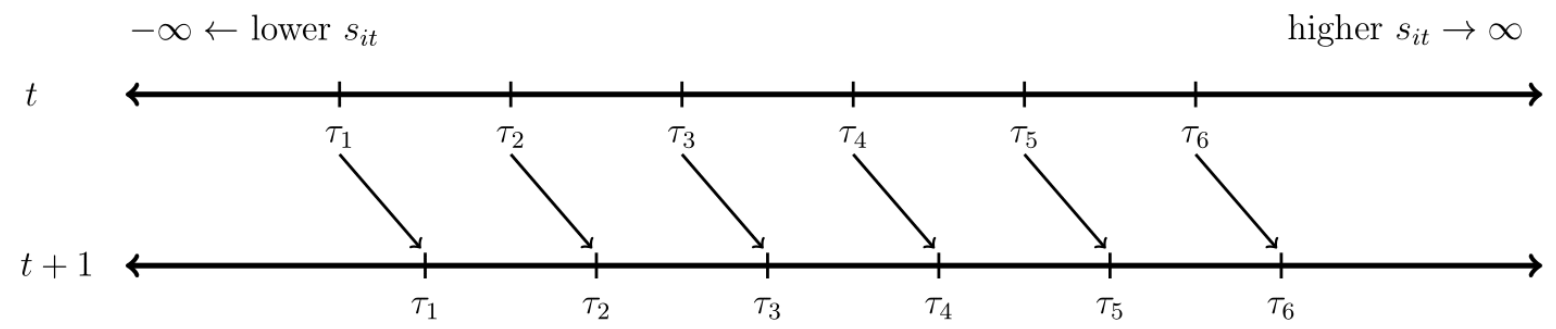

Panel B. Non-parallel Shift

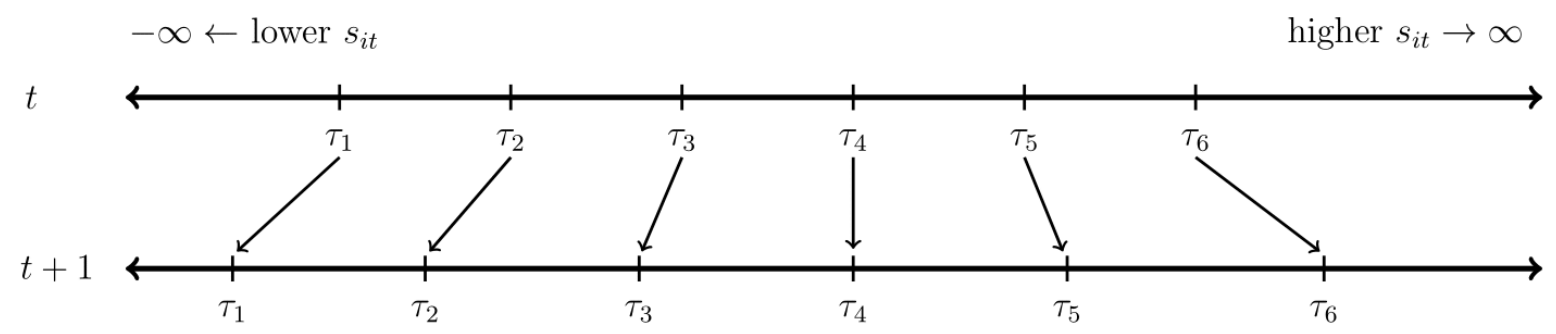

Here, $\boldsymbol{\delta}_{k}$ for $k>1$ may be interpreted as increasing the distance between adjacent thresholds (when $\boldsymbol{\delta}_{k}>0$ ) or as decreasing the distance between adjacent thresholds (when $\boldsymbol{\delta}_{k}<0$ ). In the former case, scale use is 'stretched', while in the latter case it is 'squeezed'.

In the specification of equation (11) it may occur that $\tau_{i t, k-1}>\tau_{i t, k}$ for some values of $\boldsymbol{X}_{i t}$ and some $k$ when not all corresponding entries in $\boldsymbol{\delta}_{k}$ and $\boldsymbol{\delta}_{k-1}$ have the same sign. Although theoretically undesirable, empirically this does not appear to be the case. Given its greater elegance and ease of interpretation, I prefer the specification of equation (11).

Estimates for such a model are presented in Table $6 .{ }^{19}$ The model shown in Table 6 also accounts for fixed effects. We can therefore compare these results to those of column (4) in Table 2. Results concerning overall shifts in scale use are almost unchanged in this compared to the baseline model of Table 2. To see this, compare the relevant estimates of $\boldsymbol{\delta}$ presented in Table 2 (given in column (4), panel C) to the corresponding estimates of $\boldsymbol{\delta}_{1}$ in Table 6 (given in column (3)).

I some evidence of non-parallel scale shifts (see columns (4)-(8) of Table 6). One clear such case is concerns being unemployed. There, coefficients on the fourth and fifth thresholds are significantly negative. This may indicate that for those who are unemployed, scale use is 'squeezed' at the upper end of the response scale. Similar results can also be seen for disability and poor health. Another interesting case occurs for reference incomes, where the highest threshold is significantly positive, indicating that higher reference income stretch the response scale at high satisfaction levels.

\footnotetext{
${ }^{19}$ Results using the more traditional specification of equation (10) can be found in Appendix Table E3. These are very similar to those given in Table 6 .
} 
Table 6. Allowing for non-parallel shifts in scale use when adding individual averages (linear specification)

\begin{tabular}{|c|c|c|c|c|c|c|c|c|}
\hline & $\begin{array}{l}\text { Current } \\
\text { Sat. } \\
(1)\end{array}$ & $\begin{array}{l}\text { Memory } \\
\text { of Sat. } \\
\text { (2) }\end{array}$ & $\begin{array}{c}\text { Cutoff } \\
\tau_{i t, 1} \\
(3)\end{array}$ & $\begin{array}{c}\text { Cutoff } \\
\tau_{i t, 2} \\
(4)\end{array}$ & $\begin{array}{c}\text { Cutoff } \\
\tau_{i t, 3} \\
(5)\end{array}$ & $\begin{array}{c}\text { Cutoff } \\
\tau_{i t, 4} \\
(6)\end{array}$ & $\begin{array}{c}\text { Cutoff } \\
\tau_{i t, 5} \\
(7)\end{array}$ & $\begin{array}{c}\text { Cutoff } \\
\tau_{i t, 6} \\
(8)\end{array}$ \\
\hline $\ln (\mathrm{HH}$ income $)$ & $\begin{array}{c}0.074^{* * *} \\
(0.025)\end{array}$ & $\begin{array}{l}0.053^{* *} \\
(0.023)\end{array}$ & $\begin{array}{c}0.051 \\
(0.040)\end{array}$ & $\begin{array}{l}-0.010 \\
(0.027)\end{array}$ & $\begin{array}{l}-0.027 \\
(0.021)\end{array}$ & $\begin{array}{c}0.016 \\
(0.015)\end{array}$ & $\begin{array}{c}0.010 \\
(0.013)\end{array}$ & $\begin{array}{c}0.002 \\
(0.013)\end{array}$ \\
\hline Employed (base) & & & & & & & & \\
\hline Self-employed & $\begin{array}{c}0.049 \\
(0.071)\end{array}$ & $\begin{array}{c}0.047 \\
(0.068)\end{array}$ & $\begin{array}{c}0.060 \\
(0.133)\end{array}$ & $\begin{array}{c}-0.126 \\
(0.100)\end{array}$ & $\begin{array}{c}0.067 \\
(0.074)\end{array}$ & $\begin{array}{l}-0.048 \\
(0.050)\end{array}$ & $\begin{array}{c}0.058 \\
(0.043)\end{array}$ & $\begin{array}{c}0.037 \\
(0.047)\end{array}$ \\
\hline Unemployed & $\begin{array}{c}-0.706^{* * *} \\
(0.078)\end{array}$ & $\begin{array}{l}-0.103 \\
(0.073)\end{array}$ & $\begin{array}{c}-0.290^{* *} \\
(0.125)\end{array}$ & $\begin{array}{l}-0.077 \\
(0.089)\end{array}$ & $\begin{array}{c}0.068 \\
(0.067)\end{array}$ & $\begin{array}{c}-0.166^{* * *} \\
(0.046)\end{array}$ & $\begin{array}{c}-0.184^{* * *} \\
(0.045)\end{array}$ & $\begin{array}{c}0.024 \\
(0.048)\end{array}$ \\
\hline Retired & $\begin{array}{c}0.213^{* * *} \\
(0.080)\end{array}$ & $\begin{array}{c}0.004 \\
(0.078)\end{array}$ & $\begin{array}{c}0.152 \\
(0.131)\end{array}$ & $\begin{array}{l}-0.027 \\
(0.087)\end{array}$ & $\begin{array}{c}0.032 \\
(0.067)\end{array}$ & $\begin{array}{l}-0.032 \\
(0.044)\end{array}$ & $\begin{array}{l}-0.040 \\
(0.039)\end{array}$ & $\begin{array}{c}0.010 \\
(0.039)\end{array}$ \\
\hline Not working & $\begin{array}{c}-0.164^{* * *} \\
(0.057)\end{array}$ & $\begin{array}{l}-0.076 \\
(0.054)\end{array}$ & $\begin{array}{c}0.062 \\
(0.104)\end{array}$ & $\begin{array}{l}-0.072 \\
(0.079)\end{array}$ & $\begin{array}{l}-0.002 \\
(0.057)\end{array}$ & $\begin{array}{l}-0.062 \\
(0.038)\end{array}$ & $\begin{array}{c}-0.123^{* * *} \\
(0.034)\end{array}$ & $\begin{array}{c}0.004 \\
(0.035)\end{array}$ \\
\hline Married (base) & & & & & & & & \\
\hline Widowed & $\begin{array}{c}-1.085^{* * *} \\
(0.137)\end{array}$ & $\begin{array}{c}-0.996^{* * *} \\
(0.140)\end{array}$ & $\begin{array}{c}-0.724^{* * *} \\
(0.169)\end{array}$ & $\begin{array}{l}-0.068 \\
(0.085)\end{array}$ & $\begin{array}{l}-0.008 \\
(0.074)\end{array}$ & $\begin{array}{c}0.108^{*} \\
(0.059)\end{array}$ & $\begin{array}{l}-0.015 \\
(0.053)\end{array}$ & $\begin{array}{l}-0.076 \\
(0.057)\end{array}$ \\
\hline Divorced & $\begin{array}{c}-0.455^{* * *} \\
(0.076)\end{array}$ & $\begin{array}{c}-0.428^{* * *} \\
(0.072)\end{array}$ & $\begin{array}{l}-0.199^{*} \\
(0.107)\end{array}$ & $\begin{array}{c}0.037 \\
(0.072)\end{array}$ & $\begin{array}{l}-0.035 \\
(0.056)\end{array}$ & $\begin{array}{c}0.068 \\
(0.046)\end{array}$ & $\begin{array}{l}-0.016 \\
(0.043)\end{array}$ & $\begin{array}{l}-0.074 \\
(0.052)\end{array}$ \\
\hline Never married & $\begin{array}{c}-0.392^{* * *} \\
(0.076)\end{array}$ & $\begin{array}{c}-0.281^{* * *} \\
(0.070)\end{array}$ & $\begin{array}{l}-0.132 \\
(0.117)\end{array}$ & $\begin{array}{l}-0.025 \\
(0.083)\end{array}$ & $\begin{array}{l}-0.075 \\
(0.068)\end{array}$ & $\begin{array}{c}0.055 \\
(0.050)\end{array}$ & $\begin{array}{l}-0.032 \\
(0.040)\end{array}$ & $\begin{array}{l}-0.063 \\
(0.047)\end{array}$ \\
\hline Disabled & $\begin{array}{c}-0.244^{* * *} \\
(0.052)\end{array}$ & $\begin{array}{c}-0.178^{* * *} \\
(0.054)\end{array}$ & $\begin{array}{l}-0.095 \\
(0.070)\end{array}$ & $\begin{array}{c}0.045 \\
(0.038)\end{array}$ & $\begin{array}{c}0.030 \\
(0.031)\end{array}$ & $\begin{array}{l}-0.043^{*} \\
(0.026)\end{array}$ & $\begin{array}{c}-0.074^{* * *} \\
(0.024)\end{array}$ & $\begin{array}{l}-0.016 \\
(0.026)\end{array}$ \\
\hline Poor health & $\begin{array}{c}-0.429^{* * *} \\
(0.035)\end{array}$ & $\begin{array}{c}-0.092^{* * *} \\
(0.034)\end{array}$ & $\begin{array}{c}-0.185^{* * *} \\
(0.048)\end{array}$ & $\begin{array}{c}0.028 \\
(0.030)\end{array}$ & $\begin{array}{c}0.013 \\
(0.024)\end{array}$ & $\begin{array}{l}-0.024 \\
(0.018)\end{array}$ & $\begin{array}{c}-0.049^{* * *} \\
(0.017)\end{array}$ & $\begin{array}{c}-0.068^{* * *} \\
(0.019)\end{array}$ \\
\hline $\ln (\mathrm{HH}$ size $)$ & $\begin{array}{c}-0.237^{* * *} \\
(0.055)\end{array}$ & $\begin{array}{l}0.027 \\
(0.052)\end{array}$ & $\begin{array}{l}-0.088 \\
(0.084)\end{array}$ & $\begin{array}{l}-0.044 \\
(0.057)\end{array}$ & $\begin{array}{l}-0.056 \\
(0.043)\end{array}$ & $\begin{array}{l}0.074^{* *} \\
(0.032)\end{array}$ & $\begin{array}{l}-0.009 \\
(0.027)\end{array}$ & $\begin{array}{c}0.006 \\
(0.031)\end{array}$ \\
\hline Childbirth & $\begin{array}{c}0.213^{* * *} \\
(0.051)\end{array}$ & $\begin{array}{l}0.095^{* *} \\
(0.045)\end{array}$ & $\begin{array}{l}0.209^{* *} \\
(0.097)\end{array}$ & $\begin{array}{l}-0.005 \\
(0.076)\end{array}$ & $\begin{array}{l}-0.012 \\
(0.050)\end{array}$ & $\begin{array}{l}-0.041 \\
(0.037)\end{array}$ & $\begin{array}{l}-0.056^{*} \\
(0.029)\end{array}$ & $\begin{array}{l}-0.019 \\
(0.032)\end{array}$ \\
\hline Ln(Job hours) & $\begin{array}{l}-0.010 \\
(0.016)\end{array}$ & $\begin{array}{c}0.016 \\
(0.015)\end{array}$ & $\begin{array}{l}-0.040 \\
(0.031)\end{array}$ & $\begin{array}{c}0.000 \\
(0.024)\end{array}$ & $\begin{array}{c}0.023 \\
(0.016)\end{array}$ & $\begin{array}{c}0.006 \\
(0.011)\end{array}$ & $\begin{array}{l}-0.012 \\
(0.010)\end{array}$ & $\begin{array}{l}0.023^{* *} \\
(0.010)\end{array}$ \\
\hline Reference income & $\begin{array}{l}-0.178 \\
(0.203) \\
\end{array}$ & $\begin{array}{c}0.137 \\
(0.195) \\
\end{array}$ & $\begin{array}{l}-0.324 \\
(0.257) \\
\end{array}$ & $\begin{array}{c}0.156 \\
(0.143) \\
\end{array}$ & $\begin{array}{c}0.143 \\
(0.091) \\
\end{array}$ & $\begin{array}{c}0.012 \\
(0.066) \\
\end{array}$ & $\begin{array}{c}0.059 \\
(0.058) \\
\end{array}$ & $\begin{array}{l}0.183^{* * *} \\
(0.063) \\
\end{array}$ \\
\hline Constant & & $\begin{array}{c}-0.353^{* *} \\
(0.147) \\
\end{array}$ & $\begin{array}{c}-2.482^{* * *} \\
(0.115)\end{array}$ & $\begin{array}{l}0.514^{* * *} \\
(0.072) \\
\end{array}$ & $\begin{array}{c}0.599^{* * *} \\
(0.048)\end{array}$ & $\begin{array}{c}0.690^{* * *} \\
(0.034)\end{array}$ & $\begin{array}{c}0.913^{* * *} \\
(0.031)\end{array}$ & $\begin{array}{l}0.978^{* * *} \\
(0.042)\end{array}$ \\
\hline Obs. (Respondents) & \multicolumn{8}{|c|}{$100,235(18,642)$} \\
\hline
\end{tabular}

However, the interpretation of $\boldsymbol{\delta}_{k}$ for $k>1$ is ambiguous. These parameters either indicate whether explanatory variables squeeze or expand the response scale, or they indicate heterogeneities in the effects of explanatory variables across the distribution of reported satisfaction. Indeed, via a change of notation, the linear specification of equation (12), together with equations (1) and (4), and when constraining $\boldsymbol{\delta}_{1}$ to 0 , can be seen to be equivalent to the generalized ordered logit/probit model described by Boes and Winkelmann (2004) and Williams (2006). ${ }^{20}$, both of which allow for heterogenous effects across the distribution of the response variable.

\footnotetext{
${ }^{20}$ In the probit version of that model, the probability of choosing response category $k$ is given by $\operatorname{Pr}\left(r_{i t}=k \mid \boldsymbol{X}_{i t}\right)=$ $\Phi\left(\omega_{k}-\boldsymbol{X}_{i t} \boldsymbol{\rho}_{k}\right)-\Phi\left(\omega_{k-1}-\boldsymbol{X}_{i t} \boldsymbol{\rho}_{k-1}\right)$, where we impose $\omega_{0}=-\infty, \omega_{K}=\infty$, and $\boldsymbol{\rho}_{0}=0$. This formulation allows the effects of explanatory variables on the latent variable to differ across response categories (hence the subscript
} 
Taking unemployment as an example, the negative coefficient of -0.166 for the $4^{\text {th }}$ cutoff can in that sense either be interpreted as unemployment bringing the $4^{\text {th }}$ cutoff closer to the third (i.e. unemployment 'squeezing' the response scale), or as indicating that the negative effect of unemployment is less severe for respondents whose level of life satisfaction is larger than the third response cutoff.

One avenue for future research should be to make the distinction between these different types of effects identifiable.

\subsubsection{Allowing for heteroskedasticity}

Finally, unlike OLS regressions, standard ordered probit estimates are biased in the presence of heteroskedasticity. Appendix Table F2 addresses this potential problem. There, a model analogous to the preferred baseline specification of column (4) in Table 2 is estimated. Following Williams (2009), I specify $\ln \left(\sigma_{i t}\right)=\kappa+\boldsymbol{\eta} \boldsymbol{X}_{\boldsymbol{i t} *}+\boldsymbol{\zeta} \overline{\boldsymbol{X}}_{\boldsymbol{i}}$ and $\ln \left(\sigma_{i t}^{(m)}\right)=\kappa^{(m)}+\boldsymbol{\eta}^{(\boldsymbol{m})} \boldsymbol{X}_{\boldsymbol{i t *}}+\boldsymbol{\zeta}^{(\boldsymbol{m})} \overline{\boldsymbol{X}}_{\boldsymbol{i}}$ to model the variances of the errors in equations (4) and (8). For identification, I must constrain $\kappa$ to some constant (c.f. Fontaine and Haywood 2018). Setting $\kappa=0.45$ results in the average predicted variance in the satisfaction equation being equal to 1 . This makes the models of Table 2 and F2 more easily comparable.

Overall, I find that almost every variables which increases (memories of) satisfaction decrease the error variances, and every variables which decrease (memories of) satisfaction increase the error variances. The only exception to this pattern are child births, which increase both satisfaction and the error variance. About $47 \%$ of all observations are among the top two response categories. It is hence possible that this empirical pattern is driven by ceiling effects in the satisfaction variable.

Regarding effects on latent satisfaction, the estimated effects of almost all variables - except household incomes - are slightly increased. However, all of the increases are too small to make a substantive difference. Finally, it is worth noting that the sign of the scale shift coefficient for reference incomes is switched and thus negative in Table F3 (but remains strongly insignificant). Despite this, comparing the results of Tables 2 and F3, it seems that the bias induced by a heteroskedastic error term is largely negligible.

\section{$5 \quad$ Conclusions}

The comparability of responses to survey questions is a fundamental issue for research on life satisfaction, wellbeing, and subjective attitudes more generally. With this paper, I hope to have made some progress in tackling this area.

$k$ for $\left.\boldsymbol{\rho}_{k}\right)$. In the linear specification of the model discussed in the present paper, the same probability for $k>1$ is given by:

$$
\operatorname{Pr}\left(r_{i t}=k \mid \boldsymbol{X}_{i t}\right)=\Phi\left(\left[\sum_{m=1}^{k} \gamma_{m}+\boldsymbol{X}_{i t} \boldsymbol{\delta}_{m}\right]-\boldsymbol{\beta} \boldsymbol{X}_{i t}\right)-\Phi\left(\left[\sum_{m=1}^{k} \gamma_{m-1}+\boldsymbol{X}_{i t} \boldsymbol{\delta}_{m-1}\right]-\boldsymbol{\beta} \boldsymbol{X}_{i t}\right)
$$

Where we impose $\gamma_{0}=-\infty, \gamma_{K}=\infty, \gamma_{K}=\infty$, and $\boldsymbol{\delta}_{0}=\boldsymbol{\delta}_{1}=\mathbf{0}$. Since we can write $\boldsymbol{\rho}_{k}=\boldsymbol{\beta}-\sum_{m=1}^{k} \boldsymbol{\delta}_{m}$ and $\omega_{k}=$ $\sum_{m=1}^{k} \gamma_{m}$ these formulations are equivalent. This equivalence does not hold in the case of the non-linear specification of equation (11). Nevertheless, the underlying point that we cannot separate heterogenous effects across the distribution of reported happiness from distortions of the response scale remains. This point also indicates that in order to cleanly identify non-parallel scale shifts in future work, we need additional information. Such additional information may e.g. be obtained by collecting data on memories over multiple years in the past, or by combining data on vignettes with data on memories. 
First, I clarified the biases that arise when the assumption of common scale use is not met. That analysis showed that violations of common scale use can lead to sign reversals of the effects of explanatory variables. Fortunately, such reversals are unlikely to occur in practice. Instead, downward biases in the absolute sizes of effect estimates are more likely to occur.

Second, as the paper's main contribution, I proposed a method with which over-time shifts in scale use can be separately identified from effects on latent satisfaction. The proposed method is complementary to the vignette approach: The vignette approach focuses on interpersonal comparability in cross-sectional data, while the proposed method focused on making satisfaction data intrapersonally comparable. Doing so is particularly important when analysing panel data.

Third, using the proposed memory approach, I analysed whether intrapersonal scale shifts plausibly occur in British BHPS data. To enable an assessment of the practical severity of the problems that scale shifts might cause, I focused on examining a broad set of demographics that have been widely analysed in previous work.

These analyses show, in line with theoretical expectation, that the direction in which explanatory variables affect scale use is typically the same as the direction in which explanatory variables affect latent satisfaction. I find particularly pronounced such effects for unemployment and widowhood. Although the assumption of present independence was not empirically testable, these results turned out to be robust even when assuming fairly strong violations of present independence.

Overall, estimated scale shifts are nevertheless not large enough to change conclusions about the signs and statistical significance of effects of standard socio-economic variables on latent satisfaction. Thus, when the interest is only in the sign and statistical significance of estimated effects, intrapersonal scale shifts do not seem to be a serious worry. In so far as this confirms the results of previous works, this is good news for the wider literature on subjective wellbeing and life satisfaction. 


\section{References}

Adler, Matthew D. 2013. 'Happiness Surveys and Public Policy: What's the Use?' Duke Law Journal 62 (8): 1509-1601.

Adler, Matthew D., Paul Dolan, and Georgios Kavetsos. 2017. 'Would You Choose to Be Happy? Tradeoffs between Happiness and the Other Dimensions of Life in a Large Population Survey'. Journal of Economic Behavior \& Organization 139 (July): 60-73. https://doi.org/10.1016/j.jebo.2017.05.006.

Ahmed, Sara, Nancy E. Mayo, Sharon Wood-Dauphinee, James A Hanley, and S Robin Cohen. 2004. 'Response Shift Influenced Estimates of Change in Health-Related Quality of Life Poststroke'. Journal of Clinical Epidemiology $57 \quad$ (6): 561-70. https://doi.org/10.1016/j.jclinepi.2003.11.003.

Angeles, Luis. 2010. 'Children and Life Satisfaction'. Journal of Happiness Studies 11 (4): 523-38. https:/ / doi.org/10.1007/s10902-009-9168-z.

Angelini, Viola, Danilo Cavapozzi, Luca Corazzini, and Omar Paccagnella. 2013. 'Do Danes and Italians Rate Life Satisfaction in the Same Way? Using Vignettes to Correct for IndividualSpecific Scale Biases'. Oxford Bulletin of Economics and Statistics 5. https://doi.org/10.1111/obes.12039.

Bago d'Uva, Teresa, Eddy Van Doorslaer, Maarten Lindeboom, and Owen O’Donnell. 2008. 'Does Reporting Heterogeneity Bias the Measurement of Health Disparities?' Health Economics 17 (3): 351-75.

Bell, Andrew, and Kelvyn Jones. 2015. 'Explaining Fixed Effects: Random Effects Modeling of Time-Series Cross-Sectional and Panel Data'. Political Science Research and Methods 3 (1): 133 53.

Benjamin, Daniel J, Jakina Debnam, Marc Fleurbaey, Ori Heffetz, and Miles Kimball. 2020. 'What Do Happiness Data Mean? Evidence from a Survey of Happiness Respondents'. Working Paper, 1-41.

Benjamin, Daniel J, Ori Heffetz, Miles S Kimball, and Alex Rees-Jones. 2012. 'What Do You Think Would Make You Happier? What Do You Think You Would Choose?' American Economic Review 102 (5): 2083-2110. https://doi.org/10.1257/aer.102.5.2083.

Benjamin, Daniel J., Ori Heffetz, Miles S. Kimball, and Alex Rees-Jones. 2014. 'Can Marginal Rates of Substitution Be Inferred from Happiness Data? Evidence from Residency Choices'. American Economic Review 104 (11): 3498-3528.

Bertoni, Marco. 2015. 'Hungry Today, Unhappy Tomorrow? Childhood Hunger and Subjective Wellbeing Later in Life'. Journal of Health Economics 40 (March): 40-53. https://doi.org/10.1016/j.jhealeco.2014.12.006.

Bertrand, Marianne, and Sendhil Mullainathan. 2001. 'Do People Mean What They Say? Implications for Subjective Survey Data'. American Economic Review 91 (2): 67-72.

Binder, Martin, and Alex Coad. 2013. 'Life Satisfaction and Self-Employment: A Matching Approach'. Small Business Economics 40 (4): 1009-33. https://doi.org/10.1007/s11187-0119413-9.

Blanchflower, David G., and Andrew J. Oswald. 1998. 'What Makes an Entrepreneur?' Journal of Labor Economics 16 (1): 26-60. 
2004. 'Well-Being over Time in Britain and the USA'. Journal of Public Economics 88 (7-8): 1359-86. https://doi.org/10.1016/S0047-2727(02)00168-8.

2019. 'Do Humans Suffer a Psychological Low in Midlife? Two Approaches (with and without Controls) in Seven Data Sets'. In The Economics of Happiness, edited by Mariano Rojas, 439-53. Springer.

Boes, Stefan, and Rainer Winkelmann. 2004. 'Income and Happiness: New Results from Generalized Threshold and Sequential Models'. IZA DP No. 1175: 32.

Bond, Timothy N., and Kevin Lang. 2019. 'The Sad Truth about Happiness Scales'. Journal of Political Economy 127 (4): 1629-40. https://doi.org/10.1086/701679.

Bonsang, Eric, and Arthur Van Soest. 2012. 'Satisfaction with Job and Income Among Older Individuals Across European Countries'. Social Indicators Research 105 (2): 227-54. https://doi.org/10.1007/s11205-011-9879-5.

Borah, Melanie, Carina Keldenich, and Andreas Knabe. 2019. 'Reference Income Effects in the Determination of Equivalence Scales Using Income Satisfaction Data'. Review of Income and Wealth 65 (4): 736-70. https://doi.org/10.1111/roiw.12386.

Cheng, Terence C., Nattavudh Powdthavee, and Andrew J. Oswald. 2017. 'Longitudinal Evidence for a Midlife Nadir in Human Well-Being: Results from Four Data Sets'. The Economic Journal 127 (599): 126-42. https://doi.org/10.1111/ecoj.12256.

Clark, Andrew E., Ed Diener, Yannis Georgellis, and Richard E Lucas. 2008. 'Lags and Leads in Life Satisfaction : A Test of the Baseline Hypothesis'. The Economic Journal 118 (529): 22243.

Clark, Andrew E., and Yannis Georgellis. 2013. 'Back to Baseline in Britain: Adaptation in the British Household Panel Survey'. Economica 80 (319): 496-512. https://doi.org/10.1111/ecca.12007.

Clark, Andrew E., and Andrew J. Oswald. 1994. 'Unhappiness and Unemployment'. The Economic Journal 104 (424): 648-59.

. 1996. 'Satisfaction and Comparison Income'. Journal of Public Economics 61 (3): 359-81. https://doi.org/10.1016/0047-2727(95)01564-7.

Conway, Michael, and Michael Ross. 1984. 'Getting What You Want by Revising What You Had.' Journal of Personality and Social Psychology 47 (4): 738.

Corrado, Luisa, and Melvyn Weeks. 2010. 'Identification Strategies in Survey Response Using Vignettes'. CWPE Working Paper 1031.

Crettaz, Eric, and Christian Suter. 2013. 'The Impact of Adaptive Preferences on Subjective Indicators: An Analysis of Poverty Indicators'. Social Indicators Research 114 (1): 139-52. https://doi.org/10.1007/s11205-013-0388-6.

Danzer, Alexander M., and Natalia Danzer. 2016. 'The Long-Run Consequences of Chernobyl: Evidence on Subjective Well-Being, Mental Health and Welfare'. Journal of Public Economics 135 (March): 47-60. https://doi.org/10.1016/j.jpubeco.2016.01.001.

Datta Gupta, Nabanita, Nicolai Kristensen, and Dario Pozzoli. 2010. 'External Validation of the Use of Vignettes in Cross-Country Health Studies'. Economic Modelling 27 (4): 854-65. https://doi.org/10.1016/j.econmod.2009.11.007.

Decancq, Koen, Marc Fleurbaey, and Erik Schokkaert. 2015. 'Happiness, Equivalent Incomes and Respect for Individual Preferences'. Economica 82 (s1): 1082-1106. https://doi.org/10.1111/ecca.12152. 
Dermer, Marshall, Sidney J. Cohen, Elaine Jacobsen, and Erling A. Anderson. 1979. 'Evaluative Judgments of Aspects of Life as a Function of Vicarious Exposure to Hedonic Extremes.' Journal of Personality and Social Psychology 37 (2): 247.

Di Tella, Rafael, John Haisken-De New, and Robert MacCulloch. 2010. 'Happiness Adaptation to Income and to Status in an Individual Panel'. Journal of Economic Behavior and Organization 76 (3): 834-52. https://doi.org/10.1016/j.jebo.2010.09.016.

Diamond, Peter. 2008. 'Behavioral Economics'. Journal of Public Economics 92 (8-9): 1858-62. https://doi.org/10.1016/j.jpubeco.2008.03.003.

Dolan, Paul, Georgios Kavetsos, Christian Krekel, Dimitris Mavridis, Robert Metcalfe, Claudia Senik, Stefan Szymanski, and Nicolas R. Ziebarth. 2019. 'Quantifying the Intangible Impact of the Olympics Using Subjective Well-Being Data'. Journal of Public Economics 177 (September): 104043. https://doi.org/10.1016/j.jpubeco.2019.07.002.

Dominitz, Jeff, and Charles F. Manski. 1997. 'Using Expectations Data to Study Subjective Income Expectations'. Journal of the American Statistical Association 92 (439): 855-67. https://doi.org/10.1080/01621459.1997.10474041.

Easterlin, Richard A. 1974. 'Does Economic Growth Improve the Human Lot? Some Empirical Evidence'. Nations and Households in Economic Growth 89: 89-125. . 1995. 'Will Raising the Incomes of All Increase the Happiness of All?' Journal of Economic Behavior \& Organization 27 (1): 35-47. https:// doi.org/10.1016/0167-2681(95)00003-B. 2001. 'Income and Happiness: Towards a Unified Theory'. The Economic Journal 111 (473): 465-84. https://doi.org/10.1111/1468-0297.00646.

Easterlin, Richard A., and Kelsey J. O'Connor. 2020. 'The Easterlin Paradox'.

Fabian, Mark. 2019. 'Scale Norming Undermines the Use of Life Satisfaction Scale Data for Welfare Analysis'. SocArXiv. https://doi.org/10.31235/osf.io/cg8n9.

Falk, Armin, and Markus Knell. 2004. 'Choosing the Joneses: Endogenous Goals and Reference Standards'. Scandinavian Journal of Economics 106 (3): 417-35.

Ferrer-i-Carbonell, Ada. 2005. 'Income and Well-Being: An Empirical Analysis of the Comparison Income Effect'. Journal of Public Economics 89 (5-6): 997-1019. https://doi.org/10.1016/j.jpubeco.2004.06.003.

Ferrer-i-Carbonell, Ada, and Paul Frijters. 2004. 'How Important Is Methodology for the Estimates of the Determinants of Happiness?' The Economic Journal 114 (497): 641-59. https://doi.org/10.1111/j.1468-0297.2004.00235.x.

Ferrer-i-Carbonell, Ada, and Bernard M. S. Van Praag. 2008. 'Do People Adapt to Changes in Income and Other Circumstances? The Discussion Is Not Finished Yet'.

FitzRoy, Felix R., Michael A. Nolan, Max F. Steinhardt, and David Ulph. 2014. 'Testing the Tunnel Effect: Comparison, Age and Happiness in UK and German Panels'. IZA Journal of European Labor Studies 3 (1): 24.

Fleurbaey, Marc, and Didier Blanchet. 2013. Beyond GDP: Measuring Welfare and Assessing Sustainability. Oxford University Press.

Fontaine, Xavier, and Luke Haywood. 2018. 'On the Comparison of Group Inequalities Using Subjective Data'. Economics Letters 163 (February): 17-21. https://doi.org/10.1016/j.econlet.2017.11.001.

Forgas, Joseph P. 1995. 'Mood and Judgment: The Affect Infusion Model (AIM).' Psychological Bulletin 117 (1): 39. 
Frijters, Paul, and Tony Beatton. 2012. 'The Mystery of the U-Shaped Relationship between Happiness and Age'. Journal of Economic Behavior \& Organization 82 (2-3): 525-42. https://doi.org/10.1016/j.jebo.2012.03.008.

Frijters, Paul, John P. Haisken-DeNew, and Michael A. Shields. 2004. 'Money Does Matter! Evidence from Increasing Real Income and Life Satisfaction in East Germany Following Reunification'. The American Economic Review 94 (3): 730-40.

Frijters, Paul, David W. Johnston, and Michael A. Shields. 2011. 'Happiness Dynamics with Quarterly Life Event Data'. Scandinavian Journal of Economics 113 (1): 190-211. https://doi.org/10.1111/j.1467-9442.2010.01638.x.

Gibbons, F. X. 1999. 'Social Comparison as a Mediator of Response Shift'. Social Science \& Medicine 48 (11): 1517-30. https:/ / doi.org/10.1016/S0277-9536(99)00046-5.

Gorry, Aspen, Devon Gorry, and Sita Nataraj Slavov. 2018. 'Does Retirement Improve Health and Life Satisfaction?’ Health Economics 27 (12): 2067-86. https://doi.org/10.1002/hec.3821.

Greene, William. 2004. 'The Behaviour of the Maximum Likelihood Estimator of Limited Dependent Variable Models in the Presence of Fixed Effects'. The Econometrics Journal 7 (1): 98-119. https://doi.org/10.1111/j.1368-423X.2004.00123.x.

Greene, William H., and David A. Hensher. 2010. Modeling Ordered Choices: A Primer and Recent Developments. Cambridge University Press.

Greenleaf, Eric A. 1992a. 'Improving Rating Scale Measures by Detecting and Correcting Bias Components in Some Response Styles'. Journal of Marketing Research, 13.

Greenleaf, Eric A. 1992b. 'Measuring Extreme Response Style'. Public Opinion Quarterly 56 (3): 328. https://doi.org/10.1086/269326.

Gupta, Prashant, Tapas Mishra, Nigel O’Leary, and Mamata Parhi. 2015. 'The Distributional Effects of Adaption and Anticipation to Ill Health on Subjective Wellbeing'. Economics Letters 136 (November): 99-102. https://doi.org/10.1016/j.econlet.2015.09.010.

Hanglberger, Dominik, and Joachim Merz. 2015. 'Does Self-Employment Really Raise Job Satisfaction? Adaptation and Anticipation Effects on Self-Employment and General Job Changes'. Journal for Labour Market Research 48 (4): 287-303.

Hoogstraten, Joh. 1985. 'Influence of Objective Measures on Self-Reports in a Retrospective Pretest-Posttest Design'. The Journal of Experimental Education 53 (4): 207-10. https://doi.org/10.1080/00220973.1985.10806383.

Howard, George S., and Patrick R. Dailey. 1979. 'Response-Shift Bias: A Source of Contamination of Self-Report Measures'. Journal of Applied Psychology 64 (2): 144-50.

Howard, George S., Kenneth M. Ralph, Nancy A. Gulanick, Scott E. Maxwell, Don W. Nance, and Sterling K. Gerber. 1979. 'Internal Invalidity in Pretest-Posttest Self-Report Evaluations and a Re-Evaluation of Retrospective Pretests'. Applied Psychological Measurement 3 (1): 1-23.

Howard, George S., Ronald R. Schmeck, and James H. Bray. 1979. 'Internal Invalidity in Studies Employing Self-Report Instruments: A Suggested Remedy'. Journal of Educational Measurement, 129-35.

Ifcher, John, Homa Zarghamee, and Carol Graham. 2018. 'Local Neighbors as Positives, Regional Neighbors as Negatives: Competing Channels in the Relationship between Others' Income, Health, and Happiness'. Journal of Health Economics 57: 263-76. 
Kahneman, Daniel, and Angus Deaton. 2010. 'High Income Improves Evaluation of Life but Not Emotional Well-Being.' PNAS $107 \quad$ (38): 16489-93. https://doi.org/10.1073/pnas.1011492107.

Kaiser, Caspar. 2020. 'People Do Not Adapt. New Analyses of the Dynamic Effects of Own and Reference Income on Life Satisfaction'. Journal of Economic Behavior \& Organization 177: 494513. https://doi.org/10.1016/j.jebo.2020.06.003.

Kaiser, Caspar, and Maarten CM Vendrik. 2019. 'Different Versions of the Easterlin Paradox: New Evidence for European Countries'. In The Economics of Happiness, 27-55. Springer. https://doi.org/10.1007/978-3-030-15835-4_2.

. 2020. 'How Threatening Are Transformations of Happiness Scales to Subjective Wellbeing Research?’ INET Working Paper. https://www.inet.ox.ac.uk/publications/no2020-19-how-threatening-are-transformations-of-happiness-scales-to-subjectivewellbeing-research/.

Kapteyn, Arie, James P Smith, and Arthur Van Soest. 2007. 'Vignettes and Self-Reports of Work Disability in the United States and the Netherlands'. The American Economic Review 97 (1): 461-73.

Kapteyn, Arie, James P. Smith, and Arthur Van Soest. 2010. 'Life Satisfaction'. In International Differences in Wellbeing, edited by Ed Diener, John F. Helliwell, and Daniel Kahneman. Oxford University Press.

Kassenboehmer, Sonja C., and John P. Haisken-DeNew. 2009. 'You're Fired! The Causal Negative Effect of Entry Unemployment on Life Satisfaction'. The Economic Journal 119 (536): 44862.

King, Gary, Christopher J L Murray, Joshua A Salomon, Ajay Tandon, Gary King, Christopher J L Murray, World Health, and Joshua A Salomon. 2004. 'Enhancing the Validity and CrossCultural Comparability of Measurement in Survey Research'. The American Political Science Review 98 (1): 191-207.

Klaassen, Tineke, W. J. Riedel, N. E. P. Deutz, and H. M. Van Praag. 2002. 'Mood Congruent Memory Bias Induced by Tryptophan Depletion'. Psychological Medicine 32 (1): 167.

Kohler, Hans-Peter, Jere R. Behrman, and Axel Skytthe. 2005. 'Partner + Children = Happiness? The Effects of Partnerships and Fertility on Well-Being'. Population and Development Review 31 (3): 407-45. https://doi.org/10.1111/j.1728-4457.2005.00078.x.

Köke, Sonja, and Grischa Perino. 2017. 'For "Better" or "Worse": A Direct Approach to Elicit Preference Rankings from Life-Satisfaction Data'. WiSo-HH Working Paper Series, no. 43.

Kollamparambil, Umakrishnan. 2021. 'Past and Present Subjective Wellbeing: The Role of Contrast and Memory'. Preprint. In Review. https://doi.org/10.21203/rs.3.rs-248212/v1.

Kristensen, Nicolai, and Edvard Johansson. 2008. 'New Evidence on Cross-Country Differences in Job Satisfaction Using Anchoring Vignettes'. Labour Economics 15 (1): 96-117. https://doi.org/10.1016/j.labeco.2006.11.001.

Layard, Richard, Guy Mayraz, and Stephen Nickell. 2008. 'The Marginal Utility of Income'. Journal of Public Economics 92 (8): 1846-57.

Levine, Linda J., and Susan Bluck. 2004. 'How Emotions Fade: Valence, Appraisals, and the Emotional Impact of Remembered Events.' In Advances in Psychology Research, edited by Serge P. Shohov, 30:3-20. Nova Science Publishers. 
Levy, Horacio, and Stephen P. Jenkins. 2012. 'Documentation for Derived Current and Annual Net Household Income Variables, BHPS Waves 1-18'. UK Data Archive Study Number 3909. Lewis, P. A., H. D. Critchley, A. P. Smith, and R. J. Dolan. 2005. 'Brain Mechanisms for Mood Congruent Memory Facilitation'. NeuroImage 25 (4): 1214-23.

Lucas, Richard E. 2005. 'Time Does Not Heal All Wounds: A Longitudinal Study of Reaction and Adaptation to Divorce'. Psychological Science $16 \quad$ (12): 945-50. https://doi.org/10.1111/j.1467-9280.2005.01642.x.

Lucas, Richard E., Andrew E. Clark, Yannis Georgellis, and Ed Diener. 2004. 'Unemployment Alters the Set Point for Life Satisfaction'. Psychological Science 15 (1): 8-13.

Luechinger, Simon. 2009. 'Valuing Air Quality Using the Life Satisfaction Approach'. The Economic Journal 119 (536): 482-515.

Mayer, John D., Yvonne N. Gaschke, Debra L. Braverman, and Temperance W. Evans. 1992. 'Mood-Congruent Judgment Is a General Effect.' Journal of Personality and Social Psychology 63 (1): 119.

McBride, M. 2001. 'Relative-Income Effects on Subjective Well-Being in the Cross-Section'. Journal of Economic Behavior \& Organization 45 (3): 251-78. https://doi.org/10.1016/S01672681(01)00145-7.

Montgomery, Mallory. 2017. 'Reversing the Gender Gap in Happiness: Validating the Use of Life Satisfaction Self-Reports Worldwide'. Working Paper.

Mundlak, Yair. 1978. 'On the Pooling of Time Series and Cross Section Data'. Econometrica, 69-85. Murray, Christopher JL, Emre Ozaltin, Ajay Tandon, Joshua Salomon, Ritu Sadana, and Somnath Chatterji. 2003. 'Empirical Evaluation of the Anchoring Vignette Approach in Health Surveys'. Health Systems Performance Assessment: Debates, Methods and Empiricism, 369-99.

Murtin, Fabrice, Romina Boarini, Juan Carlos Cordoba, and Marla Ripoll. 2017. 'Beyond GDP: Is There a Law of One Shadow Price?’ European Economic Review 100 (November): 390-411. https://doi.org/10.1016/j.euroecorev.2017.09.001.

Nelson, S. Katherine, Kostadin Kushlev, and Sonja Lyubomirsky. 2014. 'The Pains and Pleasures of Parenting: When, Why, and How Is Parenthood Associated with More or Less WellBeing?’ Psychological Bulletin 140 (3): 846.

Odermatt, Reto, and Alois Stutzer. 2019. '(Mis-)Predicted Subjective Well-Being Following Life Events'. Journal of the European Economic Association 17 (1): 245-83. https://doi.org/10.1093/jeea/jvy005.

Oparina, Ekaterina, and Sorawoot Srisuma. 2020. 'Analyzing Subjective Well-Being Data with Misclassification'. Journal of Business \& Economic Statistics, December, 1-14. https://doi.org/10.1080/07350015.2020.1865169.

Oswald, Andrew J. 2008. 'On the Curvature of the Reporting Function from Objective Reality to $\begin{array}{llllll}\text { Subjective Feelings'. Economics } & \text { Letters } 100 & \text { (3): }\end{array}$ https://doi.org/10.1016/j.econlet.2008.02.032.

Oswald, Andrew J., and Nattavudh Powdthavee. 2008. 'Does Happiness Adapt? A Longitudinal Study of Disability with Implications for Economists and Judges'. Journal of Public Economics 92 (5): 1061-77. https://doi.org/10.1016/j.jpubeco.2008.01.002.

Peracchi, Franco, and Claudio Rossetti. 2013. 'The Heterogeneous Thresholds Ordered Response Model: Identification and Inference'. Journal of the Royal Statistical Society: Series A (Statistics in Society) 176 (3): 703-22. 
Perez-Truglia, Ricardo. 2015. 'A Samuelsonian Validation Test for Happiness Data'. Journal of Economic Psychology 49: 74-83. https://doi.org/10.1016/j.joep.2015.05.002.

Plant, Michael. 2020. 'Life Satisfaction and Its Discontents'. Happier Lives Institute Working Paper. https://www.happierlivesinstitute.org/uploads/1/0/9/9/109970865/life_satisfaction_an d_its_discontents_jul2020.pdf.

Prati, Alberto. 2017. 'Hedonic Recall Bias. Why You Should Not Ask People How Much They Earn'. Journal of Economic Behavior \& Organization 143: 78-97.

Prati, Alberto, and Claudia Senik. 2020. 'Feeling Good or Feeling Better?' PSE Working Papers, no. 17. https://econpapers.repec.org/paper/halpsewpa/halshs-02545228.htm.

Ravallion, Martin, Kristen Himelein, and Kathleen Beegle. 2016. 'Can Subjective Questions on Economic Welfare Be Trusted?' Economic Development and Cultural Change 64 (4): 697-726.

Riedl, Maximilian, and Ingo Geishecker. 2014. 'Keep It Simple: Estimation Strategies for Ordered Response Models with Fixed Effects'. Journal of Applied Statistics 41 (11): 2358-74. https://doi.org/10.1080/02664763.2014.909969.

Schröder, Carsten, and Shlomo Yitzhaki. 2017. 'Revisiting the Evidence for Cardinal Treatment of Ordinal Variables'. European Economic Review 92 (February): 337-58. https://doi.org/10.1016/j.euroecorev.2016.12.011.

Schwarz, Norbert, and Fritz Strack. 1999. 'Reports of Subjective Well-Being: Judgmental Processes and Their Methodological Implications'. In Well-Being: The Foundations of Hedonic Psychology, 7:61-84.

Senik, Claudia. 2008. 'Ambition and Jealousy: Income Interactions in the "Old" Europe versus the "New" Europe and the United States'. Economica 75 (299): 495-513. https://doi.org/10.1111/j.1468-0335.2007.00629.x.

Sprangers, Mirjam A. G, and Carolyn E Schwartz. 1999. 'Integrating Response Shift into HealthRelated Quality of Life Research: A Theoretical Model'. Social Science \& Medicine 48 (11): 1507-15. https://doi.org/10.1016/S0277-9536(99)00045-3.

Sprangers, Mirjam A. G., Frits S. A. Van Dam, Jenny Broersen, Litanja Lodder, Lidwina Wever, Mechteld R. M. Visser, Paul Oosterveld, and Ellen M.A. Smets. 1999. 'Revealing Response Shift in Longitudinal Research on Fatigue: The Use of the Thentest Approach'. Acta Oncologica 38 (6): 709-18. https://doi.org/10.1080/028418699432860.

Steffel, Mary, and Daniel M. Oppenheimer. 2009. 'Happy by What Standard? The Role of Interpersonal and Intrapersonal Comparisons in Ratings of Happiness'. Social Indicators Research 92 (1): 69-79. https://doi.org/10.1007/s11205-008-9289-5.

Stevenson, Betsey, and Justin Wolfers. 2008. 'Economic Growth and Subjective Well-Being: Reassessing the Easterlin Paradox'. Working Paper 14282. National Bureau of Economic Research. https://doi.org/10.3386/w14282.

2009. 'The Paradox of Declining Female Happiness'. American Economic Journal: Economic Policy 1 (2): 190-225. https://doi.org/10.1257/pol.1.2.190.

Sumner, L. W. 1996. Welfare, Happiness, and Ethics. Oxford University Press.

Townsend, Michael, and Keri Wilton. 2003. 'Evaluating Change in Attitude towards Mathematics Using the "Then-Now" Procedure in a Cooperative Learning Programme'. British Journal of Educational Psychology 73 (4): 473-87. https://doi.org/10.1348/000709903322591190. 
Urban, Emily J., Susan T. Charles, Linda J. Levine, and David M. Almeida. 2018. 'Depression History and Memory Bias for Specific Daily Emotions'. PLoS ONE 13 (9). https://www.ncbi.nlm.nih.gov/pmc/articles/PMC6128594/.

Uva, Teresa Bago d', Maarten Lindeboom, Owen O'Donnell, and Eddy Van Doorslaer. 2011. 'Slipping Anchor? Testing the Vignettes Approach to Identification and Correction of Reporting Heterogeneity'. Journal of Human Resources 46 (4): 875-906.

Van Praag, Bernard M. S. 1971. 'The Welfare Function of Income in Belgium: An Empirical Investigation'. European Economic Review 2 (3): 337-69.

—. 2015. 'A New View on Panel Econometrics: Is Probit Feasible After All?' IZA Discussion Paper, no. 9345.

Van Praag, Bernard M. S., and Ada Ferrer-i-Carbonell. 2008. Happiness Quantified: A Satisfaction Calculus Approach. 2nd ed. Oxford University Press.

Van Praag, Bernard M. S., and Paul Frijters. 1999. 'The Measurement of Welfare and Well-Being: The Leyden Approach'. In Well-Being: Foundations of Hedonic Psychology, edited by Daniel Kahneman, Ed Diener, and Norbert Schwarz, 302.

Van Vaerenbergh, Yves, and Troy D. Thomas. 2013. 'Response Styles in Survey Research: A Literature Review of Antecedents, Consequences, and Remedies'. International Journal of Public Opinion Research 25 (2): 195-217. https://doi.org/10.1093/ijpor/eds021.

Vendrik, Maarten C. M. 2013. 'Adaptation, Anticipation and Social Interaction in Happiness: An Integrated Error-Correction Approach'. Journal of Public Economics 105: 131-49. https://doi.org/10.1016/j.jpubeco.2013.06.009.

Vendrik, Maarten C. M., and Geert B. Woltjer. 2007. 'Happiness and Loss Aversion: Is Utility Concave or Convex in Relative Income?’ Journal of Public Economics 91 (7-8): 1423-48. https://doi.org/10.1016/j.jpubeco.2007.02.008.

Viscusi, W. Kip. 2020. 'Wellbeing Measures of Mortality Risks: Life-Cycle Contradictions and Ordinal Index Challenges'. Behavioural Public Policy 4 (2): 245-53. https://doi.org/10.1017/bpp.2019.47.

Weijters, Bert, Maggie Geuens, and Niels Schillewaert. 2010. 'The Stability of Individual Response Styles.' Psychological Methods 15 (1): 96-110. https://doi.org/10.1037/a0018721.

Wetzel, Martin, Oliver Huxhold, and Clemens Tesch-Römer. 2016. 'Transition into Retirement Affects Life Satisfaction: Short- and Long-Term Development Depends on Last Labor Market Status and Education'. Social Indicators Research 125 (3): 991-1009. https://doi.org/10.1007/s11205-015-0862-4.

Williams, Richard. 2006. 'Generalized Ordered Logit/Partial Proportional Odds Models for Ordinal Dependent Variables’. Stata Journal 6 (1): 58-82. https://doi.org/st0097. . 2009. 'Using Heterogeneous Choice Models to Compare Logit and Probit Coefficients Across Groups'. Sociological Methods \& Research 37 (4): 531-59. https://doi.org/10.1177/0049124109335735.

Wilson, Timothy D., and Daniel T. Gilbert. 2005. 'Affective Forecasting'. Current Directions in Psychological Science 14 (3): 131.

Wilson, Timothy D., Jay Meyers, and Daniel T. Gilbert. 2003. “'How Happy Was I, Anyway?” A Retrospective Impact Bias'. Social Cognition 21 (6): 421-46.

Winkelmann, Liliana, and Rainer Winkelmann. 1998. 'Why Are the Unemployed so Unhappy? Evidence from Panel Data'. Economica 65 (257): 1-15. 
Wooldridge, Jeffrey M. 2010. Econometric Analysis of Cross Section and Panel Data. MIT press.

$\mathrm{Xu}$, Hongwei, and Yu Xie. 2016. 'Assessing the Effectiveness of Anchoring Vignettes in Bias Reduction for Socioeconomic Disparities in Self-Rated Health among Chinese Adults'. Sociological Methodology 46 (1): 84-120. https://doi.org/10.1177/0081175015599808. 


\section{Appendix}

\section{A Interpretation of absolute magnitudes of coefficients}

Life satisfaction, like most other subjective constructs, has no natural cardinal scale, with no welldefined physical phenomena to ground it and no natural zero point. Despite this feature of subjective constructs, some interpretations of the absolute magnitudes of coefficients may nevertheless be both useful and meaningful.

It might be natural to interpret the magnitudes of coefficients in relation to how a (marginal) change in covariates changes the probability of exceeding some particular response level. However, as noted in section 2.2 of the main text, covariates may affect the probability of exceeding some particular response category both by affecting scale use or by affecting latent satisfaction. Thus, interpreting variables' effects in relation to their impact on response probabilities, which are given by $\varphi\left(\boldsymbol{X}_{i t *}\left(\boldsymbol{\beta}_{*}-\boldsymbol{\delta}_{*}\right)-\gamma_{k}\right)\left(\beta_{j, 0}-\delta_{j, 0}\right)$ (c.f. section 2.2.), are contaminated by the covariates' effects on scale use, and therefore not informative about covariates' effects on latent satisfaction.

To get around this issue, one could average, for each explanatory variables $X_{j, i t}$, $\varphi\left(\boldsymbol{X}_{i t *-j}\left(\boldsymbol{\beta}_{*-j}-\boldsymbol{\delta}_{*-j}\right)+X_{j, i t} \beta_{j, 0}-\gamma_{k}\right) \beta_{j, 0}$ over all observed combinations of $\boldsymbol{X}_{i t *}$. Here, $\boldsymbol{X}_{i t *-j}$ is the same as $\boldsymbol{X}_{i t *}$ but has entry $X_{j, i t}$ removed. Vectors $\boldsymbol{\beta}_{*-j}$ and $\boldsymbol{\delta}_{*-j}$ are defined analogously. Such an exercise can be interpreted as estimating the average marginal effect of $X_{j, i t}$ on the probability of responding category $r>k$ conditional on $\boldsymbol{X}_{i t *}$ under a counterfactual in which $X_{j, i t}$ did not also affect scale use. However, this is cumbersome to compute and not a very intuitive interpretation of the absolute magnitude.

In the context of OLS regressions, one oft-used intuitive interpretation is to discuss by how many categories a respondent can be expected to change her response given a unit change in an explanatory variable's value. This is very straightforward in this context and given by $\mathrm{E}\left(r_{i t} \mid X_{j, i t}+\right.$ $\left.1 ; \boldsymbol{X}_{i t *-j}\right)-\mathrm{E}\left(r_{i t} \mid X_{j, i t} ; \boldsymbol{X}_{i t *-j}\right)=\beta_{j, 0}$.

However, in the ordered probit context, differences between thresholds are not equal. Nevertheless, an analogue may usefully indicate how much latent satisfaction changes for a unit change in $X_{j, i t}$ as a fraction of the normalized width of the satisfaction scale. Here, the natural normalization is over the number of estimated thresholds. The width of the scale can be given by the difference between the highest and lowest estimated threshold.

Formally this is given by:

$$
\begin{gathered}
{\left[\mathrm{E}\left(s_{i t} /\left(\tau_{K-1}-\tau_{1}\right) \mid X_{j, i t}+1 ; \boldsymbol{X}_{i t *-j}\right)-\mathrm{E}\left(s_{i t} /\left(\tau_{K-1}-\tau_{1}\right) \mid X_{j, i t} ; \boldsymbol{X}_{i t *-j}\right)\right](K-1)} \\
=\beta_{j, 0}(K-1) /\left(\gamma_{K-1}-\gamma_{1}\right)
\end{gathered}
$$

The effect of $X_{j, i t}$ on scale use cancels in this expression. Fortunately, this expression is directly obtained from our parameter estimates. We may hence use this as an intuitive interpretation of the absolute magnitudes of effects on latent satisfaction. 


\section{B Using vignettes to correct for violations of common scale use}

\section{B.1 Outline of approach}

The vignette approach tackles violations of common scale use by presenting respondents with short descriptions of imaginary persons' lives (King et al., 2004). An example from the SHARE survey for such a vignette is the following:

John is 63 years old. His wife died 2 years ago, and he still spends a lot of time thinking about her. He has four children and ten grandchildren who visit him regularly. John can make ends meet but has no money for extras such as expensive gifts to his grandchildren. He has had to stop working recently due to heart problems. He gets tired easily. Otherwise, he has no serious health conditions. How satisfied with his life do you think John is?'.

Respondents are asked to rate the life satisfaction of these imaginary persons. On the assumption that all respondents perceive the described person's satisfaction equally, identification of differences in scale use become possible.

More formally, assume that, from a set of $V$ vignettes, respondents give a report $r_{i t}^{(v)}$ about a particular vignette $v$ on the basis of a perceived satisfaction level $s_{i t}^{(v)}$ of that vignette. Also assume that respondents use the same response scale for their own satisfaction as for rating the vignettes. This yields a reporting rule analogous to equation (1):

$$
r_{i t}^{(v)}=k \quad \leftrightarrow \quad \tau_{i t, k-1}<s_{i t}^{(v)} \leq \tau_{i t, k}
$$

Note that the same thresholds are used in equations (1) and (A2). In the main text, and in line with the previous literature, we may call this the 'response consistency' assumption. Further assume that the perceived level of $s_{i t}^{(v)}$ does not depend on $\boldsymbol{X}_{i t}$. This assumption is known as the vignette equivalence assumption, and is a direct analogue to the 'present independence' assumption of the main text.

More specifically, consider:

$$
s_{i t}^{(v)}=\theta^{(v)}+\boldsymbol{X}_{i t} \lambda^{(v)}+\varepsilon_{i t}^{(v)}
$$

Here, $\theta^{(v)}$ is a vignette-specific parameter and $\varepsilon_{i t}^{(v)}$ is a normally distributed error term with mean 0 and standard deviation 1. Vignette equivalence entails that $\boldsymbol{\lambda}^{(v)}=\mathbf{0}$. Incorporating these additional equations, the individual contributions to the likelihood then become:

$$
\begin{aligned}
& \ell_{i t}=\sum_{k=1}^{K} \mathrm{I}\left(r_{i t}=k\right) \ln \left[\Phi\left(\gamma_{k}+\boldsymbol{X}_{i t} \boldsymbol{\delta}-\boldsymbol{X}_{i t} \boldsymbol{\beta}\right)-\Phi\left(\gamma_{k-1}+\boldsymbol{X}_{i t} \boldsymbol{\delta}-\boldsymbol{X}_{i t} \boldsymbol{\beta}\right)\right] \\
& +\sum_{v} \sum_{k=1}^{K} \mathrm{I}\left(r_{i t}^{(v)}=k\right) \ln \left[\Phi\left(\gamma_{k}+\boldsymbol{X}_{i t} \boldsymbol{\delta}-\theta^{(v)}-\boldsymbol{X}_{i t} \lambda^{(v)}\right)-\Phi\left(\gamma_{k-1}+\boldsymbol{X}_{i t} \boldsymbol{\delta}-\theta^{(v)}-\boldsymbol{X}_{i t} \boldsymbol{\lambda}^{(v)}\right)\right]
\end{aligned}
$$

When assuming $\boldsymbol{\lambda}^{(v)}=\mathbf{0}, \boldsymbol{\delta}$ and $\boldsymbol{\beta}$ are separately identified from maximising equation (A4).

\section{B.2 Plausibility of vignette equivalence and response consistency}

The vignette approach exchanges the assumption of common scale use with the assumptions of response consistency and vignette equivalence. Regarding response consistency, respondents might rate vignettes relative to reference points that vary with characteristics given in the vignette: Persons described 
to be richer might be rated with a higher reference point appropriate for richer persons, and persons described as poor might be rated less stringently. Unfortunately, statistical tests of response consistency rely on having a further objective indicator for the dependent variable. In the case of entirely subjective variables, no objective indicators can exist, making such tests impossible. However, in cases where response consistency with respect to health (for which may have objective indicators) was tested, response consistency was rejected (d’Uva et al., 2011; Datta Gupta et al., 2010).

Regarding vignette equivalence, some studies test whether respondents give a common ordering to multiple vignettes (Angelini et al., 2013; d'Uva et al., 2011; Montgomery, 2017; Murray et al., 2003). Although this test is typically passed, failure to reject does not imply that vignette equivalence holds. D'Uva et al. (2011) propose a stronger test, noting that vignette equivalence is required for only one vignette, say for $v=1$. For all other vignettes, vignette equivalence can be relaxed, thus allowing a test of $\boldsymbol{\lambda}^{(v)}=\mathbf{0}$ in $s_{i t}^{(v)}=\theta^{(v)}+\boldsymbol{X}_{i t} \lambda^{(v)}+\varepsilon_{i t}^{(v)}$ for $v=2, \ldots, V$. They find that vignette equivalence is rejected for almost all considered covariates. Rejection of this test can be interpreted as indicating that there are differences across vignettes in how perceptions of vignettes' satisfaction depend on covariates. Failure to pass this test indicates that vignette equivalence does not hold for at least one vignette. It may be useful to note that if one had data on memories about multiple years ago, say $q=1,2, \ldots, Q$ years ago, one could perform a similar test for the memory approach. In particular, we could extend equation (8) to read $s_{i t}^{\left(m_{q}\right)}=\theta^{\left(m_{q}\right)}+\boldsymbol{X}_{i t-q} \boldsymbol{\alpha}^{\left(m_{q}\right)}+\boldsymbol{X}_{i t} \lambda^{\left(m_{q}\right)}+\varepsilon_{i t}^{\left(m_{q}\right)}$, and then test if $\boldsymbol{\lambda}^{\left(m_{q}\right)}=\mathbf{0}$ for all $q>1$.

Relatedly, Peracchi and Rossetti (2013) propose a joint test of the response consistency and vignette equivalence assumption based on the observation that assuming both response consistency and vignette equivalence yields an overidentified model. In their empirical application, based on SHARE data on self-reported pain, they also tend to reject the hypothesis that response consistency and vignette equivalence hold jointly.

Vignettes are incomplete descriptions of a person's life. Some aspects relevant to life satisfaction must therefore be imagined by the respondent. For example, in the case of the vignette quoted above, respondents must make some assumptions about what it means to make 'ends meet'. It is plausible that a person's current circumstances (i.e. values of $\boldsymbol{X}_{i t}$ ), will impact how such assumptions are made. In particular, for a respondent with low incomes or who is unemployed, making 'ends meet' likely means a lower level of economic welfare compared to respondents in stable employment or for those with high incomes (Van Praag and Frijters 1999; Van Praag 1971; Crettaz and Suter 2013). Thus, while income and being employed are positively associated with latent satisfaction, they will also be positively associated with respondents' perceptions of vignettes. This implies that $\lambda_{j}^{(v)}$ and $\beta_{j}$ have the same sign for such variables. As shown in Appendix E, estimates of $\beta_{j}$ are then biased towards zero. Moreover, individuals tend to make mood-congruent judgements in both self- and non-self-relevant domains (Mayer et al. 1992; Forgas 1995). ${ }^{21}$ This

\footnotetext{
${ }^{21}$ For example, in study 3 of Mayer et al. (1992), respondents in a representative sample of the population of New Hamshire (USA) were asked to rate both their mood, as well as to make a number of other-regarding judgements. Those judgements included assessments of e.g. 'the likelihood of a marriage resulting in long-term happiness for both members of the couple?', 'the likelihood that there will be an atomic war in the next five years', or 'the likelihood that the average 30-year-old in New Hampshire will be involved in a happy, loving romance?'. For all such cases, those with a better mood provided significantly higher probabilities and thus made mood-congruent judgements.
} 
means that respondents with more positive affect can be expected to judge others more positively, too. Since affect and life satisfaction are driven by similar variables, this also suggests that $\lambda_{j}^{(v)}$ and $\beta_{j}$ have the same sign.

Hence, vignette equivalence might fail. The direction in which it is likely to fail suggests that magnitudes of $\boldsymbol{\beta}$ will be biased towards zero.

\section{B.3 Previous results using vignettes}

The vignettes methodology was previously applied to investigate e.g. variation in the reporting of subjective health (Bago d'Uva et al. 2008; Xu and Xie 2016), work disability (Kapteyn, Smith, and Van Soest 2007), subjective poverty (Ravallion, Himelein, and Beegle 2016), as well as income and job satisfaction (Kristensen and Johansson 2008; Bonsang and Van Soest 2012).

Five studies applied the vignette approach to studying life satisfaction. Kapteyn et al. (2010) use Dutch 'CenterPanel' data from 2006 and American 'Rand American Life' data from 2006-2007. For the USA, they find that accounting for scale use increases the estimated effects of income and household size (in the USA). In the Dutch sample, the effects of being employed, and being married are increased in size. Montgomery (2017) uses global Gallup World Poll data for the years 2011-2014. She shows that the relative gender gap in life satisfaction (with women being more satisfied) is driven by differential scale use. Furthermore, compared to being married, accounting for differential scale use marginally increases the magnitudes of the negative effects of being single, separation, divorce, and widowhood. The effects of unemployment and log income are also marginally increased. However, among two sets of vignettes available to her, one of these sets fails D'Uva et al.'s (2011) test of vignette equivalence. Angelini et al. (2013) use European SHARE data. They find large differences in scale use across European countries. Moreover, compared to having a partner, they also find slightly increased effects for being single and widowhood. Increased effects are also observed for not working and retirement. Finally, Bertoni (2015) and Corrado and Weeks (2010) use the same SHARE dataset. Bertoni (2015) finds that childhood deprivation is associated with less stringent scale use.

Apart from the case of gender investigated by Montgomery (2017), whenever there was a change in estimated coefficients due to accounting for variation in scale use, estimated magnitudes on latent satisfaction increased. This is despite the possible bias toward zero discussed above. 


\section{Van Praag's (2015) argument}

Van Praag's argument may be stated as follows. First, extend equation (4) by writing $\varepsilon_{i t}=u_{i}+$ $v_{i t}$. This yields:

$$
s_{i t}=\boldsymbol{X}_{i t *} \boldsymbol{\beta}_{*}+u_{i}+v_{i t}
$$

The fixed effect $u_{i}$ may be correlated with $\boldsymbol{X}_{i t *}$. Assume that $v_{i t}$ is normally distributed with constant variance and uncorrelated with $\boldsymbol{X}_{i t *}$. Now stack observations over the $T_{i}$ periods for each individual $i$ :

$$
\boldsymbol{s}_{i}=X_{i} \beta_{*}+u_{i}+v_{i}
$$

Here, $\boldsymbol{s}_{\boldsymbol{i}}=\left(s_{i 1}, \ldots, s_{i T_{i}}\right)^{\prime}$ and analogously for $\boldsymbol{X}_{\boldsymbol{i}}, \boldsymbol{u}_{\boldsymbol{i}}$, and $\boldsymbol{v}_{\boldsymbol{i}}$. Now consider the matrix $\boldsymbol{M}_{\boldsymbol{i}}=$ $\frac{1}{T_{i}} \mathbf{1 1}^{\prime}$, where $\mathbf{1}$ is a vector of $T_{i}$ ones. For any matrix $\boldsymbol{A}_{i}$, define $\boldsymbol{M}_{\boldsymbol{i}} \boldsymbol{A}_{\boldsymbol{i}} \equiv \overline{\boldsymbol{A}}_{\boldsymbol{i}}$. Each column of $\overline{\boldsymbol{A}}_{\boldsymbol{i}}$ contains the average of each column of $\boldsymbol{A}_{i}$. The demeaned matrix $\ddot{\boldsymbol{A}}_{i}$ is then obtained as $\ddot{\boldsymbol{A}}_{i}=\boldsymbol{A}_{i}-$ $\boldsymbol{M}_{\boldsymbol{i}} \boldsymbol{A}_{\boldsymbol{i}}$. Equation (A6) is a constrained version of:

$$
s_{i}=\ddot{X}_{i} \ddot{\beta}_{*}+\bar{X}_{i} \bar{\beta}_{*}+u_{i}+v_{i}
$$

Equation (A7) can be recovered from (A6) when $\ddot{\boldsymbol{\beta}}_{*}=\overline{\boldsymbol{\beta}}_{*}$. Since $\boldsymbol{M}_{\boldsymbol{i}}$ is idempotent, we can write

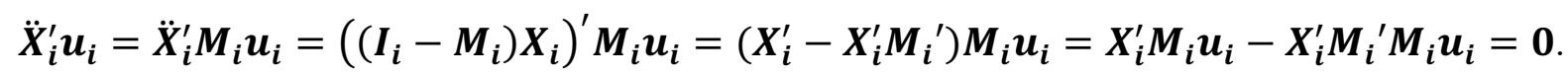

Hence, $\ddot{\boldsymbol{X}}_{\boldsymbol{i}}$ and $\boldsymbol{u}_{\boldsymbol{i}}$ are uncorrelated by construction and the inclusion of $\boldsymbol{u}_{\boldsymbol{i}}$ does not affect estimates of $\ddot{\boldsymbol{\beta}}_{*}$. By a similar manipulation we also find that $\ddot{\boldsymbol{X}}_{\boldsymbol{i}}^{\prime} \boldsymbol{\nu}_{\boldsymbol{i}}=\ddot{\boldsymbol{X}}_{\boldsymbol{i}}^{\prime} \ddot{\boldsymbol{v}}_{\boldsymbol{i}}$, where $\ddot{\boldsymbol{v}}_{\boldsymbol{i}}$ is obtained by demeaning equation (A5), as is normally done when accounting for fixed effects.

Therefore, even when omitting $\boldsymbol{u}_{\boldsymbol{i}}$, OLS estimates of $\ddot{\boldsymbol{\beta}}_{*}$ obtained from estimating equation (A7), would be identical to OLS estimates obtained by demeaning equation (A5). Also see Bell and Jones (2015) for a related discussion of this point. Although van Praag (2015) does not take this step, we can rewrite equation (A7) as:

$$
\boldsymbol{s}_{i}=\boldsymbol{X}_{i} \ddot{\boldsymbol{\beta}}_{*}+\bar{X}_{i} \widetilde{\beta}_{*}+u_{i}+v_{i}
$$

Here, $\overline{\boldsymbol{\beta}}_{*}-\ddot{\boldsymbol{\beta}}_{*} \equiv \widetilde{\boldsymbol{\beta}}_{*}$. This yields the specification proposed by Mundlak (1978).

Van Praag (2015) makes a further claim. When $\boldsymbol{S}_{\boldsymbol{i}}$ is not observed, and only $\boldsymbol{r}_{\boldsymbol{i}}$ is, an estimation of equation (A7) by ordered probit will also yield a consistent estimate of $\ddot{\boldsymbol{\beta}}_{*}$ when omitting $\boldsymbol{u}_{\boldsymbol{i}}$. However, estimates of $\ddot{\boldsymbol{\beta}}_{*}$ will only be consistent up to a proportionality factor: As explained in (Wooldridge 2010, Ch.15), we only obtain estimates of $\ddot{\boldsymbol{\beta}}_{*} \sigma / \sigma^{*}$, where $\sigma$ denotes the assumed standard deviation of $\varepsilon_{i t}$, and $\sigma^{*}$ denotes its true standard deviation.

Fortunately, estimates of the thresholds will also be scaled by the same proportionality factor $\sigma / \sigma^{*}$ as the coefficients on latent satisfaction. Hence magnitudes of coefficients that are standardized by the width of the response scale (see Appendix A) are not affected by the proportionality factor. 


\section{Monte Carlo study}

This small Monte Carlo study evaluates how well the proposed approach of using memories works at identifying variables' separate effects on latent satisfaction and scale use in the presence of fixed effects.

\section{D.1 Experimental design}

The set-up is as follows. I set $N=5,000$ and $T=6$. With respect to $T$, this is close to the BHPS data used in the main text. $N$ is somewhat smaller than what is available in BHPS to reduce computing time. Latent satisfaction is generated by:

$$
s_{i t}=\beta_{1} X_{1, i t}+\beta_{2} X_{2, i t}+\beta_{3} X_{3, i t}+u_{i}+v_{i t},
$$

where $u_{i} \sim N(0,1)$ and $v_{i t} \sim N(0,1)$. Furthermore, $X_{1, i t}=X_{1, i t-1}+e_{1, i t}$ for $t>1$ and $X_{1, i t}=$ $u_{i}$ for $t=1$, with $e_{1, i t} \sim N(0,1) . X_{2, i t} \sim N\left(u_{i}, 1\right)$. Finally, $X_{3, i t}=1$ if $u_{i}+e_{2, i t}>0$ and $X_{3, i t}=$ 0 otherwise, with $e_{2, i t} \sim N(0,1)$. Thus, each independent variable is correlated with the fixed effect $u_{i}$ and is strongly autocorrelated (as would be the case for most demographic variables). $X_{1, i t}$ and $X_{2, i t}$ are continuous, while $X_{3, i t}$ is a dummy. I further set $\beta_{1}=1, \beta_{2}=0.5, \beta_{3}=0.5$. I evaluate two different processes by which the cutoffs $\tau_{i t, k}$ are generated to determine $r_{i t}$ (which in turn is generated as in equation (1)). As a first case, I generate $\tau_{i t, k}=-7+\bar{s}+2 k$, where $\bar{s}$ is the average of $s_{i t}$ across $i$ and $t$. As a second case, I generate $\tau_{i t, k}=-2.75+\delta_{1} X_{1, i t}+\delta_{2} X_{2, i t}+\delta_{3} X_{3, i t}+$ $\bar{s}+1.25 k$. With $\delta_{1}=0.2, \delta_{2}=0.8, \delta_{3}=0.8$. In both cases, the number of response categories $K$ is set to 7 . Both cases yield equidistant cutoffs and roughly even shares across each of the seven response categories for $r_{i t}$. However, in the first case all cutoffs are independent of $\boldsymbol{X}_{i t}$, while in the latter case cutoffs strongly depend on $\boldsymbol{X}_{i t}$. Memories of satisfaction are generated by $s_{i t}^{(m)}=\alpha_{1} X_{1, i t-1}+\alpha_{2} X_{2, i t-1}+\alpha_{3} X_{3, i t-1}+u_{i}+v_{i t}^{(m)}$, with $\alpha_{1}=0.8, \alpha_{2}=0.4, \alpha_{3}=0.6$ and $v_{i t}^{(m)} \sim N(0,1)$.

I draw 250 independent sets of observations and estimate six different models on each set. Those models are:

- An OLS regression of $r_{i t}$ ('OLS'),

- An OLS regression of demeaned $r_{i t}$ ('OLS-FE'),

- A standard ordered probit regression ('OP’),

- An ordered probit regression with individual averages for each independent variable added (as discussed in Appendix C; 'OP-Avg.')

- An ordered probit regression with individual averages, extended by an equation for memories of past satisfaction ('MOP-Avg.'). For this model, memories of satisfaction are assumed to exist on a 1-7 scale.

- An ordered probit regression with individual averages, extended by an equation for memories of changes in satisfaction ('UKMOP-Avg'). For this model, data with three possible values, like those available in UK BHPS data were used.

For both MOP-Avg. and the UKMOP-Avg. model, I add individual averages to the memory and the cutoff equations as well as the equation on latent satisfaction. 


\section{D.2 Results in case of cutoffs being independent of $X_{i t}$}

Table D1 presents mean estimates of coefficients and their ratios from 250 independent trials.

Table D1. Results from Monte Carlo simulation with cutoffs independent of $X_{i t}$

\begin{tabular}{|c|c|c|c|c|c|c|}
\hline $\begin{array}{l}\text { Parameter } \\
\text { estimates }\end{array}$ & $\begin{array}{r}(1) \\
\text { OLS } \\
\end{array}$ & $\begin{array}{r}(2) \\
\text { OP }\end{array}$ & $\begin{array}{r}(3) \\
\text { OLS-FE } \\
\end{array}$ & $\begin{array}{r}\text { (4) } \\
\text { OP-Avg. }\end{array}$ & $\begin{array}{r}(5) \\
\text { MOP-Avg. }\end{array}$ & $\begin{array}{r}(6) \\
\text { UKMOP-Avg. }\end{array}$ \\
\hline$\beta_{1}$ & 0.526 & 0.988 & 0.459 & 0.958 & 0.964 & 0.938 \\
\hline$\beta_{2}$ & 0.398 & 0.729 & 0.234 & 0.478 & 0.478 & 0.463 \\
\hline$\beta_{3}$ & 0.544 & 0.930 & 0.245 & 0.479 & 0.480 & 0.466 \\
\hline$\beta_{1} / \beta_{2}$ & $1.324(0.676)$ & $1.355(0.645)$ & $1.960(0.052)$ & $2.007(0.033)$ & $2.019(0.053)$ & $2.027(0.081)$ \\
\hline$\beta_{1} / \beta_{3}$ & $0.968(1.032)$ & $1.063(.938)$ & $1.875(0.142)$ & $2.001(0.069)$ & $2.015(0.116)$ & $2.029(0.183)$ \\
\hline$\beta_{2} / \beta_{3}$ & $0.731(0.269)$ & $0.784(0.216)$ & $0.957(0.055)$ & $0.998(0.036)$ & $0.998(0.059)$ & $1.002(0.094)$ \\
\hline Norm. $\beta_{1}$ & $0.526(0.074)$ & $0.687(0.088)$ & $0.459(0.141)$ & $0.602(0.005)$ & $0.606(0.010)$ & $0.560(0.042)$ \\
\hline Norm. $\beta_{2}$ & $0.398(0.098)$ & $0.507(0.207)$ & $0.234(0.066)$ & $0.300(0.004)$ & $0.300(0.007)$ & $0.276(0.025)$ \\
\hline Norm. $\beta_{3}$ & $0.544(0.244)$ & $0.647(0.347)$ & $0.245(0.056)$ & $0.301(0.010)$ & $0.302(0.017)$ & $0.278(0.033)$ \\
\hline$\alpha_{1}$ & & & & & 0.783 & 0.767 \\
\hline$\alpha_{2}$ & & & & & 0.383 & 0.376 \\
\hline$\alpha_{3}$ & & & & & 0.576 & 0.559 \\
\hline$\alpha_{1} / \alpha_{2}$ & & & & & $2.043(0.064)$ & $2.045(0.102)$ \\
\hline$\alpha_{1} / \alpha_{3}$ & & & & & $1.361(0.059)$ & $1.377(0.099)$ \\
\hline$\alpha_{2} / \alpha_{3}$ & & & & & $0.666(0.027)$ & $0.675(0.052)$ \\
\hline$\delta_{1}$ & & & & & 0.030 & -0.043 \\
\hline$\delta_{2}$ & & & & & 0.000 & -0.039 \\
\hline$\delta_{3}$ & & & & & 0.001 & -0.038 \\
\hline$\delta_{1} / \delta_{2}$ & & & & & -4.724 & -56.582 \\
\hline$\delta_{1} / \delta_{3}$ & & & & & -0.434 & -0.292 \\
\hline$\delta_{2} / \delta_{3}$ & & & & & 0.275 & -0.147 \\
\hline$\tau_{1}$ & & $-3.848(0.903)$ & & $-4.103(0.649)$ & $-4.107(0.645)$ & $-4.321(0.431)$ \\
\hline$\tau_{2}$ & & $-2.128(0.623)$ & & $-2.210(0.541)$ & $-2.216(0.535)$ & $-2.334(0.417)$ \\
\hline$\tau_{3}$ & & $-0.401(0.350)$ & & $-0.293(0.458)$ & $-0.297(0.454)$ & $-0.313(0.439)$ \\
\hline$\tau_{4}$ & & $1.331(0.084)$ & & $1.638(0.389)$ & $1.635(0.386)$ & $1.723(0.475)$ \\
\hline$\tau_{5}$ & & $3.056(0.195)$ & & $3.554(0.306)$ & $3.553(0.305)$ & $3.744(0.496)$ \\
\hline$\tau_{6}$ & & $4.773(0.478)$ & & $5.444(0.198)$ & $5.444(0.198)$ & $5.731(0.483)$ \\
\hline$\tau_{2}-\tau_{1}$ & & $1.720(0.281)$ & & $1.892(0.110)$ & $1.891(0.111)$ & $1.987(0.031)$ \\
\hline$\tau_{3}-\tau_{2}$ & & $1.727(0.274)$ & & $1.917(0.086)$ & $1.919(0.083)$ & $2.021(0.032)$ \\
\hline$\tau_{4}-\tau_{3}$ & & $1.733(0.268)$ & & $1.931(0.072)$ & $1.932(0.069)$ & $2.036(0.042)$ \\
\hline$\tau_{5}-\tau_{4}$ & & $1.725(0.276)$ & & $1.916(0.087)$ & $1.918(0.084)$ & $2.021(0.032)$ \\
\hline$\tau_{6}-\tau_{5}$ & & $1.717(0.284)$ & & $1.890(0.112)$ & $1.891(0.111)$ & $1.986(0.032)$ \\
\hline \multicolumn{7}{|c|}{$\begin{array}{l}\text { Note: } T=6 \text { and } N=5000 \text {. Numbers show mean estimates of coefficients and their ratios from } 250 \text { independent trials. Root } \\
\text { mean squared error (RMSE) shown in parentheses. True values for each parameter are: } \beta_{1}=1, \beta_{2}=0.5, \beta_{3}=0.5, \alpha_{1}=0.8 \text {, } \\
\alpha_{2}=0.4, \alpha_{3}=0.6, \delta_{1}=0, \delta_{2}=0, \delta_{3}=0 \text {. True values for } \tau_{k} \text { depend on the mean value of latent satisfaction and thus vary } \\
\text { across runs. The true value for the differences } \tau_{k}-\tau_{k-1}=2 \text { for all } k \text {. For ratios of } \delta \text { the RMSE is not defined due to division } \\
\text { by zero. For OP regressions 'Norm. } \beta \text { ' give normalized coefficients, which are given by }(K-1) \beta /\left(\gamma_{K-1}-\gamma_{1}\right)= \\
6 \beta /\left(\gamma_{6}-\gamma_{1}\right) \text {. For OLS regressions, 'Norm. } \beta \text { ' is identical to } \beta \text { since } r \text { is rank-order coded. True values are Norm. } \beta_{1}=0.6 \text {, } \\
\text { Norm. } \beta_{2}=\text { Norm. } \beta_{3}=0.3 \text {. Finally, note that the mean of the ratio of two random variables does not generally equal the ratio } \\
\text { of their means. Therefore, ratios of the reported average parameter estimates do not equal the reported average estimated } \\
\text { parameter ratios. }\end{array}$} \\
\hline
\end{tabular}

Absolute magnitudes of coefficients are affected by arbitrary scaling choices for $\sigma$ (also see Van Praag and Ferrer-i-Carbonell 2008). As motivated in Appendix A, I therefore present estimates of normalized coefficients on latent satisfaction. These are given by Norm. $\beta=6 \beta /\left(\gamma_{6}-\gamma_{1}\right)$. True values are Norm. $\beta_{1}=0.6$ and Norm. $\beta_{2}=$ Norm. $\beta_{3}=0.3$. With respect to these targets, the OLS and OP models perform worst overall. However, interestingly, the OLS-FE model is furthest from the target value for the normalized coefficient for $\beta_{1}$. This is despite the fact cutoffs are specified to be equidistant, which is normally taken to motivate the use of OLS regressions (see section 2.1), but which is in line with footnote 5 of the main text. In contrast, the OP-Avg. and MOP-Avg. models both perform very well. The UKMOP-Avg. also performs much better than OLS-FE, though coefficients seem somewhat biased towards zero. 
Figure D1. Density plots of estimates of $\beta_{1} / \beta_{2}$ when scale use is independent of $\boldsymbol{X}_{\boldsymbol{i t}}$

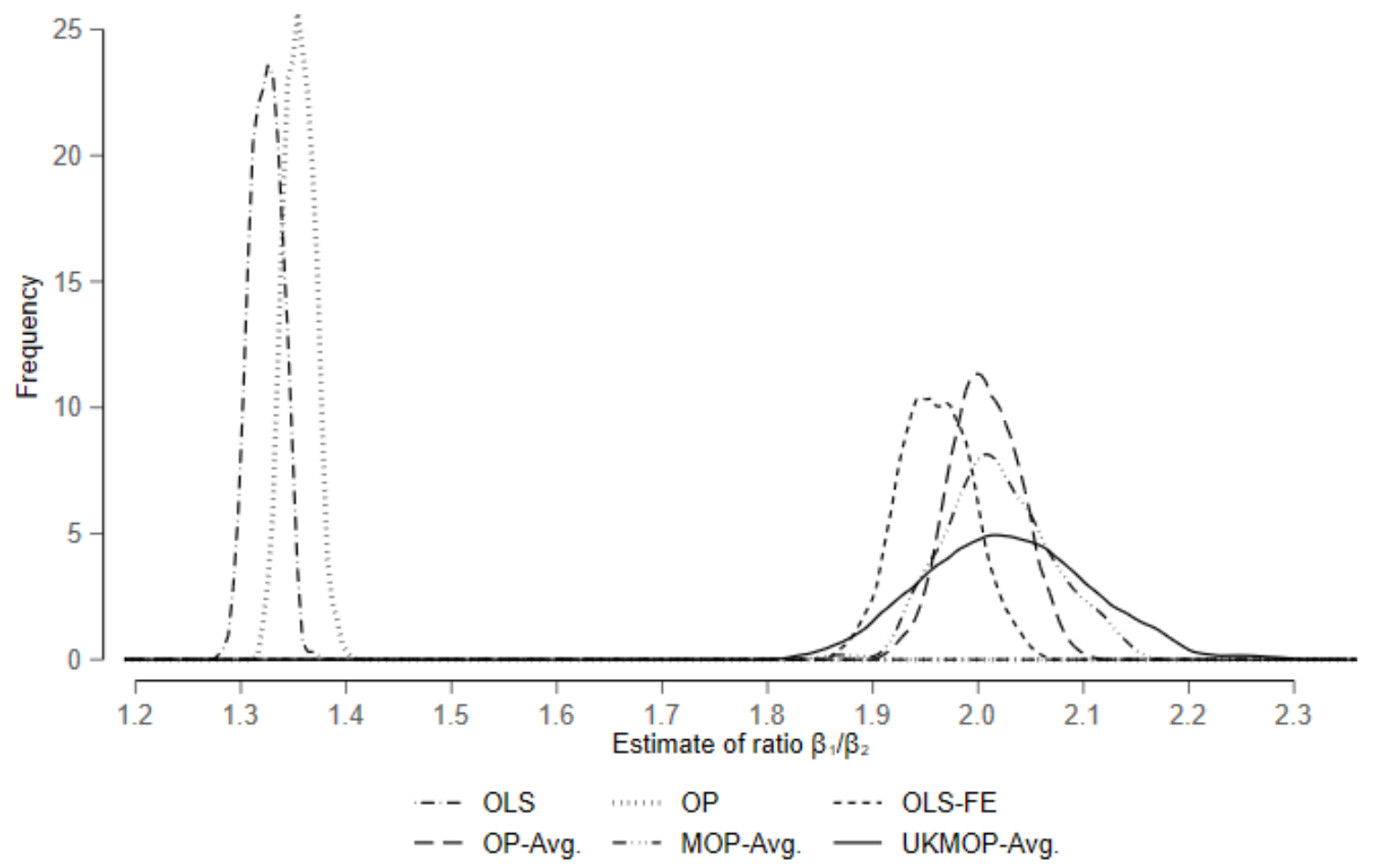

Note: The OP-Avg., the MOP-Avg. and UKMOP-Avg. model give estimates which are centred close to the true value (=2), while the OLS-FE model is somewhat negatively biased, but with little variance. The OLS and OP model also have little variance but yield a strongly negatively biased ratio of coefficients.

Moreover, from the experimental setup, it follows that the true ratios $\beta_{1} / \beta_{2}$ and $\beta_{1} / \beta_{3}$ are equal to 2 , while the ratio $\beta_{2} / \beta_{3}$ equals 1 . With respect to these target values, the OLS regressions in column (1) perform worst in terms of both the average prediction and the root mean squared error (RMSE). Simple ordered probit regressions shown in column (2) perform almost as badly, with all ratios of coefficients being far below the target. All other models perform rather similar and quite well. Of these, the OLS-FE models shows the worst average estimate of each ratio of coefficients, with a slight negative bias compared to the true value.

Hence, and encouragingly, the ordered probit model with individual averages added (see column (4)) performs best with almost no bias in either direction and low RMSE. Thus, the argument of Appendix C, namely that accounting for fixed effects in an ordered probit setting is possible, appears to be correct. Models which are extended by an equation for memories of past satisfaction ('MOP' and 'UKMOP') perform almost as well as the OP-Avg. model, with the average estimates being close to the true values. However, RMSEs are larger than for the OP-Avg. model because these models estimate the $\beta$ coefficients using one fewer wave. On top, by explicitly modelling dependence of scale use on $\boldsymbol{X}_{\boldsymbol{i t}}$, ${ }^{22}$ as well as memories of past satisfaction, these models estimate three times as many free parameters as the other models, leading to a loss in efficiency. One reason why the UKMOP model may perform worse than the MOP model is because each observation of

\footnotetext{
22 Although the coefficients are explicitly modelled, all true coefficients relating to scale use are zero in the present example.
} 
$r_{i t}^{(m)}$ in that model carries much less information than $r_{i t}^{(m)}$ in the MOP model (cf. section 3.2). The location of the cutoffs is thus less precisely estimated. This can also be seen in the estimates of $\boldsymbol{\alpha}$ and $\boldsymbol{\delta}$, which are somewhat less precise in the UKMOP model compared to the MOP model.

Finally, regarding the thresholds $\tau_{k}$, their estimated locations heavily differ between the OP model and all the models that account for individual fixed effects. Furthermore, compared to the true values, all models estimate differences between thresholds that are too small. However, recall from Appendix $\mathrm{C}$ that these differences depend on arbitrary scaling choices for the error variance $\sigma$. Nevertheless, all models estimate differences across thresholds to be roughly constant, which is in line with the equidistance of the thresholds in the true data-generating process.

Table D2. Results from Monte Carlo simulation with cutoffs depending on values of $X_{i t}$

\begin{tabular}{|c|c|c|c|c|c|c|}
\hline $\begin{array}{l}\text { Parameter } \\
\text { estimates }\end{array}$ & $\begin{array}{r}(1) \\
\text { OLS } \\
\end{array}$ & $\begin{array}{l}\text { (2) } \\
\text { OP }\end{array}$ & $\begin{array}{r}(3) \\
\text { OLS-FE } \\
\end{array}$ & $\begin{array}{r}\text { (4) } \\
\text { OP-Avg. }\end{array}$ & $\begin{array}{r}(5) \\
\text { MOP-Avg. } \\
\end{array}$ & $\begin{array}{r}(6) \\
\text { UKMOP-Avg. }\end{array}$ \\
\hline$\beta_{1}$ & 0.672 & 0.818 & 0.564 & 0.767 & 0.964 & 0.968 \\
\hline$\beta_{2}$ & 0.039 & 0.039 & -0.219 & -0.286 & 0.479 & 0.5 \\
\hline$\beta_{3}$ & 0.222 & 0.235 & -0.227 & -0.288 & 0.478 & 0.495 \\
\hline$\beta_{1} / \beta_{2}$ & $17.367(15.546)$ & $21.551(19.86)$ & $-2.58(4.581)$ & $-2.683(4.683)$ & $2.015(0.048)$ & $1.940(0.086)$ \\
\hline$\beta_{1} / \beta_{3}$ & 3.034 (1.047) & $3.490(1.504)$ & $-2.491(4.493)$ & $-2.668(4.670)$ & $2.020(0.111)$ & $1.967(0.162)$ \\
\hline$\beta_{2} / \beta_{3}$ & $0.178(0.823)$ & $0.166(0.835)$ & $0.966(0.063)$ & $0.995(0.053)$ & $10.003(0.054)$ & $10.015(0.087)$ \\
\hline Norm. $\beta_{1}$ & $0.672(0.288)$ & $0.910(0.050)$ & $0.564(0.396)$ & $0.771(0.189)$ & $0.968(0.015)$ & $0.929(0.037)$ \\
\hline Norm. $\beta_{2}$ & $0.039(0.441)$ & $0.043(0.437)$ & $-0.219(0.699)$ & $-0.288(0.768)$ & $0.481(0.010)$ & $0.479(0.015)$ \\
\hline Norm. $\beta_{3}$ & $0.222(0.258)$ & $0.262(0.219)$ & $-0.227(0.707)$ & $-0.290(0.770)$ & $0.480(0.025)$ & $0.475(0.036)$ \\
\hline$\alpha_{1}$ & & & & & 0.783 & 0.804 \\
\hline$\alpha_{2}$ & & & & & 0.383 & 0.392 \\
\hline$\alpha_{3}$ & & & & & 0.575 & 0.585 \\
\hline$\alpha_{1} / \alpha_{2}$ & & & & & $2.044(0.062)$ & $2.053(0.097)$ \\
\hline$\alpha_{1} / \alpha_{3}$ & & & & & $1.362(0.056)$ & $1.380(0.098)$ \\
\hline$\alpha_{2} / \alpha_{3}$ & & & & & $0.666(0.026)$ & $0.673(0.047)$ \\
\hline$\delta_{1}$ & & & & & 0.221 & 0.193 \\
\hline$\delta_{2}$ & & & & & 0.765 & 0.799 \\
\hline$\delta_{3}^{2}$ & & & & & 0.767 & 0.797 \\
\hline$\delta_{1} / \delta_{2}$ & & & & & 0.289 & 0.242 \\
\hline$\delta_{1} / \delta_{3}$ & & & & & 0.289 & 0.243 \\
\hline$\delta_{2} / \delta_{3}$ & & & & & 0.998 & 1.004 \\
\hline$\tau_{1}$ & & $-2.994(0.757)$ & & $-3.153(0.598)$ & $-3.159(0.592)$ & $-3.299(0.452)$ \\
\hline$\tau_{2}$ & & $-1.907(0.593)$ & & $-1.965(0.536)$ & $-1.969(0.532)$ & $-2.067(0.434)$ \\
\hline$\tau_{3}$ & & $-0.829(0.422)$ & & $-.771(0.479)$ & $-.773(0.478)$ & $-.815(0.436)$ \\
\hline$\tau_{4}$ & & $0.246(0.247)$ & & $.426(0.427)$ & $.424(0.425)$ & $.448(0.449)$ \\
\hline$\tau_{5}$ & & $1.320(0.073)$ & & $1.623(0.374)$ & $1.623(0.374)$ & $1.71(0.461)$ \\
\hline$\tau_{6}$ & & $2.398(0.104)$ & & $2.815(0.316)$ & $2.816(0.318)$ & $2.957(0.458)$ \\
\hline$\tau_{2}-\tau_{1}$ & & $1.720(0.281)$ & & $1.189(0.064)$ & $1.190(0.062)$ & $1.233(0.028)$ \\
\hline$\tau_{3}-\tau_{2}$ & & $1.727(0.274)$ & & $1.193(0.058)$ & $1.196(0.055)$ & $1.252(0.015)$ \\
\hline$\tau_{4}-\tau_{3}$ & & $1.733(0.268)$ & & $1.198(0.054)$ & $1.198(0.053)$ & $1.263(0.020)$ \\
\hline$\tau_{5}-\tau_{4}$ & & $1.725(0.276)$ & & $1.197(0.054)$ & $1.198(0.053)$ & $1.261(0.018)$ \\
\hline$\tau_{6}-\tau_{5}$ & & $1.717(0.284)$ & & $1.191(0.061)$ & $1.194(0.058)$ & $1.247(0.019)$ \\
\hline \multicolumn{7}{|c|}{$\begin{array}{l}\text { Note: } T=6 \text { and } N=5000 \text {. Numbers show mean estimates of coefficients and their ratios from } 250 \text { independent trials. Root } \\
\text { mean squared error (RMSE) shown in parentheses. True values for each parameter are: } \beta_{1}=1, \beta_{2}=0.5, \beta_{3}=0.5, \alpha_{1}= \\
0.8, \alpha_{2}=0.4, \alpha_{3}=0.6, \delta_{1}=0.2, \delta_{2}=0.8, \delta_{3}=0.8 \text {. True values for } \tau_{k} \text { depend on the mean value of latent satisfaction } \\
\text { and thus varies across runs. Displayed values for } \tau_{k} \text { are computed for } X_{1}=X_{2}=X_{3}=0 \text {. The true value for the differences } \\
\tau_{k}-\tau_{k-1}=1.25 \text { for all } k \text {. For OP regressions 'Norm. } \beta \text { ' give normalized coefficients, which are given by } \\
(K-1) \beta /\left(\gamma_{K-1}-\gamma_{1}\right)=6 \beta /\left(\gamma_{6}-\gamma_{1}\right) \text {. For OLS regressions, 'Norm. } \beta \text { ' is identical to } \beta \text { since } r \text { is rank-order coded. True } \\
\text { values are Norm. } \beta_{1}=0.96 \text {, Norm. } \beta_{2}=\text { Norm. } \beta_{3}=0.48 \text {. Finally, note that the mean of the ratio of two random variables } \\
\text { does not generally equal the ratio of their means. Therefore, ratios of the reported average parameter estimates do not equal } \\
\text { the reported average estimated parameter ratios. }\end{array}$} \\
\hline
\end{tabular}


Figure D2. Density plots of estimates of $\beta_{1} / \beta_{2}$ when scale use depends on $\boldsymbol{X}_{\boldsymbol{i t}}$

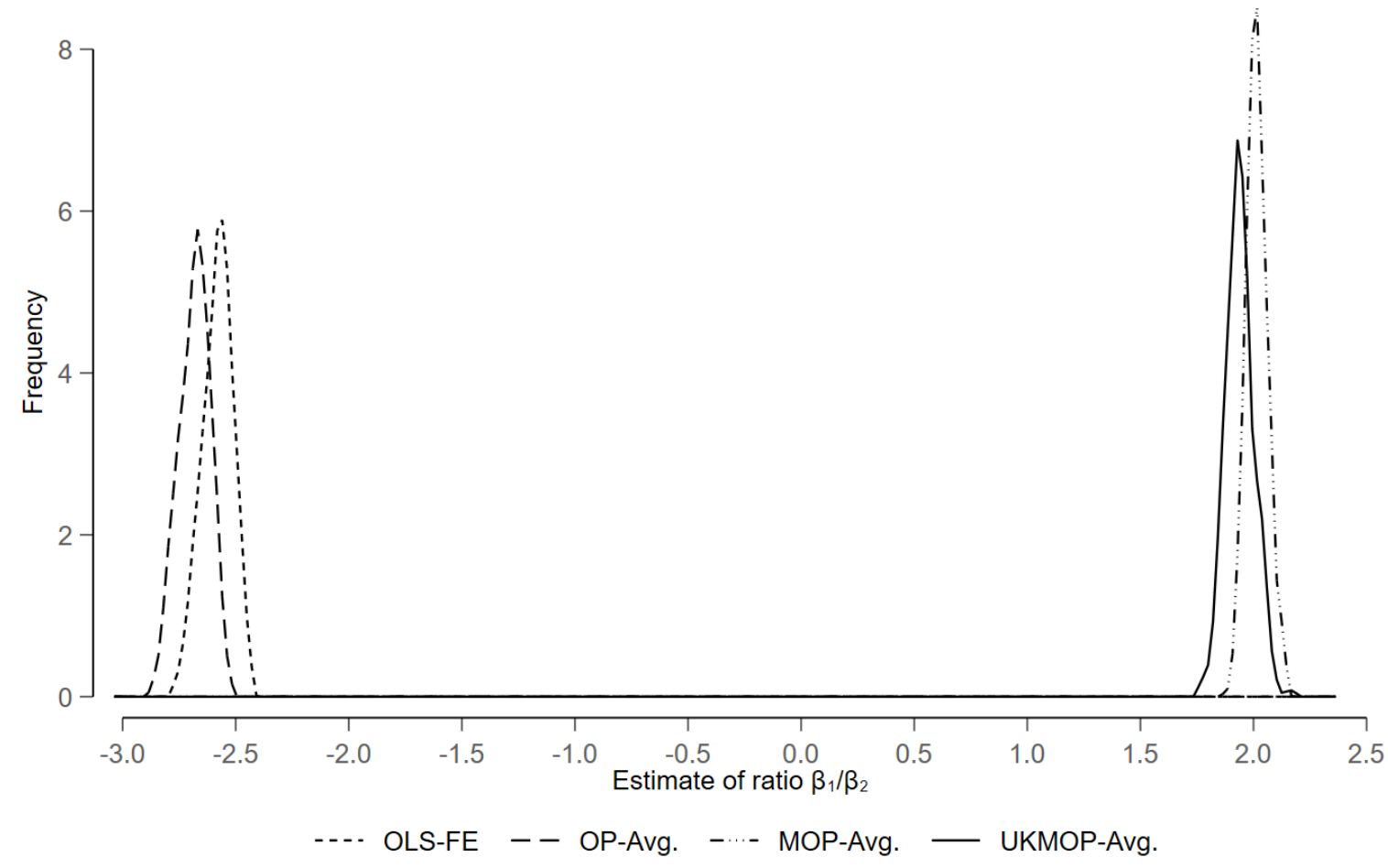

Note: The MOP-Avg. and UKMOP-Avg. model continue to give estimates which are centred close to the true value $(=2)$. The OLS-FE and OP-Avg. model now yield a strongly negatively biased estimate. The OP and OLS model are omitted from this figure.

\section{D.3 Results in case of cutoffs depending on $\boldsymbol{X}_{i t}$}

I now turn to the case in which higher values of each independent variable makes scale use more stringent. The assumption of common scale use is thus violated. Table D2 presents results from the same 250 trials as in Table D1, with only the data-generating process for the cutoffs altered. Because true differences between thresholds are now smaller, the true values for normalized coefficients are given by Norm. $\beta_{1}=0.96$, Norm. $\beta_{2}=$ Norm. $\beta_{3}=0.48$.

With respect to both target values for ratios and normalized magnitudes, the OLS and OP model continue to be strongly biased. When considering estimated ratios of coefficients, the OLS-FE and OP-Avg. model are now similarly biased. ${ }^{23}$ When considering normalized magnitudes, these models are even more biased than the simple OLS and OP models. Importantly, since the true effects of $X_{2, i t}$ and $X_{3, i t}$ on scale use are stronger than on latent satisfaction (and of the same sign), these models fail to yield the correct signs for these coefficient estimates. In contrast, the MOP-Avg. and the UKMOP-Avg. models continue to yield correct coefficient ratios for each $\beta$ coefficient. ${ }^{24}$ Indeed, these estimates of ratios are almost unaffected by the change in how cutoffs are

\footnotetext{
${ }^{23}$ However, on average the OP-Avg. provides the correct estimate for the ratio $\beta_{1} / \beta_{2}$. As flagged in section 2.2., this is because the special case $\beta_{2}=\beta_{3}$ and $\delta_{2}=\delta_{3}$ obtains here.

24 And, on average, ratios of coefficients for memories of satisfaction are also estimated correctly. RMSEs for the UKMOP model are even improved compared to Table D1.
} 
determined. Moreover, MOP and UKMOP models also yield largely correct normalized magnitudes of coefficients, though the coefficient on $\beta_{1}$ estimated by the UKMOP model seems to be underestimated slightly. Finally, ratios $\delta_{1} / \delta_{2}$ and $\delta_{1} / \delta_{3}$, which indicate relative shifts in scale use, appear positively biased for the MOP model, and negatively biased for the UKMOP model, though in the latter case that bias is negligible. The ratio $\delta_{2} / \delta_{3}$ is well estimated by both models. Signs of coefficients are always correctly estimated by both the MOP and the UKMOP model.

I draw three conclusions. First, the approach of adding individual averages to an ordered probit model in order to account for individual fixed effects works well and appears to yield consistent estimates of the normalized coefficients and trade-off ratios. Remarkably, the OLS-FE model, which is standard in empirical happiness research, performs worse than the OP-Avg. model. This is despite the fact that cutoffs are equidistant, which is an assumption normally maintained in order to motivate the OLS approach. Second, in cases where independent variables affect scale use, both the OP-Avg. and OLS-FE model yield biased estimates. Third, when scale use depends on explanatory variables, the estimates of the MOP and UKMOP models are closest to the true datagenerating process. However, the MOP and the UKMOP model yield larger RMSEs than the OPAvg. model when scale use does not depend on explanatory variables. 


\section{Appendix E Implications of violations of present independence}

To assess the exact implications of potential violations of present independence, assume that $\boldsymbol{\lambda}^{(\boldsymbol{m})} \neq \mathbf{0}$ in equation (8). In that case, equation (9) must be extended to become:

$$
\begin{aligned}
& \ell_{i t}=\sum_{k=1}^{K} \mathbb{1}\left(r_{i t}=k\right) \times \ln \left[\Phi\left(\gamma_{k}+\boldsymbol{X}_{i t} \boldsymbol{\delta}-\boldsymbol{X}_{i t} \boldsymbol{\beta}\right)-\Phi\left(\gamma_{k-1}+\boldsymbol{X}_{i t} \boldsymbol{\delta}-\boldsymbol{X}_{i t} \boldsymbol{\beta}\right)\right] \\
& \quad+\mathbb{1}\left(r_{i t}^{(m)}=-1\right) \times \ln \left[1-\Phi\left(\gamma_{k-1}+\boldsymbol{X}_{i t} \boldsymbol{\delta}-\boldsymbol{X}_{i t} \lambda^{(\boldsymbol{m})}-\theta^{(m)}-\boldsymbol{X}_{i t-1} \boldsymbol{\alpha}\right)\right] \\
& \quad+\mathbb{1}\left(r_{i t}^{(m)}=1\right) \times \ln \left[\Phi\left(\gamma_{k}+\boldsymbol{X}_{i t} \boldsymbol{\delta}-\boldsymbol{X}_{i t} \boldsymbol{\lambda}^{(\boldsymbol{m})}-\theta^{(m)}-\boldsymbol{X}_{i t-1} \boldsymbol{\alpha}\right)\right]
\end{aligned}
$$

Notice that in lines 2 and 3 of equation (A10), we can write $\boldsymbol{X}_{i t} \boldsymbol{\delta}-\boldsymbol{X}_{i t} \boldsymbol{\lambda}^{(\boldsymbol{m})}=\boldsymbol{X}_{i t}\left(\boldsymbol{\delta}-\boldsymbol{\lambda}^{(\boldsymbol{m})}\right)$. To reflect the fact that we are imposing the same thresholds for current satisfaction and past satisfaction, we can then also rewrite the first line of equation (A10) as $\boldsymbol{X}_{i t} \boldsymbol{\delta}-\boldsymbol{X}_{i t} \boldsymbol{\beta}=$ $\boldsymbol{X}_{i t}\left(\boldsymbol{\delta}-\boldsymbol{\lambda}^{(\boldsymbol{m})}\right)-\boldsymbol{X}_{i t}\left(\boldsymbol{\beta}-\boldsymbol{\lambda}^{(m)}\right)$. Rewriting terms in this manner, shows that, when present independence is violated, we can only obtain estimates of the differences $\boldsymbol{\beta}-\boldsymbol{\lambda}^{(m)}$ and $\boldsymbol{\delta}-\boldsymbol{\lambda}^{(\boldsymbol{m})}$.

If the true values of $\lambda_{j}^{(m)}$ and $\beta_{j}$ have opposite signs, then $\left|\beta_{j}-\lambda_{j}^{(m)}\right|>\left|\beta_{j}\right|$. In this case, estimates $\hat{\beta}_{j}$, which are obtained under the assumption of present independence, are biased away from zero. In contrast, if the signs of the true values of $\lambda_{j}^{(m)}$ and $\beta_{j}$ are equal and if $\left|\lambda_{j}^{(m)}\right|<\left|\beta_{j}\right|$, we find that $\left|\beta_{j}-\lambda_{j}^{(m)}\right|<\left|\beta_{j}\right|$. In that case, our estimates $\hat{\beta}_{j}$ are biased towards zero.

The results presented in section 4 can therefore be interpreted in two ways. More positive (negative) estimates $\hat{\beta}_{j}$ either indicate variables' positive (negative) effect on latent satisfaction or indicate variables' negative (positive) effect on memories of past satisfaction. Analogous statements apply to estimates of scale shifts $\hat{\delta}_{j}$.

Now assume that the absolute magnitudes of the memory biases do not exceed the magnitudes of the effects on latent satisfaction. In that case, $\left|\lambda_{j}^{(m)}\right| \leq\left|\beta_{j}\right|$ holds. Moreover, the more worrying bias (i.e. away from zero) occurs when $\lambda_{j}^{(m)}$ and $\beta_{j}$ have opposing signs. Assuming both of the above, yields a worst case of $\beta_{j}=-\lambda_{j}^{(m)}$. In turn, this worst case implies that $\left(\beta_{j}-\lambda_{j}^{(m)}\right)=$ $2 \beta_{j} \leftrightarrow 0.5\left(\beta_{j}-\lambda_{j}^{(m)}\right)=\beta_{j}$. In that case, we also have it that $\left(\delta_{j}-\lambda_{j}^{(m)}\right)=\left(\delta_{j}+\beta_{j}\right)$. Hence, $\left(\delta_{j}-\lambda_{j}^{(m)}\right)-0.5\left(\beta_{j}-\lambda_{j}^{(m)}\right)=\left(\delta_{j}+\beta_{j}\right)-\beta_{j}=\delta_{j}$.

When violating present independence, the reported estimates $\hat{\beta}_{j}$ should be interpreted as estimates of the differences $\beta_{j}-\lambda_{j}^{(m)}$. Likewise, under violations of present independence, the reported estimates $\hat{\delta}_{j}$ should be interpreted as estimates of $\delta_{j}-\lambda_{j}^{(m)}$. Thus, and given the identities derived above, we can run tests of the null hypotheses $h_{0}: 0.5 \hat{\beta}_{j}=0$ and $h_{0}: \hat{\delta}_{j}-0.5 \hat{\beta}_{j}=0$ to see whether the effects on latent satisfaction and scale use remain statistically significant under this worst-case scenario. 
Table F1. Addition of Lags and Leads

$\begin{array}{ccc}\begin{array}{c}\text { One-year lag in } \\ \text { scale shifts }\end{array} & \begin{array}{c}\text { One-year lag in } \\ \text { current satisfaction }\end{array} & \begin{array}{c}\text { One-year lag in } \\ \text { current satisfaction, } \\ \text { two-year lags in } \\ \text { memories }\end{array}\end{array}$

One-year lag and lead in current satisfaction, twoyear lags in memories, one-year lead scale use

(1) (2)

(3) (4)

\begin{tabular}{|c|c|c|c|c|}
\hline \multirow[b]{3}{*}{$\ln (\mathrm{HH}$ income $)$} & \multicolumn{4}{|c|}{ Current life satisfaction $(\beta)$} \\
\hline & \multicolumn{4}{|c|}{ Contemporaneous effects } \\
\hline & $0.071^{* * *}(0.025)$ & $0.080^{* * *}(0.025)$ & $0.114^{* * *}(0.029)$ & $0.105^{* * *}(0.034)$ \\
\hline \multicolumn{5}{|l|}{ Employed (base) } \\
\hline Self-employed & $0.052(0.068)$ & $0.052(0.069)$ & $0.052(0.078)$ & $0.026(0.093)$ \\
\hline Unemployed & $-0.704^{* * *}(0.079)$ & $-0.672^{* * *}(0.081)$ & $-0.707^{* * *}(0.095)$ & $-0.683^{* * *}(0.114)$ \\
\hline Retired & $0.242^{* * *}(0.080)$ & $0.250^{* * *}(0.081)$ & $0.300^{* * *}(0.091)$ & $0.258^{* *}(0.109)$ \\
\hline Not working & $-0.143^{* * *}(0.055)$ & $-0.126^{* *}(0.056)$ & $-0.132^{* *}(0.064)$ & $-0.123(0.075)$ \\
\hline \multicolumn{5}{|l|}{ Married (base) } \\
\hline Widowed & $-1.294^{* * *}(0.147)$ & $-1.225^{* * *}(0.153)$ & $-1.279^{* * *}(0.173)$ & $-0.796^{* * *}(0.232)$ \\
\hline Divorced & $-0.575^{* * *}(0.076)$ & $-0.570^{* * *}(0.078)$ & $-0.508^{* * *}(0.090)$ & $-0.176(0.110)$ \\
\hline Never married & $-0.448^{* * *}(0.075)$ & $-0.417^{* * *}(0.078)$ & $-0.414^{* * *}(0.092)$ & $-0.288^{* *}(0.119)$ \\
\hline Disabled & $-0.235^{* * *}(0.056)$ & $-0.227^{* * *}(0.057)$ & $-0.242^{* * *}(0.063)$ & $-0.157^{* *}(0.073)$ \\
\hline Poor health & $-0.425^{* * *}(0.036)$ & $-0.419^{* * *}(0.036)$ & $-0.431^{* * *}(0.041)$ & $-0.427^{* * *}(0.047)$ \\
\hline $\ln (\mathrm{HH}$ size $)$ & $-0.176^{* * *}(0.054)$ & $-0.225^{* * *}(0.056)$ & $-0.166^{* *}(0.067)$ & $-0.149 *(0.087)$ \\
\hline Childbirth & $0.202^{* * *}(0.049)$ & $0.199^{* * *}(0.051)$ & $0.181^{* * *}(0.059)$ & $0.233^{* * *}(0.070)$ \\
\hline Ln(Job hours) & $-0.014(0.015)$ & $-0.008(0.016)$ & $-0.006(0.018)$ & $0.006(0.021)$ \\
\hline \multirow[t]{2}{*}{ Reference income } & $-0.115(0.201)$ & $-0.297(0.213)$ & $-0.322(0.246)$ & $-0.180(0.299)$ \\
\hline & \multicolumn{4}{|c|}{ 1-year lagged effects } \\
\hline $\ln (\mathrm{HH}$ income $)$ & & $0.017^{* *}(0.008)$ & $0.011(0.010)$ & $0.011(0.011)$ \\
\hline \multicolumn{5}{|l|}{ Employed (base) } \\
\hline Self-employed & & $-0.033(0.023)$ & $-0.027(0.027)$ & $-0.033(0.031)$ \\
\hline Unemployed & & $0.018(0.028)$ & $-0.016(0.034)$ & $-0.042(0.039)$ \\
\hline Retired & & $0.019(0.024)$ & $-0.002(0.029)$ & $-0.004(0.033)$ \\
\hline Not working & & $0.009(0.019)$ & $-0.020(0.023)$ & $-0.023(0.026)$ \\
\hline \multicolumn{5}{|l|}{ Married (base) } \\
\hline Widowed & & $0.210^{* * *}(0.045)$ & $0.180^{* * *}(0.054)$ & $0.235^{* * *}(0.060)$ \\
\hline Divorced & & $0.209^{* * *}(0.031)$ & $0.210^{* * *}(0.036)$ & $0.221^{* * *}(0.040)$ \\
\hline Never married & & $0.110^{* * *}(0.027)$ & $0.156^{* * *}(0.033)$ & $0.121^{* * *}(0.037)$ \\
\hline Disabled & & $-0.046^{* *}(0.019)$ & $-0.018(0.022)$ & $-0.023(0.025)$ \\
\hline Poor health & & $-0.080^{* * *}(0.012)$ & $-0.068^{* * *}(0.014)$ & $-0.065^{* * *}(0.015)$ \\
\hline $\ln (\mathrm{HH}$ size $)$ & & $-0.087^{* * *}(0.019)$ & $-0.102^{* * *}(0.024)$ & $-0.085^{* * *}(0.028)$ \\
\hline Childbirth & & $0.010(0.016)$ & $0.024(0.020)$ & $0.033(0.022)$ \\
\hline Ln(Job hours) & & $-0.003(0.005)$ & $-0.010(0.006)$ & $-0.011(0.007)$ \\
\hline Reference income & & $-0.181^{* * *}(0.065)$ & $-0.241^{* * *}(0.080)$ & $-0.121(0.089)$ \\
\hline \multicolumn{5}{|c|}{ 1-year leaded effects } \\
\hline $\ln (\mathrm{HH}$ income $)$ & & & & $0.061^{*}(0.033)$ \\
\hline \multicolumn{5}{|l|}{ Employed (base) } \\
\hline Self-employed & & & & $-0.063(0.093)$ \\
\hline Unemployed & & & & $-0.172(0.110)$ \\
\hline Retired & & & & $0.045(0.105)$ \\
\hline Not working & & & & $-0.099(0.076)$ \\
\hline \multicolumn{5}{|l|}{ Married (base) } \\
\hline Widowed & & & & $-0.767^{* * *}(0.201)$ \\
\hline Divorced & & & & $-0.560^{* * *}(0.103)$ \\
\hline Never married & & & & $-0.250^{* *}(0.109)$ \\
\hline Disabled & & & & $-0.262^{* * *}(0.071)$ \\
\hline Poor health & & & & $-0.156^{* * *}(0.045)$ \\
\hline $\ln (\mathrm{HH}$ size $)$ & & & & $-0.047(0.077)$ \\
\hline Childbirth & & & & $0.347^{* * *}(0.077)$ \\
\hline Ln(Job hours) & & & & $-0.030(0.022)$ \\
\hline \multirow[t]{2}{*}{ Reference income } & & & & $-0.268(0.300)$ \\
\hline & & pory of last yea & $\begin{array}{l}\text { satisfaction ( } \boldsymbol{\alpha} \\
\text { ed effects }\end{array}$ & m) \\
\hline $\ln (\mathrm{HH}$ income $)$ & $0.039^{*}(0.024)$ & $0.056^{* *}(0.023)$ & $0.070^{* * *}(0.027)$ & $0.081^{* * *}(0.031)$ \\
\hline
\end{tabular}




\begin{tabular}{|c|c|c|c|c|}
\hline Employed (base) & $0.000()$. & $0.000()$. & & \\
\hline Self-employed & $0.085(0.068)$ & $0.053(0.066)$ & $0.024(0.076)$ & $0.113(0.085)$ \\
\hline Unemployed & $-0.131^{*}(0.076)$ & $-0.096(0.072)$ & $-0.100(0.085)$ & $-0.131(0.103)$ \\
\hline Retired & $0.004(0.081)$ & $0.023(0.080)$ & $-0.049(0.097)$ & $0.040(0.112)$ \\
\hline Not working & $-0.093^{*}(0.055)$ & $-0.074(0.053)$ & $-0.104 *(0.062)$ & $-0.126^{*}(0.071)$ \\
\hline \multicolumn{5}{|l|}{ Married (base) } \\
\hline Widowed & $-1.263^{* * *}(0.154)$ & $-0.972^{* * *}(0.155)$ & $-0.805^{* * *}(0.175)$ & $-0.984^{* * *}(0.218)$ \\
\hline Divorced & $-0.656^{* * *}(0.078)$ & $-0.434^{* * *}(0.072)$ & $-0.301^{* * *}(0.088)$ & $-0.230^{* *}(0.099)$ \\
\hline Never married & $-0.400^{* * *}(0.072)$ & $-0.255^{* * *}(0.069)$ & $-0.165^{*}(0.092)$ & $-0.128(0.110)$ \\
\hline Disabled & $-0.134^{* *}(0.060)$ & $-0.182^{* * *}(0.058)$ & $-0.149^{* *}(0.066)$ & $-0.174^{* *}(0.077)$ \\
\hline Poor health & $-0.021(0.036)$ & $-0.106^{* * *}(0.035)$ & $-0.082^{* *}(0.040)$ & $-0.076^{*}(0.045)$ \\
\hline $\ln (\mathrm{HH}$ size $)$ & $0.111^{* *}(0.054)$ & $-0.004(0.053)$ & $-0.064(0.073)$ & $-0.046(0.086)$ \\
\hline Childbirth & $0.093^{* *}(0.046)$ & $0.092^{* *}(0.043)$ & $0.136^{* *}(0.054)$ & $0.071(0.063)$ \\
\hline Ln(Job hours) & $0.016(0.015)$ & $0.018(0.015)$ & $0.006(0.018)$ & $0.004(0.020)$ \\
\hline Reference income & $0.342^{*}(0.203)$ & $0.055(0.197)$ & $0.044(0.249)$ & $0.132(0.288)$ \\
\hline & \multicolumn{4}{|c|}{ 2-year lagged effects } \\
\hline $\ln (\mathrm{HH}$ income $)$ & & & $0.037(0.026)$ & $0.028(0.030)$ \\
\hline \multicolumn{5}{|l|}{ Employed (base) } \\
\hline Self-employed & & & $0.135^{*}(0.073)$ & $0.094(0.084)$ \\
\hline Unemployed & & & $-0.136^{*}(0.081)$ & $-0.170^{*}(0.094)$ \\
\hline Retired & & & $0.222^{* *}(0.094)$ & $0.232^{* *}(0.107)$ \\
\hline Not working & & & $0.010(0.059)$ & $0.036(0.067)$ \\
\hline \multicolumn{5}{|l|}{ Married (base) } \\
\hline Widowed & & & $-0.544^{* * *}(0.157)$ & $-0.462^{* *}(0.181)$ \\
\hline Divorced & & & $-0.059(0.081)$ & $-0.116(0.095)$ \\
\hline Never married & & & $-0.075(0.077)$ & $-0.058(0.091)$ \\
\hline Disabled & & & $-0.105(0.068)$ & $-0.095(0.079)$ \\
\hline Poor health & & & $-0.086^{* *}(0.040)$ & $-0.069(0.046)$ \\
\hline $\ln (\mathrm{HH}$ size $)$ & & & $0.076(0.063)$ & $-0.019(0.074)$ \\
\hline Childbirth & & & $-0.015(0.052)$ & $-0.070(0.058)$ \\
\hline Ln(Job hours) & & & $0.003(0.017)$ & $0.002(0.019)$ \\
\hline Reference income & & & $-0.022(0.235)$ & $-0.080(0.267)$ \\
\hline \multirow[t]{3}{*}{ Constant } & $-1.811^{* * *}(0.597)$ & $-1.807^{* * *}(0.632)$ & $-1.498^{* *}(0.722)$ & $-1.478^{*}(0.792)$ \\
\hline & \multicolumn{4}{|c|}{ Scale shift $(\delta)$} \\
\hline & & conte & eous effects & \\
\hline $\ln (\mathrm{HH}$ income $)$ & $0.036(0.024)$ & $0.044^{*}(0.024)$ & $0.082^{* * *}(0.027)$ & $0.071^{* *}(0.032)$ \\
\hline \multicolumn{5}{|l|}{ Employed (base) } \\
\hline Self-employed & $0.002(0.063)$ & $0.007(0.064)$ & $-0.001(0.073)$ & $-0.013(0.087)$ \\
\hline Unemployed & $-0.503^{* * *}(0.074)$ & $-0.486^{* * *}(0.076)$ & $-0.540^{* * *}(0.090)$ & $-0.519^{* * *}(0.108)$ \\
\hline Retired & $0.138^{*}(0.077)$ & $0.131^{*}(0.079)$ & $0.164^{*}(0.089)$ & $0.148(0.108)$ \\
\hline Not working & $-0.099^{*}(0.051)$ & $-0.101^{*}(0.053)$ & $-0.093(0.060)$ & $-0.100(0.072)$ \\
\hline Married (base) & & & $-0.777^{* * *}(0.166)$ & $-0.545^{* *}(0.225)$ \\
\hline Widowed & $-0.797^{* * *}(0.141)$ & $-0.744^{* * *}(0.146)$ & $-0.101(0.078)$ & $0.102(0.097)$ \\
\hline Divorced & $-0.172^{* * *}(0.066)$ & $-0.181^{* * *}(0.068)$ & $-0.141^{*}(0.085)$ & $-0.145(0.110)$ \\
\hline Never married & $-0.218^{* * *}(0.069)$ & $-0.205^{* * *}(0.073)$ & $-0.104^{*}(0.062)$ & $-0.051(0.072)$ \\
\hline Disabled & $-0.091^{*}(0.055)$ & $-0.094^{*}(0.056)$ & $-0.211^{* * *}(0.040)$ & $-0.222^{* * *}(0.046)$ \\
\hline Poor health & $-0.191^{* * *}(0.035)$ & $-0.193^{* * *}(0.035)$ & $-0.134^{* *}(0.063)$ & $-0.114(0.083)$ \\
\hline $\ln (\mathrm{HH}$ size $)$ & $-0.131^{* *}(0.051)$ & $-0.182^{* * *}(0.053)$ & $0.114^{* *}(0.056)$ & $0.142^{* *}(0.067)$ \\
\hline Childbirth & $0.124^{* * *}(0.047)$ & $0.141^{* * *}(0.048)$ & $-0.018(0.017)$ & $-0.007(0.020)$ \\
\hline Ln(Job hours) & $-0.018(0.014)$ & $-0.017(0.015)$ & $-0.144(0.236)$ & $-0.103(0.290)$ \\
\hline \multirow[t]{2}{*}{ Reference income } & $0.025(0.192)$ & $-0.124(0.205)$ & $0.082^{* * *}(0.027)$ & $0.071^{* *}(0.032)$ \\
\hline & \multicolumn{4}{|c|}{ 1-year lagged effects } \\
\hline $\ln (\mathrm{HH}$ income $)$ & $-0.016^{*}(0.008)$ & & & \\
\hline \multicolumn{5}{|l|}{ Employed (base) } \\
\hline Self-employed & $0.038(0.023)$ & & & \\
\hline Unemployed & $-0.021(0.028)$ & & & \\
\hline Retired & $-0.013(0.024)$ & & & \\
\hline Not working & $-0.010(0.019)$ & & & \\
\hline \multicolumn{5}{|l|}{ Married (base) } \\
\hline Widowed & $-0.225^{* * *}(0.047)$ & & & \\
\hline Divorced & $-0.222^{* * *}(0.031)$ & & & \\
\hline Never married & $-0.125^{* * *}(0.028)$ & & & \\
\hline Disabled & $0.040^{* *}(0.019)$ & & & \\
\hline Poor health & $0.078^{* * *}(0.012)$ & & & \\
\hline $\ln (\mathrm{HH}$ size $)$ & $0.084^{* * *}(0.020)$ & & & \\
\hline Childbirth & $-0.008(0.016)$ & & & \\
\hline
\end{tabular}




\begin{tabular}{|c|c|c|c|c|}
\hline $\begin{array}{l}\text { Ln(Job hours) } \\
\text { Reference income }\end{array}$ & $\begin{array}{c}0.002(0.005) \\
0.238^{* * *}(0.069)\end{array}$ & & & \\
\hline & \multicolumn{4}{|c|}{ 1-year leaded effects } \\
\hline $\ln (\mathrm{HH}$ income $)$ & & & & $0.062^{* *}(0.031)$ \\
\hline Employed (base) & & & & $0.000()$. \\
\hline Self-employed & & & & $-0.070(0.089)$ \\
\hline Unemployed & & & & $-0.071(0.105)$ \\
\hline Retired & & & & $-0.005(0.103)$ \\
\hline Not working & & & & $-0.054(0.073)$ \\
\hline Married (base) & & & & $0.000()$. \\
\hline Widowed & & & & $-0.404^{* *}(0.199)$ \\
\hline Divorced & & & & $-0.296^{* * *}(0.093)$ \\
\hline Never married & & & & $-0.112(0.103)$ \\
\hline Disabled & & & & $-0.218^{* * *}(0.070)$ \\
\hline Poor health & & & & $-0.079^{*}(0.043)$ \\
\hline $\ln (\mathrm{HH}$ size $)$ & & & & $-0.060(0.072)$ \\
\hline Childbirth & & & & $0.242^{* * *}(0.073)$ \\
\hline Ln(Job hours) & & & & $-0.021(0.021)$ \\
\hline \multirow[t]{2}{*}{ Reference income } & & & & $-0.092(0.290)$ \\
\hline & \multicolumn{4}{|c|}{ Cutoff constants $(\gamma)$} \\
\hline$\gamma_{1}$ & $-5.229^{* * *}(0.368)$ & $-5.332^{* * *}(0.366)$ & $-5.423^{* * *}(0.441)$ & $-5.708^{* * *}(0.473)$ \\
\hline$\gamma_{2}$ & $-4.800^{* * *}(0.367)$ & $-4.904^{* * *}(0.365)$ & $-4.988^{* * *}(0.440)$ & $-5.274^{* * *}(0.472)$ \\
\hline$\gamma_{3}$ & $-4.237^{* * *}(0.367)$ & $-4.341^{* * *}(0.365)$ & $-4.415^{* * *}(0.439)$ & $-4.700^{* * *}(0.472)$ \\
\hline$\gamma_{4}$ & $-3.578^{* * *}(0.367)$ & $-3.682^{* * *}(0.365)$ & $-3.750^{* * *}(0.439)$ & $-4.030^{* * *}(0.472)$ \\
\hline$\gamma_{5}$ & $-2.675^{* * *}(0.367)$ & $-2.779^{* * *}(0.365)$ & $-2.838^{* * *}(0.439)$ & $-3.117^{* * *}(0.472)$ \\
\hline$\gamma_{6}$ & $-1.589^{* * *}(0.368)$ & $-1.693^{* * *}(0.365)$ & $-1.729^{* * *}(0.40)$ & $-2.004^{* * *}(0.473)$ \\
\hline Obs. (Respondents) & $100,235(18,642)$ & $100,235(18,642)$ & $78,358(15,577)$ & $62,897(13,549)$ \\
\hline
\end{tabular}

Note: Column (1) is identical to column (4) of Table 2. Clustered standard errors in parentheses. ${ }^{*} \mathrm{p}<0.1,{ }^{* *} \mathrm{p}<0.05,{ }^{* * *} \mathrm{p}<0.01$. All estimates include individual averages and thereby account for individual fixed effects (c.f. section 3.4). 
Table F2. Allowing for heteroskedasticity

\begin{tabular}{|c|c|c|c|c|c|c|c|}
\hline & \multirow{2}{*}{$\begin{array}{c}\text { Current satisfaction } \\
\text { (1) }\end{array}$} & \multirow{2}{*}{$\begin{array}{c}\text { Memory of satisfaction } \\
\text { (2) }\end{array}$} & \multirow{2}{*}{$\begin{array}{c}\text { Cutoff } \tau_{i t, 1} \\
\text { (3) }\end{array}$} & \multicolumn{2}{|c|}{ Log-variance for current satisfaction } & \multicolumn{2}{|c|}{ Log-variance for memory of satisfaction } \\
\hline & & & & $\begin{array}{l}\text { Current terms } \\
\text { (4) }\end{array}$ & $\begin{array}{c}\text { Lagged terms } \\
\text { (5) }\end{array}$ & $\begin{array}{l}\text { Current terms } \\
\text { (6) }\end{array}$ & $\begin{array}{l}\text { Lagged terms } \\
\text { (7) }\end{array}$ \\
\hline $\ln (\mathrm{HH}$ income $)$ & $0.070^{* *}(0.033)$ & $0.073^{* *}(0.033)$ & $0.021(0.030)$ & $-0.011(0.007)$ & $-0.006(0.007)$ & $-0.025(0.032)$ & $-0.058^{* *}(0.028)$ \\
\hline \multicolumn{8}{|l|}{ Employed (base) } \\
\hline Self-employed & $-0.013(0.080)$ & $0.072(0.081)$ & $-0.077(0.076)$ & $-0.022(0.023)$ & $0.039^{*}(0.022)$ & $-0.059(0.089)$ & $-0.084(0.088)$ \\
\hline Unemployed & $-0.847^{* * *}(0.180)$ & $-0.109(0.092)$ & $-0.602^{* * *}(0.143)$ & $0.104^{* * *}(0.024)$ & $0.021(0.023)$ & $0.311^{* * *}(0.093)$ & $0.001(0.092)$ \\
\hline Retired & $0.345^{* * *}(0.115)$ & $0.123(0.099)$ & $0.158(0.098)$ & $0.012(0.022)$ & $-0.046^{* *}(0.021)$ & $0.078(0.096)$ & $0.025(0.099)$ \\
\hline Not working & $-0.136^{*}(0.071)$ & $-0.085(0.067)$ & $-0.118^{*}(0.067)$ & $0.047^{* * *}(0.018)$ & $-0.018(0.018)$ & $0.097(0.071)$ & $-0.044(0.069)$ \\
\hline \multicolumn{8}{|l|}{ Married (base) } \\
\hline Widowed & $-1.398^{* * *}(0.324)$ & $-1.106^{* * *}(0.298)$ & $-0.867^{* * *}(0.252)$ & $0.068^{*}(0.039)$ & $-0.134^{* * *}(0.036)$ & $-0.041(0.145)$ & $0.081(0.163)$ \\
\hline Divorced & $-0.489^{* * *}(0.124)$ & $-0.385^{* * *}(0.111)$ & $-0.122(0.084)$ & $0.040(0.026)$ & $-0.095^{* * *}(0.026)$ & $0.019(0.087)$ & $0.039(0.090)$ \\
\hline Never married & $-0.399^{* * *}(0.115)$ & $-0.286^{* * *}(0.097)$ & $-0.173^{*}(0.091)$ & $0.055^{* *}(0.025)$ & $-0.007(0.024)$ & $-0.095(0.093)$ & $-0.006(0.094)$ \\
\hline Disabled & $-0.361^{* * *}(0.098)$ & $-0.168^{* *}(0.077)$ & $-0.142 *(0.076)$ & $0.032^{* *}(0.014)$ & $-0.004(0.015)$ & $0.153^{* *}(0.063)$ & $0.028(0.065)$ \\
\hline Poor health & $-0.481^{* * *}(0.096)$ & $-0.107^{* *}(0.046)$ & $-0.166^{* * *}(0.052)$ & $0.041^{* * *}(0.010)$ & $0.014(0.010)$ & $0.053(0.044)$ & $0.029(0.047)$ \\
\hline $\ln (\mathrm{HH}$ size $)$ & $-0.324^{* * *}(0.087)$ & $0.000(0.062)$ & $-0.187^{* * *}(0.072)$ & $-0.007(0.017)$ & $0.012(0.017)$ & $-0.138^{* *}(0.066)$ & $0.053(0.067)$ \\
\hline Childbirth & $0.307^{* * *}(0.083)$ & $0.097^{*}(0.057)$ & $0.183^{* * *}(0.070)$ & $0.044^{* * *}(0.016)$ & $0.044^{* * *}(0.015)$ & $0.008(0.070)$ & $-0.006(0.065)$ \\
\hline Ln(Job hours) & $-0.019(0.019)$ & $0.023(0.019)$ & $-0.027(0.018)$ & $-0.005(0.005)$ & $-0.002(0.005)$ & $0.004(0.020)$ & $-0.021(0.019)$ \\
\hline Reference income & $-0.277(0.240)$ & $0.180(0.229)$ & $-0.061(0.226)$ & $0.138^{* *}(0.065)$ & $-0.109^{*}(0.060)$ & $-0.133(0.268)$ & $0.179(0.265)$ \\
\hline \multirow[t]{2}{*}{ Constant } & & $-3.480^{* * *}(0.938)$ & $-6.764^{* * *}(2.561)$ & \multicolumn{2}{|c|}{0.45 (assumed) } & \multicolumn{2}{|c|}{$-0.736(0.705)$} \\
\hline & \multicolumn{7}{|c|}{ Further Cutoff constants } \\
\hline$\tau_{2}$ & \multicolumn{7}{|c|}{$-7.502^{* * *}(1.407)$} \\
\hline$\tau_{3}$ & \multicolumn{7}{|c|}{$-6.812^{* * *}(1.294)$} \\
\hline$\tau_{4}$ & \multicolumn{7}{|c|}{$-5.999^{* * *}(1.162)$} \\
\hline$\tau_{5}$ & \multicolumn{7}{|c|}{$-5.112^{* * *}(1.022)$} \\
\hline$\tau_{6}$ & \multicolumn{7}{|c|}{$-3.944^{* * *}(0.846)$} \\
\hline Obs. (Respondents) & \multicolumn{7}{|c|}{$100,235(18,642)$} \\
\hline
\end{tabular}


Table F3. Allowing for non-parallel shifts in scale use when adding individual averages (non-linear specification)

\begin{tabular}{|c|c|c|c|c|c|c|c|c|}
\hline & $\begin{array}{c}\text { Current } \\
\text { sat. } \\
(1)\end{array}$ & $\begin{array}{l}\text { Memory } \\
\text { of sat. } \\
\text { (2) }\end{array}$ & $\begin{array}{c}\text { Cutoff } \\
\tau_{i t, 1} \\
(3)\end{array}$ & $\begin{array}{c}\text { Cutoff } \\
\tau_{i t, 2} \\
(4)\end{array}$ & $\begin{array}{c}\text { Cutoff } \\
\tau_{i t, 3} \\
(5)\end{array}$ & $\begin{array}{c}\text { Cutoff } \\
\tau_{i t, 4} \\
(6)\end{array}$ & $\begin{array}{c}\text { Cutoff } \\
\tau_{i t, 5} \\
(7)\end{array}$ & $\begin{array}{c}\text { Cutoff } \\
\tau_{i t, 6} \\
(8)\end{array}$ \\
\hline $\ln (\mathrm{HH}$ income $)$ & $\begin{array}{c}0.079^{* * *} \\
(0.025)\end{array}$ & $\begin{array}{l}0.051^{* *} \\
(0.023)\end{array}$ & $\begin{array}{l}0.056^{*} \\
(0.032)\end{array}$ & $\begin{array}{l}-0.042 \\
(0.030)\end{array}$ & $\begin{array}{l}-0.032 \\
(0.026)\end{array}$ & $\begin{array}{c}0.014 \\
(0.020)\end{array}$ & $\begin{array}{c}0.011 \\
(0.015)\end{array}$ & $\begin{array}{l}0.033^{* *} \\
(0.015)\end{array}$ \\
\hline \multicolumn{9}{|l|}{ Employed (base) } \\
\hline Self-employed & $\begin{array}{c}0.058 \\
(0.071)\end{array}$ & $\begin{array}{c}0.043 \\
(0.068)\end{array}$ & $\begin{array}{c}0.196 \\
(0.119)\end{array}$ & $\begin{array}{c}-0.452^{* *} \\
(0.193)\end{array}$ & $\begin{array}{c}0.062 \\
(0.119)\end{array}$ & $\begin{array}{l}-0.079 \\
(0.073)\end{array}$ & $\begin{array}{l}0.076^{*} \\
(0.043)\end{array}$ & $\begin{array}{c}0.020 \\
(0.039)\end{array}$ \\
\hline Unemployed & $\begin{array}{c}-0.703^{* * *} \\
(0.078)\end{array}$ & $\begin{array}{l}-0.107 \\
(0.073)\end{array}$ & $\begin{array}{c}-0.344^{* *} \\
(0.147)\end{array}$ & $\begin{array}{l}-0.025 \\
(0.248)\end{array}$ & $\begin{array}{c}0.161 \\
(0.120)\end{array}$ & $\begin{array}{c}-0.318^{* * *} \\
(0.078)\end{array}$ & $\begin{array}{c}-0.215^{* * *} \\
(0.057)\end{array}$ & $\begin{array}{c}0.017 \\
(0.054)\end{array}$ \\
\hline Retired & $\begin{array}{c}0.224^{* * *} \\
(0.079)\end{array}$ & $\begin{array}{c}0.010 \\
(0.078)\end{array}$ & $\begin{array}{c}0.174 \\
(0.106)\end{array}$ & $\begin{array}{l}-0.067 \\
(0.105)\end{array}$ & $\begin{array}{c}0.025 \\
(0.077)\end{array}$ & $\begin{array}{l}-0.038 \\
(0.058)\end{array}$ & $\begin{array}{l}-0.041 \\
(0.041)\end{array}$ & $\begin{array}{c}0.022 \\
(0.035)\end{array}$ \\
\hline Not working & $\begin{array}{c}-0.158^{* * *} \\
(0.056)\end{array}$ & $\begin{array}{l}-0.077 \\
(0.054)\end{array}$ & $\begin{array}{c}0.027 \\
(0.083)\end{array}$ & $\begin{array}{l}-0.075 \\
(0.094)\end{array}$ & $\begin{array}{c}0.009 \\
(0.067)\end{array}$ & $\begin{array}{c}-0.097^{* *} \\
(0.049)\end{array}$ & $\begin{array}{c}-0.134^{* * *} \\
(0.034)\end{array}$ & $\begin{array}{l}-0.003 \\
(0.030)\end{array}$ \\
\hline \multicolumn{9}{|l|}{ Married (base) } \\
\hline Widowed & $\begin{array}{c}-1.065^{* * *} \\
(0.136)\end{array}$ & $\begin{array}{c}-0.995^{* * *} \\
(0.139)\end{array}$ & $\begin{array}{c}-0.657^{* * *} \\
(0.199)\end{array}$ & $\begin{array}{c}-0.645^{* *} \\
(0.295)\end{array}$ & $\begin{array}{c}0.250 \\
(0.200)\end{array}$ & $\begin{array}{c}0.162 \\
(0.108)\end{array}$ & $\begin{array}{l}-0.005 \\
(0.070)\end{array}$ & $\begin{array}{l}-0.103 \\
(0.068)\end{array}$ \\
\hline Divorced & $\begin{array}{c}-0.452^{* * *} \\
(0.076)\end{array}$ & $\begin{array}{c}-0.451^{* * *} \\
(0.072)\end{array}$ & $\begin{array}{c}0.010 \\
(0.135)\end{array}$ & $\begin{array}{c}-0.490^{* * *} \\
(0.167)\end{array}$ & $\begin{array}{c}0.123 \\
(0.143)\end{array}$ & $\begin{array}{c}0.099 \\
(0.077)\end{array}$ & $\begin{array}{c}0.014 \\
(0.053)\end{array}$ & $\begin{array}{l}-0.079 \\
(0.051)\end{array}$ \\
\hline Never married & $\begin{array}{c}-0.393^{* * *} \\
(0.076)\end{array}$ & $\begin{array}{c}-0.288^{* * *} \\
(0.070)\end{array}$ & $\begin{array}{l}-0.044 \\
(0.115)\end{array}$ & $\begin{array}{c}-0.291^{* *} \\
(0.139)\end{array}$ & $\begin{array}{l}-0.029 \\
(0.102)\end{array}$ & $\begin{array}{c}0.071 \\
(0.067)\end{array}$ & $\begin{array}{l}-0.031 \\
(0.040)\end{array}$ & $\begin{array}{l}-0.056 \\
(0.042)\end{array}$ \\
\hline Disabled & $\begin{array}{c}-0.249^{* * *} \\
(0.052)\end{array}$ & $\begin{array}{c}-0.169^{* * *} \\
(0.054)\end{array}$ & $\begin{array}{l}-0.109 \\
(0.068)\end{array}$ & $\begin{array}{c}0.112 \\
(0.084)\end{array}$ & $\begin{array}{c}0.082 \\
(0.068)\end{array}$ & $\begin{array}{l}-0.073^{*} \\
(0.043)\end{array}$ & $\begin{array}{c}-0.099^{* * *} \\
(0.034)\end{array}$ & $\begin{array}{l}-0.047 \\
(0.034)\end{array}$ \\
\hline Poor health & $\begin{array}{c}-0.431^{* * *} \\
(0.035)\end{array}$ & $\begin{array}{c}-0.091^{* * *} \\
(0.034)\end{array}$ & $\begin{array}{c}-0.206^{* * *} \\
(0.050)\end{array}$ & $\begin{array}{c}0.087 \\
(0.069)\end{array}$ & $\begin{array}{c}0.035 \\
(0.052)\end{array}$ & $\begin{array}{l}-0.041 \\
(0.031)\end{array}$ & $\begin{array}{l}-0.056^{* *} \\
(0.022)\end{array}$ & $\begin{array}{c}-0.076^{* * *} \\
(0.022)\end{array}$ \\
\hline $\ln (\mathrm{HH}$ size $)$ & $\begin{array}{c}-0.235^{* * *} \\
(0.055)\end{array}$ & $\begin{array}{c}0.030 \\
(0.052)\end{array}$ & $\begin{array}{c}-0.194^{* *} \\
(0.081)\end{array}$ & $\begin{array}{l}0.157^{*} \\
(0.083)\end{array}$ & $\begin{array}{c}-0.118^{*} \\
(0.069)\end{array}$ & $\begin{array}{l}0.095^{* *} \\
(0.045)\end{array}$ & $\begin{array}{l}-0.003 \\
(0.029)\end{array}$ & $\begin{array}{c}0.011 \\
(0.028)\end{array}$ \\
\hline Childbirth & $\begin{array}{l}0.212^{* * *} \\
(0.051)\end{array}$ & $\begin{array}{l}0.094^{* *} \\
(0.045)\end{array}$ & $\begin{array}{l}0.181^{* *} \\
(0.088)\end{array}$ & $\begin{array}{c}0.029 \\
(0.116)\end{array}$ & $\begin{array}{l}-0.016 \\
(0.093)\end{array}$ & $\begin{array}{l}-0.053 \\
(0.056)\end{array}$ & $\begin{array}{l}-0.053 \\
(0.032)\end{array}$ & $\begin{array}{l}-0.015 \\
(0.026)\end{array}$ \\
\hline Ln(Job hours) & $\begin{array}{l}-0.010 \\
(0.016)\end{array}$ & $\begin{array}{c}0.015 \\
(0.015)\end{array}$ & $\begin{array}{c}-0.062^{* *} \\
(0.029)\end{array}$ & $\begin{array}{c}0.052 \\
(0.039)\end{array}$ & $\begin{array}{c}0.025 \\
(0.023)\end{array}$ & $\begin{array}{c}0.011 \\
(0.015)\end{array}$ & $\begin{array}{l}-0.008 \\
(0.010)\end{array}$ & $\begin{array}{l}0.016^{*} \\
(0.008)\end{array}$ \\
\hline Reference income & $\begin{array}{l}-0.167 \\
(0.203)\end{array}$ & $\begin{array}{c}0.123 \\
(0.195)\end{array}$ & $\begin{array}{c}0.128 \\
(0.244)\end{array}$ & $\begin{array}{c}-0.576^{* *} \\
(0.226)\end{array}$ & $\begin{array}{c}0.201 \\
(0.164)\end{array}$ & $\begin{array}{c}0.081 \\
(0.102)\end{array}$ & $\begin{array}{c}0.047 \\
(0.065)\end{array}$ & $\begin{array}{l}0.146^{* *} \\
(0.061)\end{array}$ \\
\hline Constant & & $\begin{array}{l}-0.652 \\
(0.614) \\
\end{array}$ & $\begin{array}{l}-0.957 \\
(0.940) \\
\end{array}$ & $\begin{array}{c}-4.170^{* *} \\
(1.659) \\
\end{array}$ & $\begin{array}{l}-0.864 \\
(0.865) \\
\end{array}$ & $\begin{array}{l}1.165^{* *} \\
(0.520)\end{array}$ & $\begin{array}{c}-2.446^{* * *} \\
(0.352) \\
\end{array}$ & $\begin{array}{c}-7.094^{* * *} \\
(0.381)\end{array}$ \\
\hline Obs. (Resp.) & & & & 100,235 & ,642) & & & \\
\hline
\end{tabular}

Note: Clustered standard errors in parentheses. ${ }^{*} \mathrm{p}<0.1,{ }^{*} \mathrm{p}<0.05,{ }^{* * *} \mathrm{p}<0.01$. Estimates include individual averages and thereby account for individual fixed effects (c.f. section 3.4). 